\title{
4 Die Korrespondenz der Nuntien in Luzern
}

Ende des 16. Jahrhunderts war die Politik des Kirchenstaates dahingehend ausgerichtet, die Macht der protestantisch-reformierten Kräfte nördlich der Alpen aufzuhalten oder zumindest im Blick zu halten. Die Einsetzung eines ständigen Nuntius in der Eidgenossenschaft kann und muss aus dieser Perspektive betrachtet werden. Der Papstgesandte in Luzern hatte gemäß den ersten Instruktionen - sowie den darauffolgenden Schriften - die Hauptaufgabe, die Katholiken in der Schweiz zu unterstützen und ausfindig zu machen, was die reformierten Kantone „im Schilde führen“. Während der Pontifikate von Sixtus V. (1585-1590), Gregor XIV. (1590-1591), Innozenz IX. (1591), Clemens VIII. (15921605), Paul V. (1605-1621) und Gregor XV. (1621-1623) spielten die jeweiligen Nuntien in Luzern eine wichtige Rolle bei der Söldneranwerbung. Die Eidgenossenschaft galt nicht nur als „Bollwerk der Häretiker“, sondern auch als „Rohstoff-Land“ für gute Söldner und politische Verbündete bei Kriegshandlungen in Europa.

Die meisten Briefe und Korrespondenz sind ab der Nuntiaturperiode von Ottavio Paravicini (1587-1591) im Vatikanischen Geheimarchiv zu finden. Der Papstgesandte in Luzern war auch als Mittelsmann und Beobachter der Bischöfe in der Schweiz: So gab es immer wieder Probleme und Auseinandersetzungen zwischen der römischen Kurie und einzelnen Bischöfen. So war dies beispielsweise 1586 mit dem Bischof von Chur der Fall. ${ }^{1}$ Nuntius Santonio referierte nach Rom, was im Bistum Chur vor sich ging. Was sich in Graubünden abspielte, galt aber auch für andere Bistümer. Die Diözesanbischöfe mussten an zwei Fronten „kämpfen“: Einerseits war ihre bisherige „weltliche Macht“ durch die Reformation stark eingeschränkt worden, andererseits war auch ihre katholische Autorität bei den eigenen Gläubigen beeinträchtigt, wie die Nuntien in dieser Periode feststellen mussten. ${ }^{2}$

Die Nuntien in Luzern waren von 1586 bis 1654 alle Italiener. Diese Klassifizierung kann anachronistisch wirken. Das Italien im heutigen Sinne gab es damals noch nicht. Dennoch verband alle Nuntien in Luzern von 1586 bis 1798 die italienische Sprache, ähnliche kulturelle und religiöse Werte sowie fast gleiche Einstellungen - auch gegenüber den „Schweizern“. Sicher, auch die Bezeichnung „Schweizer“ ist mit Vorsicht zu gebrauchen. Auch hier gilt: Die Schweiz im heutigen Sinne gab es noch nicht. ${ }^{3}$

1 Vgl. Michael Durst: Studien zur Geschichte des Bistums Chur (451-2001), S. $124 \mathrm{ff}$.

2 Vgl. Brigitte Degler-Spengler: Der schweizerische Teil der ehemaligen Diözese Konstanz.

3 Wie Würgler schreibt, konnte sich schon die frühneuzeitliche Staatstheorie nicht darauf verständigen, ob es sich bei der alten Eidgenossenschaft um eine Art Bundesstaat oder nicht doch

ə Open Access. (C) 2021 Mario Galgano, publiziert von De Gruyter. $(\leftrightarrow)$ Er Dieses Werk ist lizenziert unter der Creative Commons Attribution 4.0 Lizenz. Weitere Informationen finden Sie unter 
Um die Nuntien $\mathrm{zu}$ verstehen, muss man logischerweise ihre Biographien kennen. Solche Lebensläufe haben bekanntlich das Ziel, ein möglichst lückenloses Bild des „Protagonisten“ zu zeichnen. Oftmals ist es aber so, dass Biographien über Wissenslücken stolpern, weil nicht alles immer dokumentiert ist. Das gilt auch im Falle der Nuntien im 16. und 17. Jahrhundert. Man könnte nun in Versuchung geraten, die Löcher gesicherten Wissens mit „wahrscheinlichen Fakten“ zu füllen, was aber auch dazu führen könnte, „Unwahrscheinliches“ mit zu vermischen. Eine weitere Gefahr besteht darin, die Nuntien zu „psychologisieren“, doch die Erkenntnis der Psyche eines Menschen bedarf der genausten Kenntnis von dieser Person. Biographische Lücken „auszuschmücken“ kommt auch einer Fälschung gleich, und somit ist jede Biographie in Gefahr, ihren Gegenstand zu verfehlen.

Stattdessen ist ein anderer Weg von Vorteil, wenn man nämlich die Lebensumstände der einzelnen Nuntien von den historischen Lebensbedingungen her zu verstehen versucht. Auf diese Weise können wir ihren Alltag genauso wie die historischen Prozesse besser einordnen. Denn wir können davon ausgehen, dass eine Biographie immer auch Kulturgeschichtsschreibung beinhaltet. So können wir die Nuntien in der Eidgenossenschaft sowohl aus der Nähe anhand ihrer Briefe als auch aus der Distanz anhand des historischen Kontextes der Schweiz im 16. und 17. Jahrhundert betrachten und verstehen. ${ }^{4}$

\subsection{Die 14 Nuntien in der Schweiz von 1586 bis 1654}

Mit der Einsetzung der ständigen Nuntiatur 1586 hatte der Vertreter des Papstes in Luzern vor allem die Hauptaufgabe, die Entwicklungen in der Eidgenossenschaft zu beobachten. Die 14 Nuntien, die von 1586 bis 1654 nach Luzern geschickt wurden, waren allesamt Diözesanbischöfe.

Hier die Auflistung: ${ }^{5}$

1. Giovanni Battista Santonio 1586-1587

2. Ottavio Paravicini 1587-1591

3. Giovanni della Torre 1595-1606

4. Fabrizio Verallo 1606-1608

5. Ladislao d'Aquino 1608-1613

um dreizehn verschiedene souveräne Staaten handelte. Vgl. Andreas Würgler: Verflechtung und Verfahren, S. 79.

4 Vgl. Hasso Spode: Was ist Mentalitätsgeschichte?

5 Es handelt sich um eine Auflistung, wie sie auch Fink in seiner Arbeit vorgestellt hat. Vgl. Urban Fink: Die Luzerner Nuntiatur 1586-1873. 
6. Ludovico di Sarego 1613-1621

7. Alessandro Scappi $1621-1628$

8. Ciriaco Rocci $1628-1630$

9. Ranuccio Scotti $1630-1639$

10. Girolamo Farnese 1639-1643

11. Lorenzo Gavotti $1643-1646$

12. Alfonso Sacrati $1646-1647$

13. Francesco Boccapaduli 1647-1652

14. Carlo Carafa della Spina 1653-1654

\subsection{Die Korrespondenz der Nuntien aus und nach Rom:}

Es folgen übersetzte Auszüge aus Briefen der einzelnen Nuntien. Dazu gehören auch ihre historische Einordnung und Kontextualisierung.

\subsubsection{Giovanni Battista Santonio (1586-1587) ${ }^{6}$}

Die Nuntien in Luzern hatten jeweils unterschiedliche Lebensläufe, und doch gab es - wie bereits beschrieben - auch viele Gemeinsamkeiten. Der erste ständige Nuntius war Giovanni Battista Santonio. Ausgehend von der Instruktion und den Beschreibungen von Karl Borromäus und Giovanni Francesco Bonomi, dem päpstlichen Gesandten in der Eidgenossenschaft von 1579 bis 1581, wurde die Schweiz für die Nuntien in Luzern beschrieben. ${ }^{7}$ Über die und von den ersten ständigen Nuntien gibt es im Vatikanischen Geheimarchiv wenig, da etliche Dokumente ihrer Nuntiaturzeit nicht in der „Luzerner Abteilung“ zu finden sind, sondern bei den Unterlagen der Kölner Nuntiatur hinterlegt wurden. Santonio war Bischof von Tricarico. Geboren um 1528 in der süditalienischen Stadt Tarent, begann er seine bischöfliche Karriere unter Pius V., als dieser ihn am 19. November 1568 zum Bischof von Alife ernannte. Sein Weihbischof war Felice Peretti Montalto, ${ }^{8}$ der später zum Papst gewählt wurde (Sixtus V.). Und es war dieser Papst, der Santonio nach Rom berief, um ihm den Posten des „Meisters des Apostolischen Palastes“ zu geben. Am 8. Januar 1586 ernannte Sixtus V. ihn zum Bischof von Tricarico. Bis zu seinem Tod behielt er dieses Bischofsamt. Es

6 Vgl. Caspar Wirz: Bullen und Breven aus Italienischen Archiven, S. XXXVI-XXXVII.

7 Vgl. Urban Fink: Die Luzerner Nuntiatur 1586-1873, S. 43.

8 Vgl. Peter Stephan: Transformation und Transfiguration. 
war damals - obwohl die Verkehrs- und Kommunikationswege bescheidener als heutzutage waren - üblich, dass ein Diözesanbischof auch außerhalb seiner Diözese im Dienste des Papstes stand. Im selben Jahr wurde er zum ersten Ständigen Nuntius in Luzern ernannt. Die Eidgenossenschaft wurde schon 1586 als „Svizzera“ - also Schweiz - bezeichnet und deshalb als eine „eigenständige Nation"9 betrachtet.

Dass Santonio nach Luzern entsandt wurde und eine ständige Nuntiatur eingerichtet wurde, ist - wie Fink hervorhebt - politischen und kirchlichen Umständen zu verdanken. Eine große Rolle spielte „die praktisch vollständige Abwesenheit des Konstanzer Bischofs Mark Sittich von Hohenems“..$^{10}$ So wurde an der Tagsatzung der fünf Innern Orte vom 26. Februar 1586 von der Mehrheit beschlossen, „den Papst um die Entsendung eines Nuntius zu bitten“. ${ }^{11}$ Die Antwort von Papst Sixtus V. war die Entsendung von Giovanni Battista Santonio in die Schweiz. Wie Fink weiter betont, hatte Santonio „einen rein innerkirchlichen Auftrag “. ${ }^{12}$ In dieser Phase waren keine militärische Absichten zugunsten des Kirchenstaates wie beispielsweise Söldnerwerbungen vorgesehen, ja sogar ausdrücklich ausgeschlossen. Ziel und Zweck der Nuntiatur war es, „einzig für die Erhaltung und Festigung der katholischen Schweizer in ihrem Glauben ein-

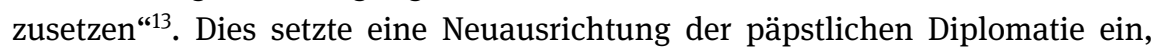
was auch dem Wunsch des Mailänder Kardinals Borromäus entsprach. ${ }^{14}$

Im Vatikanischen Geheimarchiv befinden sich unter Band 233 die Folien 1 bis 98, die ein von seinem Sekretär geschriebenes Kopierbuch seiner Korrespondenz als Nuntius, als Bischof und Privatmann für die Jahre 1586/87 festhalten. Besonders interessant sind die Folien 240 bis 347. Es handelt sich um Dechiffrate seiner Nuntiaturberichte, die von der päpstlichen Kanzlei erstellt wurden; die

9 Der Begriff „Nation“ wird eigentlich erst nach der Französischen Revolution verwendet. Hier dient er als eine Bezeichnung für eine Gemeinschaft, die von einem politischen Zugehörigkeitsgefühl getragen ist. Die Zugehörigkeit durch gemeinsame Sprache, Kultur, Geschichte, ethnische Abstammung kann dafür Bedeutung haben, aber um eine Nation zu sein, spielt das Selbstverständnis einer Zugehörigkeit und Zusammengehörigkeit eine Rolle, also ein Wollen, was im Falle der Eidgenossenschaft des 16. und 17. Jahrhunderts der Fall ist.

10 Urban Fink: Die Luzerner Nuntiatur 1586-1873, S. 43.

11 Ebd.

12 Ebd.

13 Ebd.

14 Ebd., S. 44: „Santonios Auftrag bestand darin, für die katholischen Kan tone, namentlich für Luzern, Uri, Schwyz und Unterwalden, die zum Bistum Konstanz gehörten, den abwesenden Bischof und Kardinal Mark Sittich von Hohenems zu vertreten, weswegen er mit der vollen bischöflichen Gewalt ausgestattet war. Er sollte jedoch zugleich die Forderung der Kantone nach Abtrennung von Konstanz oder nach einem apostolischen Vikariat gegenstandslos machen.“ 
Folien 99 bis 216 beinhalten das „Registrum omnium expeditionum factarum per J. Bpt. Santonium, nuntium apostolicum ad Helvetios anno 1586 et 1587 per Franciscum Verallum secretarium“; die Folien 217 bis 238 sind Vorschriften an die Geistlichkeit. Der Schluss des Bandes enthält Varia aus verschiedenen Zeiten, davon wichtig sind die Folien 356 bis 363 bzw. in einer neuen Nummerierung 376 bis 384, die ein Konzept einer Instruktion sind.

Die erste nennenswerte Folie aus Band 233 beginnt ab 376. Darin finden wir die Erläuterung zu Santonios Tätigkeit in Luzern. Der frisch ernannte Nuntius soll sich Rosenkränze, Medaillen und Kruzifixe sowie andere „profane Geschenke“ besorgen, um sie „bei Gelegenheit“ jenen zu vergeben, die sich bei der Nuntiatur verdient gemacht haben. ${ }^{15}$ Selbst die Mietkosten werden aufgezählt. Der Nuntius muss sich mit zwei Wohnungen begnügen, aber immerhin mit Seesicht, wie im Brief aus Rom betont wird. Empfohlen werden Wandteppiche („Arazzi di Mezzanini“), die besonders für die Wintertage nützlich sein werden. Somit ist klar, dass man in Rom bereits vor Antritt des neuen Nuntius Bescheid weiß, wie das Leben in der Schweiz ist und die Menschen in der Eidgenossenschaft „ticken“. Die Anreise wird bis ins letzte Detail - sogar die Raststätten genauestens beschrieben. Die Schweiz („Natione Svizzera“) wird als ein Land „der Zuneigung und des Interesses“ gegenüber Kirchenmännern beschrieben und der Nuntius müsse - so der „römische Tipp“ - zu jenen hingehen, die ihm - und somit der Kirche - etwas geben können. Die Schweizer seien untereinander meist zerstritten und das könne der „Nuntio del Papa“ für seine Zwecke ausnützen, indem er die einen gegen die anderen ausspiele. Er müsse aber vorsichtig damit umgehen, denn man könne nicht immer auf diese FreundFeind-Einteilung zählen, denn die Konstellationen können sich schnell ändern.

Schon am Anfang der Instruktion wird somit klargestellt, dass sich der Nuntius in Luzern „gut präsentieren“ soll, und dass die Schweizer Katholiken wohl auch mit Geschenken und Ehrungen zu gewinnen sind. Die Art der Geschenkund Ehrenauflistung zeigt, für wie wichtig auch der materielle Aspekt damals galt. Das heißt, in Rom ging man davon aus, dass die Schweizer gerne auf materielle Werte achten. So heißt es in der Instruktion wörtlich:

Das Haus, in der der Geistliche wohnen wird und für das eine Miete von 135 Fiorini im Jahr bezahlt werden wird, beinhaltet neben den Zimmern, die für die Familie sind, auch nur zwei Wohnungen für den Dienst, aneinandergereiht und in Seerichtung; jede hat drei bis vier kleine Zimmer, mit einer tiefen Decke und entsprechend ihrer Größe dürfen Sie

15 Segreteria di Stato, Svizzera, Volume 233, f. 376: „Bereits in Rom müssen Sie Kronen, Medaillen, Kruzifixe und andere ähnliche Devotionalien besorgen, die vom Heiligen Vater gesegnet sind, sowie andere nichtkirchliche Geschenke für Gelegenheiten der Ehrung durch die Nuntiatur.“ 
Dekorationsware mitnehmen, und Sie werden im Halbgeschoss Wandteppiche für die Winterzeit vorfinden, die angepasst werden.

Um gut als Geistlicher arbeiten zu können, müssen Sie wissen, dass Sie gute Bettwäsche, gute Hemden und auch Tischdecken mitnehmen müssen. ${ }^{16}$

Bei der Hausbeschreibung zeigt sich, wie unterschiedlich auch die Wohnvorstellungen zwischen den großräumigen römischen Palazzi und der Luzerner Wohnung ist. Als „Vorteil“ kann man wohl den Hinweis auf die Lage hin zum See deuten. Eine weitere Besonderheit besteht in der Beschreibung der „tiefen Decken“, die einen eindeutigen Unterschied zur Wohnsituation in Italien darstellen. Der Hinweis auf die Wandteppiche weist auch auf die kalte Winterzeit hin. Die praktischen Hinweise zur Bettwäsche, Kleidung und Decken hingegen sind ein Hinweis, dass man besser „aus Italien die Dinge des Lebens“ mitnehmen soll.

Für den Ersten Diener braucht es sowohl für die Reise als auch für seinen Aufenthalt eine gute Kutsche mit drei Maultieren, und der dritte bringe das Feldbett mit, damit sie den anderen beiden dienen kann, und dazu bedarf es auch eines gesattelten Pferdes, um über die schwierige Pfade hinwegzukommen, weil dies sicherlich notwendig sein wird. ${ }^{17}$

In Rom war klar, dass die Reise über die Alpenpässe nicht einfach ist und dass man sich dementsprechend gut vorbereiten soll, und zwar auch logistisch. Eine besondere Rolle - wenn auch namentlich nicht genannt - spielte sicherlich der Gotthardpass. Von 1480 bis 1798 kontrollierte der Kanton Uri die gesamte Passstrecke vom Vierwaldstättersee bis vor die Tore Bellinzonas. ${ }^{18}$

Es wäre gut, wenn Sie in Venedig die entsprechenden Kerzen besorgen sowie das notwendige Geschirr aus Kristall, und dass darunter etwa 30 große Kristallgläser sind, damit Sie mit den dortigen (politischen, Anm. d. Autors) Anführern auf deren Gesundheit anstoßen können. Sie müssen jedoch keine Lichtkerzen mitnehmen, weil es dort günstigere aus Wachs gibt. Wenn Sie nach Foligno gehen, dann besorgen Sie sich dort eine halbe Papierrolle, denn von jener Eigenschaft und Qualität werden Sie es in Ihrer neuen Residenz nicht finden. ${ }^{19}$

Die Einkaufsliste verrät uns, wie man in Rom über die materielle Situation im schweizerischen Gastgeberort dachte. Gute Produkte findet man nördlich der Alpen eher nicht, außer einige günstige Dinge. Hinzu kommt auch der Hinweis

16 Segreteria di Stato, Svizzera, Volume 233, f. 376.

17 Segreteria di Stato, Svizzera, Volume 233, f. 376.

18 Vgl. Stichwort „Gotthardpass“, in: http://www.hls-dhs-dss.ch/textes/d/D7466.php (31. Dezember 2020)

19 Segreteria di Stato, Svizzera, Volume 233, f. 376. 
auf die Anführer („Principi“), die der Nuntius in Luzern und insgesamt in der Eidgenossenschaft treffen muss. Die Devise aus Rom lautete: Netzwerke knüpfen und ein gutes Bild von sich abgeben.

Wenn Sie in Bologna vorbeikommen, dann ist es empfehlenswert, dort genügend kleine Handseifen zu erwerben, damit sie diese an jene Minister und Diener der Anführer schenken können, wo sie hinkommen.

Wenn Sie in Parma vorbeikommen, dann nehmen Sie Mortadella, Salami und Schinken mit, die als Geschenke dienen, und da diese sehr beliebt sind in jenen Orten, wo Sie hingehen, weil dort solche Spezialitäten fehlen, können Sie den Gaumen jener Leute gewinnen, weil es nichts Besseres für sie gibt.

In Mailand besorgen Sie sich Socken und Handschuhe aus Seide, die mit ein bisschen Gold und Silber verziert sind, um sie Bräuten zu schenken, die Sie an ihre Hochzeiten einladen werden. Bei den üblichen Personen ziemt es sich hingegen, jeweils kleinere Devotionalien zu schenken.

In derselben Stadt (Mailand, Anm. d. Aut.) müssen Sie sich auch kandierte Früchte, zwei Laibe guten Parmesankäse beschaffen, und organisieren Sie jemanden, der Ihnen bei Bedarf die Sachen nachschicken kann.

Den Wein, wenn er auch nicht in dieser Stadt Mailand hergestellt wird, soll der Absender oder Ihr Agent aus Monferrato im Piemont besorgen, oder aus anderen Gebieten in jener Nähe, um sie nach Luzern hinbringen zu lassen, damit Sie im Keller genug Vorrat dazu haben für den Bedarf. Was den üblichen Gebrauch des Haushalts betrifft, so reichen die Weine aus dem Elsass, Schaffhausen und aus dem Berner Gebiet. ${ }^{20}$

In dieser materiellen und geographischen Aufzählung, die sehr detailliert ist, wird klar, dass die Reise nach Luzern gut vorbereitet werden musste. Ebenfalls ersichtlich sind die angeblichen Vorlieben der Einheimischen in Luzern sowie das, was in der damaligen Zeit „Mode“ war.

Aus der genannten Stadt Mailand wird Sie die Reise weiter führen nach Como, und drei oder vier Meilen von der genannten Stadt kommen Sie nach Mendrisio, dem ersten Ort der Nuntiatur, wenn Sie aber in Arona einschiffen, auf dem Lago Maggiore, dann werden Sie nach acht oder zehn Stunden in Locarno ankommen, dem entsprechenden ersten Ort der Nuntiatur. ${ }^{21}$

Die Reise nach Luzern war lang. Bis zum 17. Jahrhundert gab es nur in besonders wichtigen Zeiten einen Botendienst. Diego Maderni aus Lugano baute 1653 den ersten regelmäßigen wöchentlichen Dienst zwischen Mailand und Luzern auf; die Boten benötigten für diese Strecke vier Tage. ${ }^{22}$

20 Segreteria di Stato, Svizzera, Volume 233, f. 378.

21 Segreteria di Stato, Svizzera, Volume 233, f. 378.

22 Vgl. Stichwort „Gotthardpass“, in: http://www.hls-dhs-dss.ch/textes/d/D7466.php (31. Dezember 2020) 
In Luzern wurde der neue Nuntius dann von allen wichtigen „Gesprächspartnern“ begrüßt, die in der Instruktion auch namentlich genannt werden. ${ }^{23}$ Sogar die Zahl der Kanonenschüsse zu Ehren des Gastes aus Rom wird erwähnt (für den Vorgänger Erzbischof Cancelli als Papstgesandten waren es 24 Salutschüsse gewesen, so der Vergleich). ${ }^{24}$

Der kirchliche Bezug des Gesandten aus Rom sollte in der „großen Kirche“ in Luzern anhand einer Prozession mit dem Klerus zum Altar hergestellt werden. Da soll der Nuntius auf Latein „ein kleines Gebet“ vortragen, um dem Papst für die Mission zu danken. ${ }^{25}$ Bei der Einsetzungsfeier seien auch die Abtbischöfe und die Ordensoberen aus den Kantonen „üblicherweise“ durch Gesandte vertreten. Dies sei eine gute Gelegenheit, um die Beziehungen zu den jeweiligen Herren, die diese Gesandten geschickt hätten, zu fördern. Es sei - und das wird besonders hervorgehoben - zu unterscheiden zwischen „Vescovetti et Abbateccoli“, also Bischöfen und Äbten minderen Ranges, und „Principi“, die als dem Adelsstand gleichgestellt galten. Namentlich genannt wird der Fürstabt von Sankt Gallen. ${ }^{26}$

Es folgt eine Auflistung der Einnahmen für den Nuntius: Berechnet wurden zweitausend Scudi, ${ }^{27}$ die er vor allem durch die Vergabe von Ehedispensen einnimmt. ${ }^{28}$ Dies sei zwar eine „traurige Angelegenheit“, wird festgehalten. Um die Papiere auszugeben, bedarf es aber eines Kanzlers, der zehn Scudi erhält, was viel Einnahmen einbringen könne, wenn man bedenke, dass vorangegangene Kanzler über dreißigtausend Scudi angesammelt hatten. Der Kanzler hatte in allen Gebieten der Nuntiatur „ein oder zwei Mitverantwortliche“ (,uno o due Corresponsali“), die für die konkrete Herstellung der Dokumente und Austeilung der Dispensen zuständig waren und mit dem Kanzler die Einnahmen teilten. Doch obwohl dies der ehemalige Kanzler „im Namen der Nuntiatur“ getätigt hatte, hätte er viele dem Nuntius verschwiegen und so „Geld gestohlen“, so der Vorwurf. So hätte er nur 22 Dispensen angegeben, obwohl allein aus dem „Elsass und dem Bistum Basel“ mehr Dispensen erteilt worden seien, so die Berechnung in der Instruktion. ${ }^{29}$

Doch nicht genug, der Kanzler, der in der Instruktion nicht namentlich genannt wird, hätte auch das Gericht in Rom („Corte di Roma“) bestohlen und so einen größeren Skandal verursacht (,altro più scandaloso“) als in der Schweiz

\footnotetext{
23 Vgl. Segreteria di Stato, Svizzera, Volume 233, f. 379.

24 Vgl. Segreteria di Stato, Svizzera, Volume 233, f. 380.

25 Vgl. Segreteria di Stato, Svizzera, Volume 233, f. 381.

26 Vgl. ebd.

27 Fabio Gigante: Monete italiane dal '700 all'avvento dell'euro.

28 Vgl. Segreteria di Stato, Svizzera, Volume 233, f. 381.

29 Vgl. Segreteria di Stato, Svizzera, Volume 233, f. 382.
} 
mit den Dispensen. Es ging konkret um das Stehlen von Geldern, die durch den Ablasshandel eingenommen wurden. ${ }^{30}$

Eine weitere wichtige Aufgabe des Nuntius in Luzern sei bei der Abwesenheit eines Bischofs oder Abtes zu beachten: So müsse der Nuntius bei der Wahl eines neuen Bischofs oder Abtes mitwirken. Auch hier kommen weitere Einnahmen hinzu, denn der frisch gewählte Bischof oder Abt „schenkt in der Regel“ dem Nuntius „und seiner Familie“31 gemäß dem „Brauch des Landes“ eine bestimmte Summe und zwar in der Höhe, wie es in dem jeweiligen Gebiet üblich sei. $^{32}$

Beim Umgang mit juristischen Fragen sei es nicht nötig, die Gesetzesbücher der Länder zu beachten, es reiche, den „gesunden Menschenverstand“ zu benutzen und vor allem das Verhältnis zu den anderen Botschaftern, Ordensleuten und „Freunden“ Aufmerksamkeit zu schenken. Hier geht die Instruktion auf die komplexe Lage in der Eidgenossenschaft ein, ohne jedoch ins Detail zu gehen. Es sei wichtig, in jedem Kanton Freunde zu haben, insbesondere mit den Kapuzinern, die sich um die „Glaubenssicherung“ kümmern. Die Geschäfte könne man am besten mit guten Freunden regeln, so der Tenor der Instruktion.

Unter den Botschaftern wird jener von Spanien, der sich aber vor allem um Rätien kümmert, genannt. Auf jeden Fall müsse man sehr eng mit der spanischen Krone verbunden bleiben, deshalb lohne es sich, gut mit dem Gesandten befreundet zu sein. Auch sei diese Freundschaft wichtig, um sich mit dem ,anderen“ Botschafter - und damit ist der Gesandte Frankreichs gemeint - auszutauschen. Der Botschafter Frankreichs residiere in Solothurn, wird in der Instruktion festgeschrieben. Darin wird auch festgehalten, dass die „französische Fraktion“ eine wichtige Rolle in der eidgenössischen Politik spiele. ${ }^{33}$

Und dann gab es noch den Botschafter Savoyens, der aber ,unter dem Botschafter Spaniens steht“, nachdem er zuvor unter jenem Frankreichs war. Und was daraus die Lehre sei: Die Schweiz entstand „durch Liebe oder durch Interesse“ und nicht durch Gewalt. ${ }^{34}$ Man müsse also die einzelnen Interessen berücksichtigen, um die Interessen des Papstes zu verteidigen. Wichtig sei, dass man jene Seite unterstütze, die „etwas hergebe“. Die Schweiz sei kein Feindesland, aber man müsse vorsichtig mit ihren Bewohnern umgehen, weil es wenig brauche, damit sie sich gegen einen stemmten. Es gelte der Grundsatz, der auch

30 Vgl. Segreteria di Stato, Svizzera, Volume 233, f. 382.

31 Damit ist die Begleitung und engsten Mitarbeitern des Nuntius gemeint.

32 Vgl. Segreteria di Stato, Svizzera, Volume 233, f. 382.

33 Vgl. Segreteria di Stato, Svizzera, Volume 233, f. 383.

34 Vgl. Segreteria di Stato, Svizzera, Volume 233, f. 383. 
bei anderen Ländern gilt: Lieber sich frühzeitig zurückziehen, anstatt die Lage zuzuspitzen. ${ }^{35}$ Die Instruktion endet ohne Punkt und weitere Angaben.

Wie die anderen Gesandten europäischer Mächte in der Eidgenossenschaft ging es Santonio darum, genau wahrzunehmen, wer ein Franzosen- oder Spanienfreund sei. Wichtig waren hierbei personale Verflechtungen mit den politischen Entscheidungsträgern der Kantone und der Eidgenossenschaft. Hier versuchte er die Netzwerke zu kontrollieren und einzuhegen. ${ }^{36}$

Ein für damals internationaler Coup Santonios in Luzern war seine Unterzeichnung des „Goldenen Bundes“37 vom 5. Oktober 1586. Vor allem die Protestanten waren von dem Geschick des Papstgesandten beeindruckt. Santonio verstand sich als „Macher“, der ein klares Freund-Feind-Bild vor sich hatte. Mit den Katholiken ging es aus seiner Sicht problemlos, und so führte er strenge Maßnahmen ein, um die Disziplin der Diözesan- und Ordenspriester zu verbessern und im Sinne des Konzils von Trient umzusetzen. Die katholischen Gastgeber sahen in ihm einen Verbündeten, und deshalb wundert es nicht, dass er auch verstärkt „bischöfliche Funktionen“ ausübte, was dem Verhältnis der Nuntiatur zu den Ortsbischöfen nicht sonderlich förderlich war. ${ }^{38}$

Nuntius Santonio war trotz seiner kurzen Amtszeit in Luzern auch gegen die Meinung der römischen Kurie vorgegangen, als er beispielsweise die Badener Verträge von 1585 über das Bistum Basel guthieß. Mit diesem Vertrag erwarb die Stadt Basel auch formal alle bischöflichen Herrschaftsrechte in der Stadt und über ihr Gebiet und wurde so endgültig unabhängig. Weniger erfolgreich, sondern konfliktreicher war das Verhältnis zu den Mächtigen Luzerns, die seinen Weggang forderten, nachdem Santonio versucht hatte, die Einflussnahme der Laien in kirchlichen Angelegenheiten einzuschränken, was im damaligen Luzern Usus war. ${ }^{39}$

35 Vgl. Segreteria di Stato, Svizzera, Volume 233, f. 384.

36 Vgl. Rudolf Bolzern: Spanien, Mailand und die katholische Eidgenossenschaft, S. 68-70.

37 Vgl. Stichwort „Goldener Bund“ (Borromäischer Bund), in: https://hls-dhs-dss.ch/de/articles/017187/2005-09-09/ (31. Dezember 2020).

38 Insbesondere das Verhältnis zum damaligen Bischof von Konstanz war schwierig. Kardinal Mark Sittich von Hohenems kümmerte sich vor allem um seine persönliche Stellung und zeigte wenig Interesse, was die Belange der Schweizer Katholiken betraf. Dem Wunsch nach einem Bischofsvikar für die Zentralschweiz wurde nicht stattgegeben, und so begnügten sich die Zentralschweizer Katholiken mit einem Papstgesandten. Vgl. Michael F. Feldkamp: La diplomazia pontificia.

39 Urban Fink: Die Luzerner Nuntiatur 1586-1873, S. 44: „Er reiste bereits am 7. Oktober 1587 wieder aus Luzern ab, nachdem er sich mit den Luzerner Behörden wegen Benefizialangelegenheiten überworfen hatte. Santonio kämpfte gegen das bereits vorreformatorisch verankerte Patronatsrecht, das oftmals in weltlichen Händen lag und mehr als ein bloßes Gewohnheitsrecht war. Er stieß sich an diesen für ihn offensichtlich unverständlichen Gegebenheiten und 
Santonios Amtszeit in Luzern zeigt aber auch die „doppelte Rolle“ der Außenbeziehungen der Schweizer. Wie der Schweizer Historiker Georg Kreis aufzeigte, muss man zwei Arten der Außenpolitik unterscheiden: so waren einerseits die Bündnisse der Kantone untereinander eine erste Ebene, in der es Santonio gelang, die katholische Kantone zu einen. Auf der anderen Ebene ging es um die „äußere Außenpolitik“, die die gesamte Eidgenossenschaft betraf und die Santonio eher störend wirkte, da ihm die Einheit zwischen katholischen und protestantischen Orte nicht passte. ${ }^{40}$

Santonio kehrte als „Präfekt des Apostolischen Palastes“ nach Rom zurück. Er starb am 29. Februar 1592 und ist in der römischen Basilika von Santa Prassede begraben, wo ein Neffe des Verstorbenen beim jungen Gian Lorenzo Bernini eine Grabesskulptur in Auftrag gab. ${ }^{41}$

Bei Santonio war der Einfluss von Kardinal Karl Borromäus sehr ausgeprägt. Wie Santonio die Schweizer sah, war durch die Beschreibungen Borromäus geformt. Die politische Dimension spielte jedoch in dieser Nuntiaturzeit eine größere Rolle als die wirtschaftliche. Es ging ihm auch nicht darum, das von Borromäus geprägte Schweiz-Bild zu revidieren. ${ }^{42}$

\subsubsection{Ottavio Paravicini (1587-1591) ${ }^{43}$}

Die römische Kurie entsandte danach Ottavio ${ }^{44}$ Paravicini. Er war Bischof von Alessandria. Im Gegensatz zu seinem Vorgänger war Paravicini ein gebürtiger Römer. ${ }^{45}$ Er kam am 11. Juli 1552 auf die Welt und wurde ,aus gesundheitlichen Gründen“ Priester, da er nicht die Physis für eine militärische oder politische Karriere gehabt haben soll. ${ }^{46}$ Als junger Mann gehörte er zum Kreis des damals in Rom geschätzten Geistlichen Filippo Neri, der später heiliggesprochen wurde

trat gegenüber dem Luzerner Rat mit solch neapolitanischer Heftigkeit auf, dass der Rat vom Papst die Abberufung verlangte, die von Sixtus V. schließlich auch zugestanden wurde. Als Gründe wurden vom Heiligen Stuhl das vorgerückte Alter des Nuntius und das unzuträgliche Klima angeführt.“

40 Vgl. Georg Kreis Artikel zu „Außenpolitik“ in HLS: https://hls-dhs-dss.ch/de/articles/ 026455/2012-05-24/ (31. Dezember 2020).

41 Vgl. Dizionario biografico degli Italiani, unter dem Stichwort „Santonio“.

42 Vgl. Rudolf Bolzern: Spanien, Mailand und die katholische Eidgenossenschaft.

43 Vgl. Caspar Wirz: Bullen und Breven aus Italienischen Archiven, S. XXXVII.

44 In einigen Dokumenten wird sein Vorname auch als Ottaviano bezeichnet.

$45 \mathrm{Zu}$ Paravicini: Ernest Giddey: Le nonce Ottavio Paravicini; Girolamo Prigione: Prigione, Gerolamo: Ottavio Paravicini Vescovo di Alessandria e la nunziatura svizzera.

46 Vgl. Stefano Tabacchi: Dizionario Biografico degli Italiani. Paravicini hatte einen Bruder, der heiratete und so den Geschlechtsnamen weitervererben konnte. 
und sich für eine Kirche einsetzte, die im karitativen und erzieherischen Bereich sehr aktiv sein sollte. Paravicini folgte von 1580 bis 1583 Kardinal Antoine Perrenot de Granvelle nach Spanien. Papst Gregor XIII. ernannte Paravicini am 5. März 1584 zum Bischof von Alessandria in Norditalien. Da er noch nicht geweiht war, erhielt er vom Papst eine Dispens und wurde dann am 15. Juli desselben Jahres in Mailand vom dortigen Erzbischof Karl Borromäus geweiht. Es folgte die Ernennung zum ständigen Nuntius in Luzern. Mit seiner Ernennung wollte Gregor XIII. einen Kirchenmann mit starken Prinzipien in der Eidgenossenschaft haben, der das Verhältnis zu den Schweizer Katholiken fördern sollte.

Die Originalbriefe vom 30. Dezember 1587 bis Ende 1588 befinden sich im Vatikanischen Geheimarchiv in Band 2; für das gesamte Jahr 1589 ist es Band 2 (a); vom Januar 1590 bis 10. März 1591 in Band 3; vom März bis Juni 1591 in Band 4 (die Hälfte des Bandes besteht aus Beilagen); Dechiffrate vom 6. März bis 12. Dezember 1589 in Nunziatura di Polonia 30; Gegenbriefe vom Januar 1588 bis August 1590 in Principi 151; Dezember 1590 bis Juli 1591 Principi 150; chiffrierte Briefe vom Februar bis August 1589 Principi 183; seine Fakultäten vom 18. November 1587 in Armadio 45, 43; das Konzept dazu in Armadio 42, 47.

In Paravicinis Briefwechseln steht - neben der Instruktion - viel Aufschlussreiches, das sein "Schweiz-Bild“ aufzeigt. ${ }^{47}$ Die in Band 2 befindlichen Relationen betreffen vor allem die Situation im Appenzell, das bereits zu Paravicinis Amtszeit mit Abspaltung drohte..$^{48}$ In Band 3 unterstreicht er in einem Brief nach Rom sein Engagement bei der Tagsatzung in Baden. So erfahren wir, dass sein Ziel vor allem darin bestand, so viele Ortschaften zum Katholizismus zu konvertieren wie möglich. So heißt es in Folio 7 (Band 3):

Es tröstet zu hören, dass es Fortschritte in dem Ort Laufen gibt, sowohl für das bekehrte Volk als auch bei der guten Unterweisung zum heiligen Glauben, deshalb werden in den kommenden vierzig Tagen zwei Jesuitenpatres geschickt, wie ich es mit dem Ordensprovinzial und mit dem Bischof von Basel abgesprochen habe. ${ }^{49}$

Dies geschah im Pontifikat von Sixtus V. - der Franziskaner-Papst prägte auch die „Sicht“ der Nuntien auf die Eidgenossenschaft. In einem Brief vom 29 Mai 1587 an den Bischof von Chur ermahnte der Papst diesen „zu würdigem Wandel“. Ein weiteres Beispiel ist die Haltung des Papstes gegenüber Genf. Da zeig-

47 Die Beschreibungen in seinen Briefen über die Schweiz sind vor allem auf sein Verhältnis zu den Eidgenossen in den Versammlungen zurückzuführen.

48 Die äußeren Rhoden stimmten bei einer außerordentlichen Landgemeinde von 1597 einer Landteilung zu, die Kirchhörigkeit Appenzell ein paar Wochen später. Vgl. Stichwort „Appenzell“, in: https://hls-dhs-dss.ch/de/articles/007389/2019-10-25/ (31. Dezember 2020).

49 Segreteria di Stato, Svizzera, Volume 3, f. 7. 
te er ebenfalls, welche Einstellung Rom gegenüber den Protestanten einnahm. ${ }^{50}$ Unter Sixtus V. fand der „Borromäische Bund“51 seinen Abschluss. Paravicini erhielt deshalb auch besondere, den Verhältnissen angepasste, ausführliche Fakultäten. Zur Erinnerung: Dem Bischof von Basel trug sein mit der Stadt Basel 1585 abgeschlossener Vergleich eine scharfe Zurechtweisung ein; der Wunsch des Herzogs von Savoyen dagegen, Genf zu überfallen, ging dem Papst zu weit; er mahnte den ungeduldigen Fürsten zur „fortwährenden Vorsicht“ 52

Nuntius Paravicini hingegen war sehr aktiv bei der „Bekämpfung der Protestanten“. So schrieb er am 23. Januar 1590 in einem Brief nach Rom:

Gegen die Häretiker im Kanton Appenzell, die nicht ruhig sein wollen, werden in Baden viel Lärm und auch Androhungen gemacht. In der Provinz von Thurgau werden gute Beschlüsse gefasst, um die Heilige Katholische Religion zu bewahren. Doch auf diesen und andere Geschäfte, die behandelt wurden, damit ich sie lösen sollte, will ich mit diesem Brief nicht weiter eingehen, sondern - wenn ich dazu komme, es Ihnen zu schreiben - in einer Relation. ${ }^{53}$

In einem Briefwechsel Paravicinis, der sich in Paris aufhielt und Söldner aus der Eidgenossenschaft für die „Armee Navarras“54 anheuerte, schrieb der Nuntius am 28. Dezember $1589^{55}$ :

Da nun die Geldschulden größer als angenommen sind, geht es nun darum, die betreffenden Nationen zu entlohnen, wie es sich gehört, und die Schweizer haben zwei Zahlungen erhalten, mit dem Versprechen durch den Legaten, dass in diesem Monat noch eine weitere Zahlung folgen wird, und die weiteren zwei Zahlungen, die noch ausstehen, sollen in

50 Vgl. Caspar Wirz: Bullen und Breven aus Italienischen Archiven, S. CVI.

51 Damit ist die Fortführung des „Goldenen Bundes“ gemeint.

52 Vgl. Urban Fink: Die Luzerner Nuntiatur 1586-1873, S. 44-45: „Paravicini trat für eine Regelung der kirchlichen Verhältnisse in der Schweizer Quart des Bistums Konstanz ein, indem er in Rom empfahl, eine Schweizer Diözese oder ein bischöfliches Kommissariat zu errichten. Mit der Förderung der Jesuiten und Kapuziner setzte er sich für die Kirchenreform ein, und er betrieb die Ernennung eines Koadjutors für Konstanz.“

53 Segreteria di Stato, Svizzera, Volume 3, f. 7.

54 Vgl. Urban Fink: Die Luzerner Nuntiatur 1586-1873, S. 45: „Der sonst beliebte zweite Schweizer Nuntius scheiterte jedoch daran, dass die Schweizer Söldner, die er nach anfänglichem Zögern für die Französische Liga gegen den König von Navarra geworben hatte, ihren Sold nicht ausbezahlt erhielten. So musste er die Schweiz - wie sein Vorgänger - 1591 in Windeseile verlassen, weil sogar Gewalttätigkeiten gegen ihn zu befürchten waren.“

55 Damit ist die Auseinandersetzung um die Nachfolge der Valois in Frankreich gemeint. Im sogenannten „Krieg der drei Heinrichs“ waren die Schweizer vor allem als Söldner involviert und so war der Nuntius als „Vermittler der katholischen Seite“ dazu orientiert, die Schweizer Katholiken ruhig zu halten, damit sie aus wirtschaftlichen Gründen militärisch abspringen. 
Lyon und Mailand durchgeführt werden. Ähnliche Abmachungen sollen mit den Bündnern und Alemannen (Deutschen) getätigt werden. ${ }^{56}$

Die Geldfrage spielte während der Dienstzeit Paravicinis eine große Rolle. Immer wieder ging er auf Anforderungen von Schweizern ein. In einem weiteren Brief vom 30. Januar 1590 schrieb Nuntius Paravicini nach Rom:

Der Kanton Bern hat, was das Geld angeht, 100000 Scudi, und seit zwei Tagen sieht es so aus, dass die Vertreter Berns hier in Luzern herumgehen, um von den Luzerner Herren durch große Versprechungen 50000 davon auszuleihen, doch sie können das nicht tun, und ich selber glaube es auch nicht, dass sie so viel Geld haben, auch ist mir nicht bekannt, dass sie überhaupt so reich sein sollen und dass ihre Kirche so viel Geld übrig hat. $^{57}$

Bei der Beschreibung spricht der Nuntius Klartext: Für ihn sind die Kantone nicht einfach in gute Katholiken und schlechte Häretiker aufgeteilt. Einzig bei den rein protestantischen Kantonen sparte er nicht mit expliziten Äußerungen:

Große Lügen verbreiten die Genfer und die Berner ... doch die Genfer haben sich gar nicht bemüht, dies zu verbergen ... ${ }^{58}$

Ein paar Seiten später schrieb der Nuntius in einem ähnlichen titellosen und nicht datierten Brief:

Die Stille, die wir in diesen Tagen erlebt haben, sei es von den weltlichen Dingen, sei es von anderen Seiten, hat uns sehr überrascht, weil sie unüblich ist. Von Frankreich hat man keine Neuigkeiten gehört, nur von einigen Häretikern wurde das Gerücht verbreitet, dass die Katholiken großen Verlust in Navarra erlebt hätten, und sie wiederholen dies, dass, wenn die Nachrichten aus Navarra stimmen, dann würden sie zusammen mit England einige Häfen in Frankreich zur Verfügung stellen und große Hilfe leisten, doch diese Dinge haben sie in einem solch kühlen Ton gesagt und dann dazu geschwiegen, und wir kennen allzu gut ihre Eitelkeit. ${ }^{59}$

Während sein Vorgänger Santonio im militärischen Bereich (Söldner, Bündnisse) durchaus Erfolg verzeichnen konnte, musste Paravicini mit etlichen Schwierigkeiten umgehen. In seinem Brief beschrieb der Nuntius das Vorgehen der Schweizer:

56 Segreteria di Stato, Svizzera, Volume 3, f. 14. Bei dem Konflikt geht es um den Pfälzischen Erbfolgekrieg bzw. Orléanischer Krieg, in dem sich der französische König Ludwig XIV. um die Anerkennung der Erwerbungen im Rahmen seiner Reunionspolitik bemühte.

57 Segreteria di Stato, Volume 3, f. 32.

58 Segreteria di Stato, Svizzera, Volume 3, f. 53.

59 Segreteria di Stato, Svizzera, Volume 3, f. 83. 
Von den Geschäften hört man hier nicht viel, da sie sich weiterhin über ihre Beschwerden schämen gegenüber Unserem Herrn (Papst gemeint, Anm. d. Autors), da sie die Hilfe sehen, die sie in Frankreich erhalten haben, und ich lasse nicht nach, da ich vom Legaten die Bestätigung der Hilfe bekommen habe ...

Da mir der Legat aus Frankreich über die Merkwürdigkeiten der Schweizer Katholiken betreffend die Hilfe für die Katholiken sowohl Frankreichs als auch anderer Länder berichtet, so schweigen sie, und auch bei anderen ordentlichen Geschäften, die sie betreffen, empfinde ich sie als verändert.

Der Legat hat mir geschrieben, dass die Schweizer Katholiken sich nicht rühren, solange sie keinen Sold erhalten, ich habe meine Beschwerden bekundet und sie entschuldigen sich hierfür ... ${ }^{60}$

1590 prägte der Konfessionskonflikt in Appenzell die Tätigkeit des Nuntius in Luzern. Paravicini schrieb über die Lage im „Cantone di Apezzel“ am 5. März 1590:

Auch wenn Pater Ludovico, mein Guardian, wegen der großen Kälte fast erledigt von seiner Fußreise zurückkam, und deshalb hat er nicht geschrieben, ist es für ihn dennoch eine Freude, über die große Frucht zu berichten, die er geschaffen hat, denn er hat einige von der Ewigen Verderbnis gerettet.

Er ging durch ein häretisches Land, traf viele versammelte Menschengruppen, er untersuchte die Lage und man bat ihn, dorthin zu gehen, um für einen armen Mann Gerechtigkeit walten zu lassen. Man bat ihn zu predigen, damit dieser friedlich sterben konnte, und dies tat er auch. Auf dem Land predigte er viel und mit so tiefer Inbrunst, sodass er am Ende der Predigt den Menschen versprach, öfters dorthin zu reisen, um die Menschen zu trösten, und deshalb hofft er jetzt auch, dass er wieder gesund wird, damit er Ihrer Hochwürden noch besser dienen kann.

In diesem Ort Appenzell ist noch mit der Güte des Herrn die wundersame Bekehrung festzustellen, wie einer der reichsten und hartnäckigsten Häretiker unter ihnen ins Kloster einzog, und nach langem Austausch mit dem Priester Guardian, vom Herrn berührt, wollte er nicht weggehen, bevor er nicht gebeichtet hatte, und versprach, seine Güter zu verkaufen, die er außerhalb dieser Stadt besaß, und die Häretiker zu verlassen, um mit den Katholiken zu leben. Wir hoffen deshalb auf weitere Bekehrungen. Ja, sogar heute ist ein weiterer Fall geschehen, indem einer weinend um ein Treffen und um Befreiung der Häresie bat. Er gehörte zu den ersten der Häretiker in diesem Gebiet. Wir hoffen mit der Güte des Herrn, dass wir in diesem Monat weitere gute Nachrichten Ihrer Hochwürden zuschicken können. ${ }^{61}$

Nuntius Paravicini musste sich auch um konkrete interkonfessionelle Auseinandersetzungen kümmern, die das schwierige Verhältnis zwischen Katholiken und Protestanten Ende des 17. Jahrhunderts aufzeigen. So ging es um den Fall

60 Segreteria di Stato, Svizzera, Volume 3, f. 83.

61 Segreteria di Stato, Svizzera, Volume 3, f. 85. 
eines Protestanten, der sich gegen eine katholische Prozession wandte. In dem Brief vom 10. Juni 1590 nach Rom schrieb Paravicini dazu:

In der Nähe von Konstanz auf Schweizer Territorium fand eine Prozession statt, wie es üblich ist, von einem Ort zum anderen. Sie gingen zu einer Kirche bei einem katholischen Ort. Das Land aber wurde vor Kurzem von einem Häretiker gekauft. Den Katholiken wurde die Türe vor ihren Nasen versperrt und er drohte, falls sie nicht weggehen würden, dann würde er sich beim Präfekten wegen Aufhetzung beschweren, denn dieser war ebenfalls ein Häretiker aus Zürich. Sie gingen somit in diesen Tagen zur besagten Satzung, um über diesen Fall zu sprechen und von anderen ähnlichen Fällen, damit sie Lösungen finden. Ich enthielt mich aber, schriftliche Vorschlägen zu unterbreiten, wie ich es üblich tat. Auch untersagte ich, dass man in meinem Namen ähnliche Geschäftsordnungen behandelt, denn derzeit würde es nur Nachteile bringen, weil der Augenblick ungünstig ist. ... ${ }^{62}$

Aus Rom aber kamen andere Anweisungen, als sich der Nuntius gedacht hatte. Verfolgte Nuntius Paravicini eine vorsichtige Linie, weil er die protestantischen Kontrahenten durchaus als schlaue Gegner betrachtete, war die Einstellung der römischen Kurie anders und zwar, dass die Schweizer Katholiken immer alles dafür tun sollten, um ihre Rechte einzufordern und die Protestanten zurückzuweisen. Und so schreibt Nuntius Paravicini in seinem oben bereits zitierten Brief weiter:

Es besorgt mir unendlich viel Leid zu hören, dass ich nicht im Sinne Unseres Herrn gehandelt hätte, weil ich mit Sanftmut verhindert hätte, dass sie ihre Anführer nach Rom schicken würden, um über diese Angelegenheiten vorzusprechen. Was mich dazu bewegt hat, war neben der Tatsache, dass diese Leute in dieser Nation keine Vernunft oder Prinzipien haben, damit sie auf vernünftige Weise den rechten Weg gehen, da sie nie mit Fürsten verhandeln, die nicht ihre Reisekosten übernehmen und weil sie auch Hunderte von Scudi für alle, die sich an den Reisen beteiligen, verlangen, und es ist an den Fürstenhöfen bekannt, dass sie geldgierig sind, was sie aber als Verpflichtung betrachten. Um diese Kosten zu vermeiden und all die Unannehmlichkeiten und Lasten, die hätten entstehen können, habe ich mich enthalten. Nun gehorche ich Ihren Befehlen, indem ich meine Haltung in den Hintergrund bringe und sie ihre Gedanken einbringen können. ...

Ich bin aber auch gezwungen zu sagen, dass durch ihre Schlichtheit (,rusticità“) und Dummheit in diesen Ländern, weil sie nicht wissen, was es heißt, Nuntien und ähnliche Güte eines Papstes zu haben, hat Gott mir die Güte geschenkt, ohne mein Verdienst die Stelle auf die beste Art und Weise zu führen, wie es in diesen Ländern nur möglich ist. Es gibt keinen Zweifel, dass sie meine Person achten, unser Haus würdigen und meine Dienerschaft ebenfalls, weil ich sie in fast monastischer Klausur führe. Sie lieben und respektieren das. Nie gab es ein schlechtes Wort oder eine Beschwerde, auch gab es keine Beschwerden von Dienern anderer Herren oder Verhaftungen oder andere ähnliche Nettigkeiten, wie sie diese Herren sonst gerne machen und weil von ihren Herren darüber kein

62 Segreteria di Stato, Svizzera, Volume 3, f. 247/248: „Affronto fatto da un'heretico a Cath.(ci) in una processione“. 
Aufsehen gemacht wurde, haben sie sich gut und unverletzlich gezeigt mit den Fremden, die sie, wie Sie selbstverständlich wissen, hassen. ${ }^{63}$

Nuntius Paravicini engagierte sich - wie bereits erwähnt - vor allem für die „Rettung“ Navarras ${ }^{64}$ und versuchte die katholischen Schweizer dafür zu rekrutieren. Im Gebiet der Eidgenossenschaft versuchte er die protestantischen Orte zurückzuerobern, musste aber auch feststellen, dass die katholischen Orte gewisse Schwierigkeiten gegenüber seiner Person hatten. Paravicini interessierte sich sehr für die Grafschaft Baden, Laufen, Fribourg, Solothurn und die Zentralschweiz (inkl. Zug).

Man merkt bei Paravicini auch eine merkliche Distanz zur Schweiz, zumindest in den Briefen. Zwar werden die Entwicklungen in verschiedenen Ortschaften erläutert, doch der Nuntius machte selten Bemerkungen. Er interessierte sich für seine Sache (Stärkung der katholischen Seite in Frankreich, Anliegen des Tridentinischen Konzils) und beschrieb weniger das Land und die Leute.

Das hat - wie Fink hervorhebt - wohl damit zu tun, dass ,in den Anfangsjahren der Luzerner Nuntiatur die Aufrechterhaltung und Wiederaufrichtung der kirchlichen Hierarchie, die Durchsetzung der Disziplin in Welt und Ordensklerus, die Festigung des katholischen Volkes in seinem Glauben und die Wiedergewinnung der bereits Abgefallenen die Hauptaufgabe und das Hauptziel der Nuntien" waren. ${ }^{65}$

Papst Gregor XIV. holte ihn nach Rom zurück, und beim Konsistorium vom 6. März 1591 wurde Paravicini zum Kardinal kreiert. Er nahm am Konklave von 1591 teil, bei der Innozenz IX. gewählt wurde, und auch am Konklave von 1592 war Paravicini dabei, als Clemens VIII. auf den Stuhl Petri kam. ${ }^{66}$

Der Papstgesandte ging zum Teil bis ins kleinste Detail auf die für die katholische Kirche relevanten Ereignisse seiner Zeit ein. Paravicini beschrieb beispielsweise, wie am 1. Januar 1590 ein katholischer Priester von einem Laien tätlich angegriffen wurde. ${ }^{67}$ Sehr technisch und nüchtern schrieb Paravicini, dass

63 Ebd.

64 Damit ist die Förderung der katholischen Seite in Frankreich gemeint, die Paravicini dahingehend unterstützen wollte, indem er als Söldner-Vermittler fungierte.

65 Vgl. Urban Fink: Die Luzerner Nuntiatur 1586-1873, S. 45. Fink schreibt, dass die Jahre nach 1560 bis 1605 ,in jeglicher Beziehung eine Art Notzeit“ waren, „in welcher dementsprechende Notmaßnahmen ergriffen werden mussten.“

66 Ottavio Paravicini wurde 1591 zum Legaten von Gallien ernannt, da ihn Innozenz IX. den Auftrag erteilt hatte, zum Schutz der „deutschen Nation“, eine „Congregatio Germanica“ zu gründen, was Paravicini auch unter Klemens VIII. und Paul V. fortführte. 1596 verzichtete er auf das Amt des Bischofs von Alessandria. Von 1608 bis 1609 war er Camerlengo des Kardinalskollegiums und starb am 3. Februar 1611 und wurde in der Basilika der heiligen Bonifaz und Alex auf dem Aventin begraben. 
der Priester wegen der Frau des Täters gestritten habe. ${ }^{68}$ Der Nuntius sah sich also nicht nur als einfacher Beobachter der Ereignisse und Entwicklungen in seinem Gastland, sondern gab auch konkrete Hinweise, wie die katholische Kirche in der Eidgenossenschaft ihre Position bewahren könne oder zumindest nicht geschwächt werde. Im selben oben genannten Brief ging er auch auf die zweite Aufgabe des Nuntius in der Schweiz ein: Die Konversion der Reformierten zählte zu den wichtigsten Tätigkeiten, die ein Ständiger Nuntius in dem Land übernehmen musste. Dies geschah vor allem durch den Einsatz von Ordensleuten, die sich um die Bildung der Konvertiten kümmerten. ${ }^{69}$

Die komplexe Struktur der Eidgenossenschaft zeigte sich vor allem darin, dass die einzelnen Orte gerade im religiös-konfessionellen Bereich sehr unterschiedlich waren. Dennoch gelang es Paravicini trotz der komplizierten Verknüpfungen, auch einzelne relevante Ziele zu erreichen, die seinem Dienst als „Konversionsgesandter“ zugutekamen. ${ }^{70}$ Hier zählte wohl seine Mission, die Grafschaft Baden nicht nur katholisch zu halten, sondern auch deren Grafen zum Katholizismus zu bekehren. ${ }^{71}$

Neben der Beobachtungsstelle und Konfessionsfrage ging es dem Nuntius in der Eidgenossenschaft auch um das Söldnergeschäft. In Paravicinis Zeit war dies vor allem im Zusammenhang mit den Hugenottenkriegen ${ }^{72}$ zu sehen. Der Nuntius nahm hier auch die Aufgabe wahr, die Söldnergeschäfte der Eidgenossenschaft zu beobachten, aber gleichzeitig selber aktiv mitzumischen bzw.

67 Segreteria Stato, Svizzera Volume 3, Foglio 7.

68 Vgl. Segreteria Stato, Svizzera Volume 3, Foglio 7. Darin wurde beschrieben, dass der Priester nicht getötet sondern „nur“ verletzt wurde, obwohl er mit „zwei Messerstichen“ angegriffen wurde. Der Nuntius betonte, dass es sich beim Täter um einen „Weltlichen“ (Laien) handelte. Bei dem Angriff ging es darum, dass der Täter den Priester wegen der Beziehung des Geistlichen mit dessen Ehefrau angegriffen habe. Der Nuntius hob hervor, dass er dem Priester geschrieben habe und ihm angeraten habe, sich beim regierenden Rat zu entschuldigen. Der Täter hingegen sei exkommuniziert worden. Auch habe der Nuntius den Priester aufgefordert, sich an das Volk zu wenden, um über die von der Kirche angegebene Ordnung aufzuklären. 69 Vgl. Segreteria Stato, Svizzera Volume 3, Foglio 7. Darin ging der Nuntius auf die Entsendung zweier Jesuiten nach Laufen. Er habe diesbezüglich beim Provinzial angefragt, sowie den Bischof von Basel angeschrieben.

70 Vgl. Segreteria Stato, Svizzera Volume 3, Foglio 28 (gleicher Brief). Der Nuntius hob hervor, dass die Haltung der Häretiker in Appenzell dazu geführt habe, dass bei der Tagsatzung viel darüber diskutiert wurde. Es seien auch Drohungen geäußert worden. Dies habe dazu geführt, dass im Thurgau die katholische Seite die Oberhand gewinnen könnte, urteilte Paravicini.

71 Segreteria Stato, Svizzera Volume 3, Foglio 21. Paravicini hob hervor, dass der Graf von Baden ihn persönlich gar nie getroffen habe, doch habe dieser ihm mitgeteilt, dass er von dem Bericht des Nuntius über die Lage der Katholiken in der Schweiz sehr angetan gewesen sei.

72 Vgl. Söldnerführer in den Hugenottenkriegen, in: Jahrbuch für solothurnische Geschichte. 
Söldner anzuwerben. ${ }^{73}$ Bei der Beobachtung der Entwicklungen fügte Nuntius Paravicini auch viele eigene Kommentare hinzu und war somit einer der ersten, der sich nicht nur auf die reine „Beobachtungsaufgabe“ beschränkte. ${ }^{74}$ Als um 1590 das reformierte Zürich mit dem katholischen Teil Appenzells Verhandlungen aufnahm, reagierte Paravicini sofort und sandte einen Brief nach Rom. ${ }^{75} \mathrm{Im}$ selben Brief vom 8. April 1590 beschrieb er auch die Fortschritte bei der Rekatholisierung in der Eidgenossenschaft. Dennoch gebe es da noch etliche Probleme, die bei allen Instruktionen - auch zu späteren Zeiten - immer wieder zur Sprache kommen: die „schlechten“ Priester, die unmoralisch lebten und/oder keine theologische Kenntnisse hätten. ${ }^{76}$

Auf Paravicini folgte in Luzern Lewis Goodwin Owen (1591-1595), ${ }^{77}$ der einzige Nicht-Italiener unter den Nuntien, die in Luzern residierten. Unter den Dokumenten im Vatikanischen Geheimarchiv befinden sich aber keine nennenswerte Briefe oder Dokumentation während dieser Nuntiatur.

Im August 1591 wurde Paravicini zum Legaten in Frankreich gewählt. Er wurde dann von Papst Innozenz IX. beauftragt, zum Schutz der deutschen Nation die Congregatio Germanica zu gründen, eine Position, die er auch unter dem Pontifikat von Clemens VIII. und Paul V. innehatte.

1596 verzichtete er auf das Bistum Alessandria, zu dessen Kirche er trotz der wichtigen Verpflichtungen außerhalb der Diözese nicht nur geistig, sondern auch wirtschaftlich einen bemerkenswerten Beitrag leistete.

73 Segreteria Stato, Svizzera Volume 3, Foglio 14: "Dieta intimata dai 7 Cantoni et alcuni Capitani di quei Cantoni inclinano alla fattione di Nauarra.“

74 Wie Fink hervorhebt, kamen die Hauptangriffe „vom größtenteils reformunwilligen Klerus. Aber auch die katholischen Kantone, die im allgemeinen zu Reformen bereit waren, machten Opposition, da sie sich in ihren staatskirchenrechtlichen Ansprüchen und Gewohnheiten bedroht sahen." Urban Fink: Die Luzerner Nuntiatur 1586-1873, S. 45.

75 Segreteria Stato, Svizzera Volume 3, Foglio 108. Paravicini stellte fest, dass die Kapuziner gehasst wurden. Grund hierfür sei ihr Erfolg gewesen, schrieb Paravicini. Die Kapuziner hätten „Schritt für Schritt“ die Häresie in jenem Kanton beseitigt. Die Gegner würden mit „Unordnung“ dagegen vorgehen. Er fügte an, dass die Häretiker leicht zu schlagen seien und „schweigen, wenn man ihnen Paroli bieten kann“.

76 Segreteria Stato, Svizzera Volume 3, Foglio 108. Paravicini ging auf einen Brief des Fürstabtes von St. Gallen, der über die Lage im Toggenburg einging. Es ging um die „schlechte Konversion“ in jener Gegend. Grund hierfür seien die schlechten Priester, die es dort gebe, urteilte der Nuntius. Andererseits seien die Zürcher (Protestanten) schlauer, wie auch der St. Galler Fürstabt in seinem Brief feststellte. Paravicini schlug deshalb vor, die Priester zu bestrafen.

77 Vgl. Caspar Wirz: Bullen und Breven aus Italienischen Archiven, S. XXXVII; Ein Originalbrief von ihm an Kardinal Federico Borromeo die Schweiz betreffend befindet sich in der Biblioteca Ambrosiana G. infer. T. 153, einige andere aus frühere Zeit in T. 144. 
Von 1608 bis 1609 hatte er das Amt des Kämmerers der Heiligen Römischen Kirche inne. Er starb am 3. Februar 1611 in Rom und wurde in der Basilika der Heiligen Bonifatius und Alexis auf dem Aventin begraben. ${ }^{78}$

\subsubsection{Giovanni della Torre (1595-1606)}

$\mathrm{Zu}$ Giovanni della Torres Zeit als Nuntius in Luzern gibt es viele Dokumente. Er hat auch eine Instruktion verfasst. $\mathrm{Zu}$ seiner Person: Sein genaues Geburtsdatum ist nicht bekannt, muss aber nach 1549 gewesen sein. Geburtsort ist die norditalienische Stadt Bergamo. ${ }^{80}$ Er stammte aus einer noblen Familie, die in Udine lebte. Giovanni della Torre hatte in Padua studiert und schloss die Universitätsstudien in beiden Rechten ab. Seine Mutter Giulia Bembo di Gian Matteo war Enkelin des Kardinals Pietro Bembo. Die Familie della Torre gehörte dem Adelsstand an und residierte in Udine. Sein Onkel Michele della Torre war Nuntius in Frankreich und wurde 1583 zum Kardinal kreiert. Dieser war auch für den Aufstieg Giovanni della Torres verantwortlich. ${ }^{81}$

Giovanni della Torre begann als Kanoniker in der Diözese Ceneda, da sein „Protektor“ diesem Bistum vorstand. Am 21. Februar 1586 starb sein Onkel, und das führte zu einer neuen Karriere für Giovanni della Torre. Er musste einen guten Eindruck in seinem Bistum hinterlassen haben, da namhafte Mitglieder der Bistumsgemeinschaft ihn bei Papst Sixtus V. als neuen Bischof vorschlugen. Der Pontifex entschied anders und ernannte Marcantonio Mocenigo zum Bischof von Ceneda. Giovannis Bruder Sigismund forcierte ihn im selben Jahr zum Bischof von Gorizia - ebenfalls ohne Erfolg. So schien, dass della Torres Karriere und Prestige ein Ende nahmen. Doch der Nuntius in Graz, Bischof Giovanni Andrea Cagliari, empfahl ihn bei der Kurie als sein Nachfolger. ${ }^{82}$

Giovanni della Torre wurde jedoch am 25. September 1589 zum Bischof von Veglia ${ }^{83}$ ernannt. ${ }^{84}$ Die Einsetzung ging aber alles andere als gut über die Büh-

78 Vgl. Stichwort „Ottavio Paravicini“, in: https://hls-dhs-dss.ch/de/articles/017911/2009-0609/ (31. Dezember 2020).

79 Vgl. Archivio Segreto Vaticano, Fondo Borghese, II 6; III, 14 B, 1-16; III, 22 A; III, 29; III, 48 M; III, 128 I; Segreteria di Stato, Svizzera, Volume 5, 7-9.

80 Vgl. Dizionario biografico degli Italiani, Roma 1971, Vol. 37.

81 Vgl. Stichwort „Giovanni della Torre“, in: https://hls-dhs-dss.ch/de/articles/015448/201205-18/ (31. Dezember 2020).

82 Ebd.

83 Es handelt sich um das heutige Bistum Krk in Kroatien. Das Gebiet war damals in das venezianische Staatskirchensystem eingebunden.

84 Vgl. Caspar Wirz: Bullen und Breven aus italienischen Archiven, S. 447, 455-59, 462, 464, 468. 
ne: Venedig war gegen ihn, da sie einen anderen, eigenen Kandidaten bevorzugt hatten. Er leitete sechs Jahre das Bistum, bis dann Papst Clemens VIII. ihn am 13. November 1595 zum Nuntius in der Schweiz ernannte. Diese Wahl hing auch damit zusammen, dass der einzige nicht-italienische Nuntius Lewis Owen gestorben war und der Papst unbedingt die Stelle in Luzern wieder besetzen wollte. Die ständige Nuntiatur in Luzern steckte zu della Torres Zeit erst in den Anfängen, was die feste Stelle in der Eidgenossenschaft betraf. ${ }^{85}$ Es fehlte eine gewisse Kontinuität, die der Kardinal und Mailänder Erzbischof Karl Borromäus als Visitator unbedingt empfohlen hatte. Hinzu kam die Auseinandersetzung zwischen Schweizern und dem Papst. Die Schweizer hatten es Papst Gregor XIII. übelgenommen, dass das Kirchenoberhaupt ihnen etwa 40000 Scudi schuldete. Es ging um die Bezahlung von Schweizer Truppen, die bei einem militärischen Angriff in Frankreich eingesetzt wurden. Das Söldnerwesen gehörte zu den wichtigsten Aufgaben der Nuntien in Luzern des 16. und 17. Jahrhunderts. $^{86}$

Auch hatte es della Torre als Nuntius in Luzern mit einer komplexen Lage zu tun: Die Eidgenossenschaft war ein Bund mit großen Unterschieden unter ihren Bürgern. Ein weiteres Problemfeld für die Nuntiaturstelle in Luzern waren die diplomatischen Herausforderungen: Spanien und Frankreich lösten einen Wettkampf aus, um ihre jeweiligen Interessenssphären $\mathrm{zu}$ vergrößern. Dabei spielte der Alpenzugang eine wichtige politische, militärische und vor allem auch wirtschaftliche Rolle. ${ }^{87}$

Als Giovanni della Torre in Luzern ankam, musste er zunächst sein Image aufpolieren, da er als zu franzosenfreundlich eingestuft wurde. Wenige Wochen nach seiner Fahrt in die Schweiz im April 1596 hatte er bereits vor seiner Ankunft seine erste Auseinandersetzung mit den Einheimischen, die von ihm das vom Papst geschuldete Geld verlangten. ${ }^{88}$ Als er versprach, dass er diese Schulden ratenweise bezahlen werde, wurde die Lage wieder etwas ruhiger. In Luzern kam er erst im Juni an. Über seine Anfangsschwierigkeiten schrieb er am 1. März 1596 nach Rom:

85 Vgl.: Archivio Segreteria Vaticano, Fondo Borghese, II 6; III, 14 B, 1-16; III, 22 A; III, 29; III, 48 M; III, 128 I; ebd., Segreteria di Stato, Svizzera, Volume 5, 7-9; Klaus Jaitner: Die Hauptinstruktionen Clemens' VIII. für die Nuntien und Legaten an den europäischen Fürstenhöfen, S. CL, CLII, CCLIX-CCLXI, 365-389; Giovanni Giuseppe Capodagli: Udine illustrata, S. 339; Henri Biaudet: Les nonciatures apostoliques permanentes jusqu'en 1648, S. 169, 184, 189.

86 Vgl. Daniel Robert Kramer: Das Söldnerwesen.

87 Vgl. Lea Haller: „Transithandel“.

88 Archivio Segreteria Vaticana, Fondo Borghese, II 6, c. 220: „Il 9 maggio a Bellinzona era già sottoposto a "gran calca per la rifattione di quel pagamento che pretendono“. 
Ich habe Eurer Majestät den Bericht über die Resolution gegeben, und ich sollte meine Reise beginnen, um zu sehen, ob die Vorschläge bei den Schweizern eingedrungen sind, denn bis zu diesem Tag meine ich, dass diesbezüglich nichts geschehen ist. Jetzt, da ich mir dort Gehör verschafft habe und mehr über sie weiß, scheint es mir nicht angebracht zu sein, Ihnen in Briefen darüber zu berichten. Sobald ich in Mailand bin, können Sie mir die Berichte dorthin schicken, damit ich erfahre, was zu tun ist, falls sie weiterhin mit ihrer Härte vorgehen. Das scheint mir dem besseren Ruf dieses Heiligen Stuhls zu dienen.“ 89

Im selben Brief ging er auf sein Schweiz-Bild ein. Für ihn müsse man mit Härte mit den Katholiken umgehen und sich nicht erweichen lassen. Er stellte aber auch fest, dass man mit Versprechen bei den Schweizern vieles erreichen könne. Einerseits ging es ihm um den eigenen Ruf, andererseits musste er einen Ausweg finden, um überhaupt in die Schweiz einreisen zu können.

Es war mit viel Demut verbunden, von meiner Seite festzustellen, dass ich einen gewissen guten Ruf in die Angelegenheit gebracht habe, was mir aber derzeit einen Ausschluss gebracht hat. Das lag an einem Missverständnis, was dazu führt, dass ich jetzt auf gewisse Weise mit meinen Füßen besser vorwärts gehen kann und muss, und deshalb erlaube ich mir, Sie wieder anzuflehen, damit ich mit meinem eigenen Kopf regieren darf, dass Sie mir besondere Gebote schicken mögen, zu dem, was ich tun muss. ${ }^{90}$

In den ersten vier Jahren seiner Amtszeit besuchte er viele Orte in der Schweiz, um vor allem nachzuprüfen, inwieweit die Beschlüsse des Konzils von Trient auch wirklich umgesetzt wurden. Seine Hauptzielorte waren neben Luzern Chur, Konstanz, St. Gallen und Freiburg im Üechtland. Am 6. Januar 1597 schrieb er aus Luzern nach Rom:

Mit all dem, hoffe ich, dass wir mit der Zeit etwas Gutes mit den Mitteln der Beichte tun werden, denn diese Nation muss man mit Bestimmtheit und mit Geduld aufnehmen, um das höchste Gebot des Allerheiligsten auszuführen, und ich warte darauf, den Bücherindex zu bekommen. In der Zwischenzeit sende ich mit einem anderen Brief getrennt einen Katalog und eine Sammlung, die aus Büchern besteht, die im vergangenen Jahr von Ketzern gedruckt wurden ...91

1598 besuchte er auch das Elsass. Was er vorfand, stellte er in seinen Briefen und „Dispacci“ fest. Er betonte aber nicht nur die negativen Seiten der Schweizer. In einem Brief vom 3. April 1596 aus Mailand nach Rom:

(...) Ich habe aber auch eine gute Anzahl an Freunden, die meine Sachen mit großer Höflichkeit unterstützen, und ich folgte dem Ruf, dass man sich hier nicht für ein paar Tage

89 Segreteria di Stato, Svizzera, Volume 5, Nr. 4, f. 8-9.

90 Ebd.

91 Segreteria di Stato, Svizzera, Volume 5, Nr. 77, f. 170. 
festsitzen sollte wegen den neuen Gerüchten über die Pest, was in diesen Kantonen für Aufregung sorgte, sodass das ganze Land der Schweiz alles aus diesem Staat verbannt hat, wie Eure Majestätische Herrschaft auf dem beiliegenden Blatt sehen wird, das ich Ihnen mitschicke. ...

Was in Luzern geschieht, für den Fall, dass diese Männer grundlos Herrn Kardinal Paravicini aus irgendeinem Grund nicht ertragen konnten, denn wenn sie sich beschweren, dass er in der Durchsetzung der Gesetze ihnen nicht ganz günstig geneigt war und dass sie von ihm auch mit Worten schlecht behandelt worden waren, dann war das nicht ich, da er das hätte besser tun können, um dem Apostolischen Stuhl zu dienen, gegen den jetzt diese gemeinsamen Handlungen ausgeübt werden, aber ich hoffe auf einen kurzfristigen Ausweg, (...) $)^{92}$

$\mathrm{Zu}$ seinen Beschreibungen zählen auch Konversionen und die seiner Meinung nach erfolgreichen Kämpfe gegen die „Ungläubigen“. Auch stellte er fest, dass es zahlreiche Kirchen gebe, die sehr gut gehalten, gepflegt und geführt werden. ${ }^{93}$ Doch musste er auch feststellen, dass es „unwürdige“ Bischöfe und Äbte gab, die ein „skandalöses Leben“ führten. Er fand auch Klöster vor, die sich nicht an die jeweiligen Ordensregeln hielten oder so viele Schulden auf sich geladen hatten, dass sie eigentlich bankrott waren. Auch Vorwürfe des Konkubinats und die Nichteinhaltung der Klausurregel sind in seinen Beschreibungen oft anzutreffen. Della Torres Verbündete waren die Kapuziner, die seiner Meinung nach „die Besten und Fruchtbarsten“ beim Predigerdienst seien. Die Jesuiten hingegen seien seiner Einschätzung nach vor allem gute Kontrolleure in den Priesterseminaren und Klöstern. Als Nuntius ging er bei Nichteinhaltung der kirchlichen Vorgaben radikal vor, auch wenn er von Rom aufgefordert wurde, „mit Sorgfalt“ umzugehen. Unter seiner Nuntiatur wurden auch zahlreiche neue Klöster eröffnet, wie beispielsweise in Freiburg (Schweiz) (1601), Konstanz (1602) und Ensisheim (1603). ${ }^{94}$

Da er sich vor allem der kirchlichen Pastoral widmete, war die politisch-diplomatische Seite eher sekundär in seiner Zeit als Nuntius in Luzern. Er beschränkte diesen Bereich auf die Beobachtung, Informationsweitergabe und Durchführung der Befehle aus Rom. Della Torre unterstützte aber auch die Vermittlerrolle Roms im Zwist zwischen Spanien und Frankreich. Viel eindeutiger war allerdings die Unterstützung della Torres für den „Goldenen Bund“. Er war aber auch sehr aufmerksam, was die Tagsatzung in Baden betraf, und pflegte

92 Segreteria di Stato, Svizzera, Volume 5, Nr. 6, f. 14.

93 Segreteria di Stato, Svizzera, Volume 5, c. 70: „Con chiese molto ben a l'ordine et con ottima custodia de' sacramenti et ricamente [sic!] ornate ... religiosi di vita et dottrina non solo competente ma in alcuni esquisita et esemplare.“

94 Vgl. Stichwort „Giovanni della Torre“, in: https://hls-dhs-dss.ch/de/articles/015448/201205-18/ (31. Dezember 2020). 
somit eine enge Verbindung $\mathrm{zu}$ den katholischen Kantonen. Bei seinen Besuchen ist er aber ein gerngesehener Gast. So schrieb er in einem Brief vom 6. Mai 1596 aus Bellinzona nach Rom:

Ich werde intensiv aufgesucht auch in diesem Land der Schweizer, und wenn ich ihnen sage, dass ich keine Befugnisse habe, dann werfen sie mir vor, dass ihre Herren doch recht hätten, wenn sie sagen, dass sie ohne einen Nuntius leben können. Ich hätte niemand, der mir ähnlich sei und solche Autorität hätte, wie es eben einige Nuntien innehätten. Ich glaube, dass ich in einem anderen Brief Ihnen bereits einmal ähnlich berichtet hatte, ohne dass Sie mir eine Lösung angegeben haben ...95

Er scheute sich aber nicht, auch Lügen vorzutragen, wenn es nötig war. So leugnete er öffentlich seine Kenntnisse über einen Angriffsplan der Savoyer ab, die am 21. und 22. Dezember 1602 Genf angreifen wollten. Daraufhin versuchte er mit dem Traktat von Saint-Julien, am 21. Juli 1603, diese Situation wieder zurechtzubiegen. Über die Verhandlungen und Bündnisse mit Frankreich schrieb dalla Torre am 9. Juni 1604 von Luzern nach Rom:

Der Botschafter von Frankreich sagt, dass sie sich vor den Schweizern fürchten, weil sie in ihre Heimat eindringen würden. Doch das behauptet er nur, damit das Volk diesem Ruf Glauben schenkt. Und es fehlen auch keine Ketzer-Prediger, die wie immer auf seiner Seite sind, wie sie in ihren teuflischen Versammlungen das tun, und diese Woche ist die nächste Versammlung. ${ }^{96}$

Die wirtschaftlich-militärische Seite seines Amtes bestand darin, Söldner zu erwerben, die Papst Clemens VIII. in Ungarn gegen die Ottomanen einsetzen wollte. ${ }^{97}$

Im Gegensatz zu Paravicini schreibt er weniger über politische Begebenheiten im In- und Ausland. Della Torre geht vielmehr auf die pastorale Tätigkeit in der Schweiz ein. Eine wichtige Rolle spielt dabei die Missionsarbeit der Kapuziner, die nicht nur für die Konversionsversuche der katholischen Seite eingesetzt werden, sondern auch, um die „Spiritualität“ in den katholischen Landen zu „stärken“. Wie bei Paravicini zeigt sich auch bei della Torre eine einigermaßen gute Kenntnis der Schweiz betreffend Geographie sowie der politisch-religiösen Lage. In den meisten Briefen der Nuntien geht es um die Zusammenkünfte bei den Tagsatzungen der katholischen Orte. ${ }^{98}$

95 Segreteria di Stato, Svizzera, Volume 11, f. 26.

96 Segreteria di Stato, Svizzera, Volume 6, f. 254.

97 Vgl. Stichwort „Giovanni della Torre“, in: https://hls-dhs-dss.ch/de/articles/015448/201205-18/ (31. Dezember 2020).

98 Vgl. Helmut Meyer: Die Schweiz im Zeitalter der konfessionellen Spaltung. 
Die religiöse Situation versuchte er vor allem im Wallis zu beeinflussen, um den Katholizismus in diesem Kanton zu festigen, da vor allem bei den führenden Familien sich auch immer mehr der reformierte Geist durchzusetzen schien. So gelang es wichtigen Walliser Persönlichkeiten am 5. August 1600 mit dem rätischen Dreibund, der protestantisch war, ein Bündnis abzuschließen. Im Oktober 1602 gab es einen Aufstand der Katholiken, die von della Torre gefördert wurden, indem er Kapuzinern ordnete, das Volk gegen die protestantischen Lokalbehörden aufzubringen. Im August 1603 wurde dieser Aufstand erfolgreich für della Torre beendet, da das Wallis wieder vollständig katholisch wurde. Wie Fink erklärt, entsandte Luzern als katholischer Vorort 1604 Priester in den Kanton Wallis und „brachte der katholische Vorort seinen Einsatzwillen zugunsten der katholischen Reform deutlich zum Ausdruck“. ${ }^{99}$ Diese Mission ermöglichte nämlich die religiöse Stärkung und Erneuerung des Oberwallis. Die reformierten Lokalpolitiker mussten den Platz räumen. Häretische Bücher wurden beschlagnahmt. Und man hatte zwei Monate Zeit, um zum Katholizismus zu konvertieren, um nicht aus dem Kanton verwiesen zu werden. Einzig der deutschsprachige Teil des Wallis blieb nicht linientreu. ${ }^{100}$

Ein weiterer Konfliktpunkt betraf die Beziehung zwischen Graubünden und Venedig. Die „Serenissima“ war in vielerlei Hinsicht eine direkte Konkurrenz des Papststaates. Deshalb wies della Torre mit großer Sorge auf das am 15. August 1603 in Davos geschlossene Bündnis hin. Damit sicherte sich Venedig eine wichtige Söldnerquelle sowie den Getreide- und Salzhandel. In einem Brief vom 23. Mai 1604 schreibt della Torre über die Bündnisse Frankreichs und Venedigs und die Bedeutung von Graubünden:

Um den Anhängern Frankreichs und Venedigs keinen Raum für Zank in der Bevölkerung $\mathrm{zu}$ lassen, wie sie bereits versuchen zu tun, und indem sie auch sehen, dass, wenn man den Schweizern nicht die Macht erteilt, das zu Unzufriedenheit und wenig Freundschaft führt, doch da sie dies akzeptiert haben, zeigen sie sich als wahre Freunde. ${ }^{101}$

99 Urban Fink: Die Luzerner Nuntiatur 1586-1873, S. 49.

100 Vgl. Stichwort „Wallis“, in: https://hls-dhs-dss.ch/de/articles/007396/2018-01-11/ (31. Dezember 2020): „Zu Beginn des 17. Jahrhunderts wurden die Konflikte zwischen fürstlicher und kommunaler Herrschaft zugunsten der Zenden entschieden: Nachdem die sogenannten Patrioten, die Mitglieder der einflussreichsten Familien der Landschaft Wallis, dem Bischof und dem Domkapitel Sitten 1613 zwischenzeitlich und 1634 schließlich definitiv den Verzicht auf die Carolina und damit auf die Landeshoheit abgerungen hatten, besiegelten die Beschränkung der politischen Rolle des Fürstbischofs auf Ehrenrechte (z. B. Vorsitz im Landrat) und der Ausschluss des Domkapitels aus dem Landrat das Ende der weltlichen Herrschaftsrechte des geistlichen Stands. Obschon der Bischof bis 1798 den Titel eines Reichsfürsten (comes et praefectus) führte, setzten Gemeinden und Zenden demokratische Strukturen durch.“

101 Segreteria di Stato, Svizzera, Volume 6, f. 248. 
Della Torre fand eine schwierige Lage vor. Das lag einerseits daran, dass es lange Zeit keine stabile Nuntiatur in der Eidgenossenschaft mehr gab, und andererseits die Schweizer Söldner Papst Gregor XIII. zürnten, der sie für 40000 Scudi für die militärische Kampagne in Frankreich angeheuert hatte, ohne aber sie bezahlt zu haben, was - wie wir bereits gesehen haben - die größte Schwierigkeit in der Nuntiaturzeit von Paravicini war. ${ }^{102}$

Sorgen bereitete della Torre auch die politische und religiöse Fragmentierung in der Schweiz. Hinzu kam auch die diplomatische Einmischung aus Frankreich und Spanien, die sich vor allem für die alpinen Zugänge interessierten und auch für die Anwerbung neuer Söldner. Diese Themen prägten seinen fast zehnjährigen Aufenthalt in der Eidgenossenschaft. ${ }^{103}$

In der Instruktion, die er zu Beginn seiner Amtszeit erhielt, wurde ihm aufgetragen, sich im kirchenrechtlichen Sinne des Papstes der Verteidigung der römisch-katholischen Kirche zu befleißigen. Dies sei wichtig nicht nur gegenüber den protestantischen Kantonen, sondern auch gegenüber den Katholiken in der Eidgenossenschaft, indem bei diesen die Autorität der römischen Kirche und ihre Vorgaben als „Garant für die Freiheit“ der Katholiken in der Eidgenossenschaft präsentiert werden sollten, heißt es in der Instruktion. Was seine Aufgabe bei den Protestanten betraf, so wurde ihm aufgetragen, bei diesen so viele Informationen wie möglich in Erfahrung zu bringen. Da er nicht direkt bei den Protestanten eingreifen konnte, ging es auch darum, jene Teile der Bevölkerung zu bewahren, die „von der Häresie“ befallen werden könnten. ${ }^{104}$

Bevor er nach Luzern reiste, blieb della Torre von Januar bis März 1596 in Padua, wo er mit Selbstzweifeln an seinen diplomatischen Fähigkeiten rang. Er dachte, dass die Spanier wenig von ihm hielten, da er als Frankophiler galt. In Mailand tauschte er sich mit Federico Borromeo aus, um dann Anfang April 1696 in die Schweiz zu reisen. Am 9. Mai wurde er in Bellinzona empfangen, doch dort erwartete ihn „eine große Menge, die auf jene Zahlung wartete, auf der sie beharren. “105

Einzig als della Torre der Menge versprach, die Zahlung in Raten baldmöglichst vorzunehmen, beruhigten sich die protestierenden Menschen. ${ }^{106}$ In Luzern ging er vor allem dadurch vor, dass er die Beschlüsse des Konzils von Trient umzusetzen versuchte. Hierbei kümmerte er sich um die Einstellung des

102 Vgl. Dizionario biografico degli Italiani, Roma, Volume 37, S. 568.

103 Ebd.

104 Vgl. Klaus Jaitner: Die Hauptinstruktionen Clemens' VIII. für die Nuntien und Legaten an den europäischen Fürstenhöfen 1592-1605. Im Auftrag des Deutschen Historischen Instituts in Rom bearbeitet, Tübingen 1984, S. 370.

105 Vgl. Archivio Segreto Vaticano, Fondo Borghese, II 6, c. 220.

106 Vgl. Dizionario biografico degli Italiani, Volume 37, S. 568. 
Klerus, die Klosterreform und die Umsetzung der „moralischen Vorgaben“ innerhalb der Ortskirche. Zu den weiteren Aufgaben zählten auch die Anwendung der Liste der verbotenen Bücher gemäß dem „clementinischen Index“, den er im August 1596 von Rom erhielt, sowie die Kontrolle der Liturgiepraxis in dem Gastland. So schreibt der Nuntius am 1. Juli 1597 von Zug nach Rom:

\begin{abstract}
Als ich vor einer Woche hierher kam, wurde den Bedürfnissen dieser Völkern mit den Gottesdiensten entsprochen, um ihre Zuneigung gegenüber dem Heiligen Stuhl zu stärken; und ich verspreche Ihrer Hoheit, dass dies alles sehr viel Früchte hervorbringen wird, da dieser Kanton bei der Gelegenheit, die ich gestern mit einem Mittagessen für die Anführer dieses Ortes gab, mir all ihren nötigen und verpflichtenden Gehorsam versprochen haben gegenüber Unserem Herrn. Das äußerten sie nicht nur mit sehr eindrucksvollen Worten, die mich sehr erfreuten, sie sagten dies auch freiwillig, was die Reform des Frauenklosters betrifft. Das Kloster der Kapuziner werde ich morgen besuchen, und dort werde ich den Befehl dieser ersten Regel geben. Ich betrachte dies als nötig, und um sie nicht zu erzürnen, werde ich mit Bestimmtheit diese ungehemmte Freiheit beseitigen .... ${ }^{107}$
\end{abstract}

In den ersten vier Jahren seiner Nuntiaturzeit in Luzern besuchte della Torre viele Orte in der Eidgenossenschaft, um die Konversion von Protestanten zu begutachten und „falsche Katholiken“ zu verfolgen. Vor allem berichtete er über „Ortskirchen, die sehr gut geführt und sakramental geleitet werden und die auch reichlich geschmückt sind ... die ein religiöses und kirchenlehramtlich vorbildliches Leben führen, die zum Teil außerordentlich und vorbildhaft sind“. ${ }^{108}$

Doch andererseits musste er auch feststellen, dass es Bischöfe und Äbte gab, die „peinlich und ungeeignet“ waren. Auch berichtete er von Klöstern, die falsche Entwicklungen durchmachten oder ohne Regeln geführt werden. Des Weiteren stellte della Torre fest, dass es monastische Gemeinschaften gab, die mit Geldschulden zu kämpfen hatten oder in andere unrechtmäßige Machenschaften verwickelt waren. Was er ebenfalls feststellte, waren Geistliche, die im Konkubinat lebten, oder Klausurmönche und -nonnen, die sich nicht an die Abgeschiedenheitsregel hielten. ${ }^{109}$

Die wichtigsten Orte, die della Torre aufsuchte, waren Luzern, Chur, Konstanz (Bistum), Sankt Gallen und Freiburg im Üechtland. 1598 besuchte er auch das Elsass. An seiner Seite waren vor allem Kapuziner, die seiner Meinung

107 Segreteria di Stato, Svizzera, Volume 5, Nr. 111, f. 256.

108 Vgl. Segreteria di Stato, Svizzera, Volume 5, f. 70.

109 Vgl. Stichwort „Konkubinat“, in: https://hls-dhs-dss.ch/de/articles/016107/2007-09-10/ (31. Dezember 2020): „Im 16. Jahrhundert nahmen die Bemühungen zu, das im kath. Klerus häufig vorkommende Konkubinat zu unterdrücken. Trotz strenger Strafen ging diese Form des Konkubinats nur langsam zurück und verschwand in den Randregionen der heutigen Schweiz (z. B. im Bistum Basel) erst gegen Mitte des 17. Jahrhunderts und nur unter Androhung der Exkommunikation.“ 
nach, „die besten und erfolgreichsten“ 110 Ordensvertreter waren, was das Predigen - also die Glaubensvermittlung und Katechismus - betrifft, während della Torre die Jesuiten als „Kontrolleure der Priesterseminare und Klöster“111 einsetzte. Bei Ahndungen von Fehlern ging er mit Personalersetzungen oder Abmahnungen vor. Wie aus der Korrespondenz aus Rom nachzulesen ist, ging er nicht immer sonderlich „diplomatisch“ vor.

Erfolgreich war er bei der Mitgründung von Kapuzinerklöstern in Freiburg im Üechtland (1601), Rapperswil (1602), Konstanz und Ensisheim (1603), auch förderte er die Priesterseminare in den Jesuitenkollegien in Freiburg im Üechtland, Konstanz (ab 1603) und Luzern. Im Juli 1602 förderte er nach einem Treffen mit den Äbten von Sankt Gallen, Muri und Fischingen die Gründung einer Schweizer Kongregation der Benediktiner ${ }^{112}$.

Während er sich vor allem um innerkirchliche Entwicklungen kümmerte, vernachlässigte er die politisch-diplomatischen Aktivitäten als Nuntius. Diese beschränkten sich vorwiegend auf Beobachtungen und Informationsvermittlung nach Rom. Was die Diplomatie betraf, die in jener Zeit besonders von den Spannungen zwischen den Monarchen Spaniens und Heinrich IV. gekennzeichnet war, so kümmerte sich darum vor allem der Neffe des Kardinals Pietro Aldobrandini, Giulio Aldobrandini. ${ }^{113}$ Della Torre unterstützte jedoch den „Goldenen Bund“ von 1587 (Luzern, Uri, Schwyz, Nid- und Obwalden, Zug, Freiburg im Üechtland und ab 1598 auch der katholische Teil Appenzells). ${ }^{114}$

Bei der Tagsatzung in Baden nahm della Torre die Stellung des Beobachters ein, der vor allem versuchte, mit jenen „Verbündeten des Papsttums“ der aggressiven und radikalen Haltung der reformierten Kantone Zürich, Bern, Basel und Schaffhausen entgegenzutreten. ${ }^{115}$

Della Torre ging mit den Katholiken nicht immer sehr diplomatisch um und log sie offen an, wie beispielsweise, als Karl Emanuel von Savoyen Genf angriff. Die Einnahme vom 21. und 22. Dezember 1602 war ein Desaster für Karl Emanuel und auch ein Affront gegenüber den eidgenössischen Katholiken. Della Torre dementierte öffentlich, dass er vom Vorhaben Karl Emanuel wusste, obwohl dies anhand der Korrespondenz eindeutig bewiesen werden kann, dass er davon im Vorfeld wusste. ${ }^{116}$

110 Vgl. Dizionario biografico degli Italiani, Volume 37, S. 568.

111 Vgl. ebd.

112 Vgl. Dizionario biografico degli Italiani, Volume 37, S. 569.

113 Vgl. ebd.

114 Vgl. Stichwort „Goldener Bund“, in: https://hls-dhs-dss.ch/de/articles/017187/2005-0909/ (31. Dezember 2020).

115 Vgl. Dizionario biografico degli Italiani, Vol. 37, S. 569.

116 Vgl. ebd. 
Aus Rom kam ebenfalls keine Unterstützung gegenüber Savoyen, dennoch scheint, dass della Torre versuchte, Karl Emanuel zu unterstützen. Er versuchte, sein missliches Verhalten diplomatisch zu umgehen, indem er den Vorfall kleinredete und sich für die Friedensverhandlung von Saint-Julien am 21. Juli 1603 einsetzte. Dieses Traktat brachte den politischen und militärischen Schutz Genfs ein. ${ }^{117}$

Was die militärische Tätigkeit betraf, so setzte sich della Torre vergeblich für die Anwerbung neuer Söldner aus der Eidgenossenschaft ein, um die antiottomanische Expedition von Papst Clemens VIII. in Ungarn zu unterstützen. 1598 setzte er sich erfolgreich gegen die Hilfesuche von Francesco Donato, dem Gesandten von Cesare d'Este, ein. Dieser wollte die Grafschaft von Ferrara neu ordnen. ${ }^{118}$

Ebenfalls erfolgreich war er bei der „Verteidigung“ der Katholizität im Wallis, in der zu seiner Zeit das Verhältnis zwischen Katholiken und Reformierten konfliktreich war. Die Reformierten gewannen dort immer mehr an Einfluss. Am 5. August 1600 erreichten reformierte Walliser Anführer ein Bündnis mit den protestantischen Kreisen aus Graubünden. Im darauffolgenden Jahr weitete sich dieser Bund auf Bern aus. Der Nuntius sah diesen Bund, der auch auf Zürich ausgeweitet werden sollte, als Gefahr gegenüber den Katholiken. Er beschrieb diesen Bund als eine Gruppe, die die Bistümer von Sitten und Chur abschaffen sowie den Einfluss der Katholiken eindämmen wolle.

Im Oktober 1602 koordinierte della Torre deshalb eine katholische Antwort auf diesen Bund, indem er mithilfe der Kapuziner eine massive Propaganda einsetzte. Vor allem rief er die Katholiken zu einer Einstellung des Mitleids und sittlicher Strenge auf („esercizio della pietà“ und „rigore morale“). ${ }^{119}$ Damit spielte er vor allem die katholische ländliche Bevölkerung gegen protestantische Beamte aus.

Druck übte della Torre auf die katholischen Anführer aus, damit diese sich für das katholische Wallis einsetzten. Hierfür setzte er sich für Adrien de Riedmatten ein, Neffe des Bischofs von Sitten, Hildebrand de Riedmatten, der als Bischof umsichtig umging - zu umsichtig in den Augen della Torres. Adrien de

117 Vgl. Stichwort „Savoyen“, in: https://hls-dhs-dss.ch/de/articles/006641/2015-01-15/ (31. Dezember 2020): „Der Krieg zwischen Karl Emmanuel und Frankreich wurde 1601 mit dem Vertrag von Lyon beendet. Der Herzog verlor das Pays de Gex und besaß nun nördlich der Alpen nur noch Savoyen. Die Escalade von 1602 rief eine Gegenreaktion Genfs und seiner Verbündeten hervor, die das Gebiet nördlich des Salève, das Chablais und das Bas-Faucigny überfielen. Im Frieden von Saint-Julien von 1603 anerkannte der Herzog schließlich Genfs Unabhängigkeit.“

118 Vgl. Helmut Meyer: Die Schweiz im Zeitalter der konfessionellen Spaltung. 119 Vgl. ebd. 
Riedmatten wurde 1604, nach dem Tod seines Onkels, zum Nachfolger als Bischof von Sitten. ${ }^{120}$

Im August 1603 spitzte sich die Lage zu, indem unter der Leitung von Luzern die katholische Präsenz im Wallis gestärkt wurde. Hierzu setzte sich der Kapuzinerpater Chérubin bei der Versammlung von Viège vom 25. bis 27. März 1604 ein, bei der protestantische Beamte abgesetzt und „häretische Bücher“ beschlagnahmt wurden. Es wurde auch eine Frist von zwei Monaten vereinbart, in der Nicht-Katholiken zum Katholizismus konvertieren oder den Kanton verlassen mussten. Dies galt vor allem im südlichen französischsprachigen Teil des Wallis, im deutschsprachigen Teil ließ della Torre die Protestanten noch gewähren. Was ihm nicht gelang, war eine Anbindung des Kantons an Spanien, da sich die französische Diplomatie querstellte. ${ }^{121}$

Was Graubünden betraf, so setzte er sich gegen das Bündnis mit Venedig ein, das am 15. August 1603 in Davos besiegelt wurde. Bei diesem Bund ging es vor allem darum, dass Venedig bündnerische Söldner anwerben und militärische Güter kaufen sowie den Weizen- und Salzhandel fördern konnte. Gerade der Handel führte zu einem Konkurrenzkampf zwischen dem Papsttum und Venedig, da beide dieselben Interessen in diesem Bereich hatten. Nachdem die Grafschaft von Ferrara Teil des Kirchenstaates wurde, versuchte della Torre, die Salz-Salinen von Comacchio zu fördern, indem er einige florentinische Händler in Mailand dafür gewann. ${ }^{122}$

Er würdigte den Bund von Luzern vom 28. April 1604 zwischen dem „Goldenen Bund" und Spanien, ohne sich selber dafür persönlich einzusetzen. Dieser Bund führte zu einem diplomatischen Ausgleich zwischen dem Kirchenstaat, Spanien und Frankreich, nachdem die französische Diplomatie im Januar 1602 ein Bündnis Heinrichs IV. mit der Eidgenossenschaft geschlossen hatte. ${ }^{123}$ Damit hatten die Katholiken auch eine uneingeschränkte Kontrolle der Alpenpässe zwischen Mailand und den Flandern inne, was den Handel beeinflusste.

Giovanni della Torre verließ Luzern im Juni 1606. ${ }^{124}$

Nach seinem Weggang im Juni 1606 warf man ihm vor, für die Habsburgischen Kaiser Rudolf und Matthias diplomatisch aktiv gewesen zu sein, ${ }^{125}$ was aber anhand der Dokumentenlage nicht zu beweisen ist. ${ }^{126}$

120 Vgl. Emil Tscherrig: Bartholomäus Supersaxo 1638-1640 und Adrian III. von Riedmatten 1640-1646.

121 Vgl. Dizionario biografico degli Italiani, Volume 37, S. 570.

122 Vgl. Hermann Kellenbenz: Finanzen und Staatsräson in der frühen Neuzeit Europas.

123 Vgl. Dizionario biografico degli Italiani, Volume 37, S. 570.

124 Ebd.

125 Vgl. Giovanni Giuseppe Capodagli: Udine illustrata, S. 339.

126 Vgl. Dizionario biografico degli Italiani, Volume 37, S. 570. 
Am 15. Februar 1606 erhielt della Torre die Ehrenbürgerschaft Roms. 1607 schrieb er eine „Descriptio Helvetiae“, die er Kardinal Scipione Borghese widmete. Darin beschrieb er die wichtigsten Schweizer Orte, und sie ist mit detailgetreuen Illustrationen geschmückt. ${ }^{127}$

Nach seiner Rückkehr nach Italien gibt es wenige Dokumente über ihn. Man weiß, dass er 1617 der Kathedrale von Padua einen Teil der Reliquie des Heiligen Kreuzes schenkte sowie Restaurierungsarbeiten ausführen ließ. Er starb Anfang 1623 und wurde in der Kapelle des Heiligen Kreuzes in jener Kathedrale bestattet. ${ }^{128}$

Mit der Nuntiatur dalla Torres reiht sich ein Papstgesandter ein, der auch den Auftrag hatte, das Bild des Heiligen Stuhls bei den Schweizer Katholiken zu verbessern. So hatte warnte Papst Clemens VIII. dalla Torre beispielsweise die Katholiken im Appenzell zu besuchen, da die katholischen Gläubigen in jenem Ort von einem früheren Papst-Legaten geschockt gewesen seien. Der Vertreter des Apostolischen Stuhls, vermutlich ein Legat aus der Zeit der Mailänderkriege, sei durch „einen kurzen Rock und schlechten Sitten, Unkeuschheit, Geiz und unfrommes Gebaren“ aufgefallen. ${ }^{129}$ Deshalb ging dalla Torre so um, dass er „durch regen Briefverkehr und mündliche Besprechungen mit den appenzellischen Tagsatzungsboten und den Kapuzinern des Klosters Appenzell“"130 eine Annäherung aufsuchte.

\subsubsection{Fabrizio Verallo (1606-1608)}

Wiederum war es ein Römer, der nach Luzern gesandt wurde: Verallo ${ }^{131}$ ist um 1560 in Rom geboren. Und auch er hatte enge familiäre Beziehungen zu einem Papst, und zwar war er mit Papst Urban VII. (1590) verwandt. Nach seiner Karriere an der Kurie als Signaturreferendar (1594) und dann als Inquisitor in Malta (1600) sowie als Mitarbeiter der römischen Inquisition (1605) wurde er zum Bischof von San Severo ernannt. Im selben Jahr erfolgte auch die Ernennung zum

127 Vgl. Caspar Wirz: Bullen und Breven aus Italienischen Archiven, S. XXXVII.

128 Vgl. Dizionario biografico degli Italiani, Volume 37, S. 570.

129 Zit. nach: Rainald Fischer: Der Besuch der päpstlichen Nuntien Giovanni Francesco Bonhomini (1579) und Giovanni della Torre (1599) in Appenzell, S. 7.

130 Ebd.

131 Vgl. Stichwort „Fabrizio Verallo“, in: https://hls-dhs-dss.ch/de/articles/034833/2013-0221/ (31. Dezember 2020). 
Nuntius in Luzern. ${ }^{132}$ Seine Bischofsweihe nahm der Kardinal und Jesuitenpater Roberto Bellarmino vor. ${ }^{133}$

Der frisch in Luzern angereiste Nuntius Verallo schreibt in seinen ersten Briefen vorwiegend über Geldangelegenheiten. So geht es ihm zunächst um die Finanzierung des Collegio Heleviticum sowie um Beiträge für Rom und den Söldnerkauf. ${ }^{134}$

Viele Briefe sind jedoch verdorben oder in schlechtem Zustand. Seine „Dispacci“ sind in „Buchform“ fortlaufend aufgeschrieben und, wie bei den „Avvisi“ üblich, es fehlt die Anrede. ${ }^{135}$

Nuntius Verallo kümmerte sich wie seine Vorgänger um die Lage der Katholiken und die Politik einer „Reconquista“. So wurde aus Rom in einem Brief vom 16. Januar 1606 an den Nuntius in Luzern voller Lob festgehalten:

Wirklich gute Neuigkeiten, und am liebsten für Unseren Lieben Herrn war das, was Euer Hochwohlgeboren uns von der Bekehrung der sechs Ortschaften im Thurgau berichtet haben. Das, was Sie schreiben und ekelhaft für die Häretiker klingt, sorgt für Freude, und es ist nun notwendig, dass die Herren der katholischen Kantone den Schutz der Bekehrten einnehmen, da sie ja denselben Stamm haben, und Eure Hoheit soll sie weiterhin unterstützen, wie es sein muss [...]. ${ }^{136}$

In Rom sah man die Probleme in jener Zeit eher beim Verhältnis der Bischöfe zu ihren Gläubigen. Insbesondere die Lage im Bistum Basel schien schwierig. In dem Brief aus Rom vom 16. Januar 1606 heißt es dazu:

Wer Recht hat, kann gut sprechen und muss es mit Leidenschaft verteidigen, und es ist Feigheit, sich in seinem eigenen Turm einzuschließen und zu schweigen, wie dies der Bischof von Basel gegen die Leute von Biel getan hat, und wegen seiner Abwesenheit konnten die Rebellen bequem handeln, auch wenn er gegen sie die Warnung aussprach und den Schutz der katholischen Kantone ersuchte. Doch diese konnten nur das tun, was aus ihrer Sicht angebracht war. So blieb nichts anderes übrig, als diesen Umstand zu akzeptieren, und diese dienten nun den Herren von Zürich. Es gelang ihm nicht, mit seiner Autorität die Kühnheit von Biel zu unterdrücken und damit sicherzustellen, dass die Herren von Bern die Rebellion nicht noch weiter nähren konnten ... ${ }^{137}$

132 Vgl. Urban Fink: Die Luzerner Nuntiatur unter Paul V. als Ausnahmeerscheinung?, S. 429-456, v. a. S. 432, S. 451-456.

133 Robert Bellarmin (1542-1621) war ein Hauptverfechter des römischen Katholizismus und der päpstlichen Vorherrschaft im 16. Jahrhundert. Am 13. Mai 1923 wurde er von Papst Pius XI. selig- und am 29. Juni 1930 heiliggesprochen. 1931 wurde er zum Kirchenlehrer erhoben. Vgl. Thomas Dietrich: Die Theologie der Kirche bei Robert Bellarmin.

134 Vgl. Segreteria Stato, Svizzera Volume 10.

135 Vgl. Segreteria Stato, Svizzera Volume 11.

136 Segreteria Stato, Svizzera Volume 11, f. 34.

137 Segreteria Stato, Svizzera Volume 11, f. 49. 
Aus Rom kommt ein Hinweis auf den Umgang mit Ordensleuten und insbesondere gegenüber Ordensfrauen. In einem Brief aus Rom vom 30. Januar 1608 heißt es:

Alle Skandale sind schlimm, die durch Ordensleute verursacht werden, aber jene, die durch Hochwürden an Nonnen verübt werden, sind noch schlimmer und bedürfen einer Korrektur, deshalb ist die Reform so wichtig ...138

Es ging konkret um den Fall eines Damenstifts (Frauenklosters) von Säckingen $^{139}$ des Franziskaner-Ordens. Nach Schwierigkeiten um 1600 kam der Aufschwung: Das baufällige Kloster konnte von 1609 bis 1616 neu errichtet werden, 1622 zählte man 22 Schwestern. Die Blüte ermöglichte eine Tochtergründung in Ensisheim, die 1625 unabhängig wurde. 1632 zerstörten schwedische Truppen das Kloster. ${ }^{140}$

Eine klare Aversion hatte Verallo gegen Protestanten, die er argwöhnisch beobachtete, und so lässt die römische Kurie in einem Brief vom 23. März 1610 folgendes erläutern:

Die Neigung der Natur zum Bösen ist immer gefährlich in der Kommunikation der Häretiker mit den Katholiken, so dass es für die Freiburger Herren sehr nützlich und notwendig wäre, zu ihnen zu kommen [...], um sich den Ketzern und ihrer bösen Absicht zu widersetzen, und doch müssen Sie den Katholiken umso mehr eintrichtern, dass es getan sein

138 Segreteria Stato, Svizzera Volume 11, f. 51.

139 Wie es in den Briefen heißt, habe sich die Äbtissin „vom Wandel der Zeit hinreißen lassen“ und vergaß dabei die „klösterliche Zucht“ und ließ sich mit einem Diakon ein. Die beiden wollten heiraten, doch wurde dieses Vorhaben verraten, so dass der Diakon die Flucht ergreifen musste. Als die Äbtissin ihm folgte, wurde sie von den Bürgern festgehalten. Kaiser Ferdinand I. verurteilte sie daraufhin zur Haft in einem stiftseigenen Gebäude, dem „Alten Hof“, unter Aufsicht des damaligen Stiftsverwalters und Meiers Johann Jakob Freiherr von Schönau. Da sich die Äbtissin „hatte verführen lassen“, musste sie der klösterlichen Würde entsagen. Daraufhin wurde von den drei noch verbliebenen Chorherren des Dominikanerordens Agatha Hegenzer von Wasserstelz zur Äbtissin gewählt, die man eigens dafür vom Kloster St. Katharinental bei Diessenhofen geholt hatte. Das Kloster wechselte die Ordensgemeinschaft und folgte fortan den Ordensregeln des Heiligen Augustinus. Die Ordensfrauen mussten deshalb das Gelübde der Armut, des Gehorsams und der Keuschheit ablegen. Zusätzlich wurde ihnen „alle Rückkehr in die Welt“ untersagt, ihnen all ihr Eigentum abgesprochen. Diese strengen Ordensregeln stießen bei den noch vorhandenen Stiftsdamen auf großen Widerstand, und so kam es, dass sich keine der Stiftsdamen zur Wiederaufnahme meldete. Vgl. Hugo Ott (Hrsg.): Geschichte der Stadt Säckingen; Ute Ströbele: Zwischen Kloster und Welt: die Aufhebung südwestdeutscher Frauenklöster unter Kaiser Joseph II.

140 Vgl. Hugo Ott (Hrsg.): Geschichte der Stadt Säckingen; Ute Ströbele: Zwischen Kloster und Welt: die Aufhebung südwestdeutscher Frauenklöster unter Kaiser Joseph II. 
muss, und jede Ihrer Stunden dafür einsetzen, der dem Anliegen hilft, um einen Weg zu finden. ${ }^{141}$

„Die Absprachen mit den Ketzern waren immer unsicher“, heißt es in einem Brief aus Rom vom 23. Oktober 1610. ${ }^{142}$ Der Wunsch aus Rom gegenüber dem Nuntius in Luzern bestand darin, vorsichtig beim Umgang mit Bündnissen zu sein. Bündnisse mit den Häretikern sollten den Katholiken immer "suspekt“ sein, heißt es in einem Schreiben aus Rom vom 25. August $1612 .{ }^{143}$ Einige Wochen später hieß es, dass aus päpstlicher Sicht ein Bündnis der katholischen Kantone mit Venedig wünschenswert wäre, doch sehe man die komplizierte Lage in Bezug auf die ebenfalls katholisch orientierte französische Krone. ${ }^{144}$

Trotz oder gerade wegen seiner Nuntiaturstelle versuchte er 1608 erfolglos, die schweizerischen Zisterzienserklöster in einer Kongregation zusammenzuführen und den Einsiedler-Abt zum Bischof der Urkantone zu erheben. ${ }^{145}$ Verallo wurde nach Rom einberufen und von Papst Paul V. im Konsistorium vom 24. November 1608 zum Kardinal kreiert. Er schrieb einige Monate später über die Schweizer in einem Brief vom 20. Juli 1609:

Ich fand so demütige, fromme und wohlmeinende Menschen, dass ich mir die sichere und ausgezeichnete Leitung dieser Kirche und die Zunahme der Religion an den Orten verspreche, die sowohl im geistlichen als auch im weltlichen Bereich entstanden sind; ${ }^{146}$

Im selben Brief beschrieb er auch die Bischöfe, die in der Schweiz waren, und ging auf einen von ihnen ein, ohne ihn namentlich zu nennen. Es handelte sich vermutlich um den damaligen Bischof von Konstanz, da er in dem Brief auch Deutschland nannte:

Und weil ich sah, dass einer von ihnen nach dem Brauch seiner Vorgänger und fast ganz Deutschlands ${ }^{147}$ nicht die üblichen bischöflichen Gewänder trug, sondern als einfacher Priester herumlief, machte ich mich daran, dass er am selben Abend die entsprechenden richtigen Gewänder nach dem römischen Brauch bekam, und er versprach mir, sie nicht nur bei dieser Gelegenheit zu tragen, sondern sich ab sofort und bis ans Ende seines Lebens mit dieser Kleidung zu zeigen, damit er für seine Nachfolger ein Vorbild sein kann, die dasselbe tun müssen: Und nachdem ich mit ihm ernsthaft über seinen persönlichen

141 Segreteria Stato, Svizzera Volume 11, f. 69.

142 Segreteria Stato, Svizzera Volume 11, f. 120.

143 Segreteria Stato, Svizzera Volume 11, f. 222.

144 Segreteria Stato, Svizzera Volume 11, f. 223.

145 Vgl. Stichwort „Fabrizio Verallo“, in: https://hls-dhs-dss.ch/de/articles/034833/2013-02-

21/ (31. Dezember 2020).

146 Segreteria Stato, Svizzera Volume 10C, f. 318.

147 Er verwendet den Begriff „Germania“. 
Besuch in seiner Diözese gesprochen hatte, da die Gläubigen seit langer Zeit das Gesicht ihres Hirten gar nicht gesehen hatten, verblieben wir auf einem Termin, damit er anfangen sollte, seine Diözese zu besuchen. Ich sagte ihm, dass er einen schlechten Ruf hatte, und dass er dies schnell ändern sollte, damit er auch fleißig für die Diözese etwas tun konnte und neben diesem Verdienst, den er von Gott erhalten wird, noch etwas Dankbares für unseren Herrn tun wird .... ${ }^{148}$

In seinem Brief ging er auch auf einen konkreten Vorschlag ein, eine diözesane Versammlung durchführen zu lassen.

Ich schlug ihm die Notwendigkeit einer Diözesansynode vor. Er antwortete mir aber, dass es in diesen Ländern sehr teuer zu stehen komme, sei es für die Größe der Diözese, sei es für die große Anzahl der Priester, sowie weil sich diese Nation nicht mit einer gewöhnlichen Mahlzeit zufrieden gibt, wie in Italien. Ich antwortete ihm, dass wenn man Synoden nicht so oft wie in anderen Ländern durchführen kann, so soll er so schnell zumindest formell eine durchführen. ... ${ }^{149}$

Zum Anliegen der Bestimmungen des Konzils von Trient fügte er an:

Ich wünschte mir auch, dass sich dort nach den Bestimmungen des Konzils von Trient eine theologische Kommission errichten ließ. Er versprach mir, es zu versuchen. Dies scheint aber schwierig zu sein. Ich verstand erst später, dass dieser Bischof viele Feinde in Gerichtsstreitigkeiten mit bei der kaiserlichen Kammer von Ensisheim im Elsass hatte, $[\ldots . .150$

Seine Titularkirche war Sant'Agostino in Campo Marzio, wo er nach seinem Tod am 17. November 1624 begraben wurde. ${ }^{151}$

Unter Verallo setzte die römische Kurie auf eine konfessionelle Profilschärfung. Die Strategie wurde diesbezüglich geändert, dass der Nuntius - in diesem Fall Verallo - nicht nur wie Borromäus es gewünscht hatte, die Katholiken in der Schweiz beschützen solle. Es ging nun auch darum, in gemischtkonfessionellen Gebieten viele Konversionen zu erzielen. Dies solle durch die Vorbildfunktion der Nuntien geschehen. Andererseits zielte diese aus Rom stammende Strategie darauf, die „falschen Prädikanten“152 als schlechte Vorbilder darzustellen. Die Hoffnung bestand darin, durch möglichst viele Konversionen die Bekehrung protestantischer Geistlicher zu erreichen. Um einen solchen Dominoeffekt zu bewirken, wies der Heilige Stuhl den Nuntius in der Schweiz an,

\author{
148 Ebd. \\ 149 Ebd. \\ 150 Segreteria Stato, Svizzera Volume 10C, f. 318. \\ 151 Vgl. Gaetano Moroni: Dizionario di erudizione storico-ecclesiastica da San Pietro sino ai \\ nostri giorni, Volume 7, S. 147.
}

152 Zit. nach: Klaus Jaitner: Hauptinstruktionen Clemens' VIII., Bd. 1, S. 368. 
sich bei den katholischen Kantonen für die Versorgung der Konvertiten einzusetzen. ${ }^{153}$

\subsubsection{Ladislao d'Aquino (1608-1613) ${ }^{154}$}

Ladislao d'Aquino ${ }^{155}$ stammte von einer neapolitanischen Adelsfamilie ab. Geboren ist er um 1546 in Neapel als drittes von neun Geschwistern. Er studierte Kirchenrecht und wurde 1571 zum Priester geweiht, im selben Jahr berief ihn Papst Pius V. nach Rom. In der Ewigen Stadt war d'Aquino zunächst Kammerpriester, um dann als Referendar bei den Zwei Signaturen zu arbeiten. Am 20. Oktober 1581 ernannte ihn Papst Gregor XIII. zum Bischof von Venafro, dennoch arbeitete d'Aquino weiter an verschiedenen päpstlichen Kongregationen als Rechtsberater. 1608 vertraute ihm Paul V. die Nuntiatur in Luzern an. ${ }^{156}$

Seinen Dienst nahm er am 24. Juni 1608 auf. ${ }^{157}$ Sein zuständiges Gebiet umfasste wie seine Vorgänger die katholische Schweiz, Tessin, Veltlin und die Bistümer Basel und Konstanz, dem auch ein Teil des Elsass angehörte. Auch das Breisgau und ein Teil Schwabens gehörten $\mathrm{zu}$ seinem Nuntiaturgebiet dazu. ${ }^{158}$ Während seines fünfjährigen Aufenthalts in der Eidgenossenschaft hatte er es mit einem im Gleichgewicht zwischen Katholiken und Protestanten liegenden Land zu tun. Deshalb versuchte er vor allem die katholische Seite zu fördern beziehungsweise die protestantische Seite zu schwächen.

Seine Aufgabe sah er vor allem darin, die Moralität der Geistlichen, sei es die der Diözesanpriester, sei es die des Ordensklerus, zu stärken und führte deshalb zahlreiche Pastoralvisiten durch. Vor allem erfolgreich war er bei den Pfarreipriestern, weniger hingegen bei den Diözesanpriestern ohne Pfarreibindung. ${ }^{159}$

Ein besonderes Augenmerk legte er auf die Seelsorge für die zum Katholizismus Bekehrten. Dabei halfen ihm die Jesuiten, die ab 1600 wieder im Wallis Fuß fassen durften, sowie die Kapuziner. D’Aquino ging sogar soweit, in Luzern

153 Zit. nach: ebd., S. 559.

154 Vgl. Dizionario biografico degli Italiani, Volume 3, S. 672-673; Vgl. Caspar Wirz: Bullen und Breven aus Italienischen Archiven, S. XXXVIII.

155 Vgl. Stichwort „Ladislao d'Aquino“, in: https://hls-dhs-dss.ch/de/articles/017880/200108-14/ (Stand: 20. November 2019)

156 Ebd.

157 Vgl. Dizionario biografico degli Italiani, Volume 3, S. 672.

158 Vgl. ebd.

159 Vgl. Jakob Burkhardt: Die päpstliche Nuntiatur in der Schweiz 1612. 
Gruppen von Konvertiten auf seine Kosten zu versorgen ${ }^{160}$ und führte auch etliche von ihnen Klöstern zu. Eines seiner wichtigsten Projekte diesbezüglich war der Schutz des Instituts von Thonon bei Genf, das für die Neophyten zuständig war. Er wollte andere ähnliche Einrichtungen einführen, doch mit dem Ausbruch der Pest wurde ihm das verwehrt.

Diplomatisch hatte er vor allem Mühe, mit den in spanische und französische geteilten Fraktionen zusammenzuarbeiten. Die Anhänger der französischen Seite trauten d'Aquino nicht, da er aus dem spanischen Neapel stammte, und deshalb hatte d'Aquino meist Schwierigkeiten, mit der französischen Fraktion zusammenzuarbeiten. Das ging sogar so weit, dass die französische Seite provokativ mit den Protestanten zusammenarbeitete beziehungsweise diese in Schutz nahm. Man muss aber hinzufügen, dass die Oberschicht der Katholiken in der Eidgenossenschaft an sich eher der spanischen Seite zugetan war, und die Zusammenarbeit mit dem Papstgesandten war in dieser Hinsicht erfolgreich. Auch respektierte d'Aquino ihren ,ausgeprägten persönlichen und nationalen Stolz“, ${ }^{161}$ wie es im Biographischen Lexikon der Italiener von 1971 heißt. Schwierigkeiten hatte er damit, dass sich die Lokalbehörden in kirchliche Angelegenheiten einmischten, was er als Usurpation und Ausbeutung brandmarkte.

Seine Nuntiaturzeit war geprägt von den Beschlüssen des Fürstbischofs von Konstanz Jakob Fugger. Dieser führte eine Diözesansynode im Jahr 1609 durch, sodass es zu einem Reformprogramm der Diözese kam, die dem Nuntius dienlich waren. So besserte sich nach Ladislao d'Aquino und unter Jakob Fugger auch das Verhältnis der Schweizer Kantone zum Konstanzer Bischof, so dass in der ersten Hälfte des 17. Jahrhunderts von allen Seiten her von „normalisierten Beziehungen“ gesprochen wurde. So stellt Fink fest, dass es „kein Zufall“ sei, „dass im Zeitraum 1592-1643 im Staatsarchiv Luzern keine Akten über Streitigkeiten von Luzernern mit dem Nuntiaturpersonal überliefert sind“. Die genannten 50 Jahre könne man als die harmonischste Periode der ganzen Luzerner Nuntiaturgeschichte bezeichnet werden. ${ }^{162}$

Er verließ die Nuntiatur am 15. September 1613 und hinterließ eine „Relation der Nuntiatur der Schweizer“, die er Bischof Feliciano von Feligno sandte. Darin analysierte d'Aquino minutiös die Lage der Schweiz zu Beginn des 17. Jahrhunderts, indem er die Fortschritte der katholischen Reform hervorhob und die Stärke gegenüber den Protestanten betonte. Er ging aber auch auf die Bräuche in der Schweiz ein und würdigte die Frömmigkeit und den Respekt gegenüber dem katholischen Klerus. Er nannte aber auch die negativen Seiten, die

160 Vgl. Dizionario biografico degli Italiani, Volume 3, S. 672.

161 Ebd.

162 Urban Fink: Die Luzerner Nuntiatur 1586-1873, S. 49. 
sein Nachfolger angehen sollte. Einen wichtigen Aspekt widmete d'Aquino dem Verhältnis der Nuntiatur mit den Schweizer Bischöfen. So solle der Nuntius sich nicht in Dinge einmischen, welche die Bischöfe tun können und ihnen zustehen. Denn dadurch würden die Bischöfe nur verstimmt, opponierten und schadeten auch sonst dem Nuntius. Er hob hervor, dass die Nuntien vom Papst in die Schweiz entsandt seien, um die bischöfliche Autorität zu stützen, nicht um dieselbe zugrunde zu richten. Was die Bischöfe befehlen, habe außerdem größere Dauer. Auch merkte er an, dass die Schweizer mehr „ihren Bischöfen“ trauten als den italienischen Nuntien. Die Nuntien sollten auch nicht die Weihbischöfe der Ordinarien sein. Die Bischöfe könnten in einem Monat mehr tun als die Nuntien in einem Jahr. Die markanten Äußerungen beendet d'Aquino mit dem Ratschlag, sich um einen guten Kontakt mit den Bischöfen zu bemühen und diese nicht zu verärgern. Fink beurteilt diesen Nuntius deshalb folgendermaßen: „Von einer antiepiskopalen und arroganten Haltung kann zumindest bei diesem Luzerner Nuntius nicht die Rede sein!“163

Die Karriere nach dem Aufenthalt in Luzern war weniger erfolgreich für d'Aquino, er starb als Kardinal während des Konklaves vom Februar 1621. ${ }^{164}$

Unter d'Aquino wurde die Strategie, die bereits unter seinem Vorgänger Verallo eingesetzt wurde, fortgesetzt. In dieser Phase wurde versucht, eine Art „Reconquista“ vor allem in den gemischtkonfessionellen Gebieten durchzuführen. Das Schweiz-Bild von Borromäus und das Söldnerwesen spielten keine große Rolle in dieser Phase. Vielmehr kann man von einer vorübergehenden Umbruchphase sprechen, in der die Nuntiatur in Luzern nicht nur als Bollwerk gegen die Verbreitung des Protestantismus betrachtet wurde, sondern gleichzeitig auch als Vorposten, um in den protestantischen Gebieten, in denen auch Katholiken lebten, durch Proselytismus Erfolge zu erzielen. ${ }^{165}$

\subsubsection{Ludovico di Sarego (1613-1621)}

Der 1558 in Verona geborene Ludovico di Sarego war vor seiner Gesandtschaft als Nuntius in der Schweiz ${ }^{166}$ Bischof von Adria gewesen. ${ }^{167}$ Er stammte von den Grafen von Canossa ab. Als Nuntius in der Schweiz verschaffte Sarego dem

163 Urban Fink: Die Luzerner Nuntiatur 1586-1873, S. 52.

164 Dizionario biografico degli Italiani, Volume 3, S. 673.

165 Vgl. Jakob Burkhardt: Die päpstliche Nuntiatur in der Schweiz 1612.

166 Vgl. Caspar Wirz: Bullen und Breven aus Italienischen Archiven, S. XXXVIII.

167 Vgl. Stichwort „Ludovico di Sarego“, in: http://www.hls-dhs-dss.ch/textes/d/D17918.php (31. Dezember 2020). 
Schweizer Benediktinerorden ${ }^{168}$ die 1622 von Papst Gregor XV. bestätigte Exemtion von der bischöfliche Jurisdiktion und Visitation und schuf eine oberdeutsche Zisterzienserkongregation, der sich auch Hauterive, Wettingen und St. Urban widerstrebend anschlossen. Er hielt die Jesuiten zur Weiterarbeit im Wallis an und unterstützte die vom Protestantismus bedrohten Bistümer Sitten und Chur. So besuchte er 1614 Bischof Johann Flugi. ${ }^{169}$ In den Auseinandersetzungen nach dem Bieler Tauschhandel (1599) zwischen dem Bischof von Basel und Bern trat Sarego für ein Schiedsgericht ein. Er förderte auch die Residenznahme des Bischofs von Lausanne in Freiburg (1615) mit der Vertragskonfirmation durch Sarego.

Eine enge Beziehung pflegte Sarego auch mit dem Bischof von Konstanz, mit dem er eine rege Korrespondenz führte. Sarego ermahnte ihn mehrmals, die „Vorgaben des Konzils“ anzuwenden. Vor allem pochte Sarego darauf, dass der Bischof auch den „Schweizer Teil“ des Bistums von Konstanz persönlich besuchen soll. In einem Brief, der zwar kein genaues Datum vorweist, jedoch um den Monat Februar 1615 verfasst sein könnte, schreibt Sarego:

Denn der Teufel verfehlt nicht, durch die Wut dieser Menschen so gute Werke zu verhindern, wie gestern bei der Firmung vieler Jungen (...), nachdem er all jene abgelehnt hatte, die jünger als sechs Jahre alt waren, pochte ein Bürger darauf, einem Kind das Sakrament der Firmung spenden zu lassen, das vier Jahre alt war, und der Bischof sah sich nicht in der Lage, dies zu tun, und als der Bischof diesen Mann zu ermahnen versuchte und ihn bat, sich zurückzuziehen, sagte dieser zu ihm unverschämte Worte, dass er die Dinge nur aus Gefälligkeit und Vorlieben tue und dass der Bischof sich noch an ihn erinnern werde wegen einer solchen Abstoßung, und dass dies dem Bischof von Konstanz noch leidtun werde. Aber was noch schlimmer ist, war der Luzerner Pfarrer, der dem Bischof einen Jungen von drei Jahren präsentierte (....). ${ }^{170}$

Bei Sarego ist festzustellen, dass er mit den Leuten direkt sprach, um sich ein Bild von Situationen machen zu können. Das führte aber auch dazu, dass man ihn direkt um Hilfe bat, wie beispielsweise aus dem Brief vom 25. März 1615 hervorgeht, den er aus Altdorf nach Rom verschickt:

Das beigefügte Memorial enthält den Fall eines Priesters, und er wird mir von so vielen frommen Menschen wegen des Eifers für die Gesundheit der Seelen dazu empfohlen, denn dieser hat durch Simonie einen Nutzen erlangt durch die Seelsorge, und es sind bereits

168 Zum Benediktinerkloster in Engelberg, siehe: Segreteria Stato, Svizzera Volume 10A, f. 93. 169 Johann Flug (1550-1627) empfing am 22. Juli 1601 durch den Nuntius in Luzern die Bischofsweihe. Vermutlich 1606 erhielt er von Kaiser Matthias das Adelsprädikat von Aspermont. Vgl. Albert Fischer: Biographische Notizen über Johann V. Flugi bis zu seiner Wahl zum Churer Bischof 1601, S. 5-29.

170 Segreteria Stato, Svizzera Volume 10A, f. 46. 
sechs Monate vergangen, und er hat Buße getan, und bittet nun nicht nur um Absolution von der kirchlichen Missbilligung und die Dispensation über die Unregelmäßigkeit für diesen Vertrag, aber auch um die Konsequenz, die sich daraus ergibt, dass man von berechtigtem Zuspruch sprechen soll. [...] $]^{171}$

\section{Über die Protestanten in der Eidgenossenschaft schreibt Sarego in einem Brief vom 10. August 1615 nach Rom:}

Nicht ohne Grund sagte ich in einem anderen von meinen Briefen, dass die Ketzer hier und dort unsere katholische Religion stören, und die Verbreiter unter ihnen versuchen, (unseren Glauben) zu unterdrücken und ihre böse Sekte zu erweitern; und dass unsere Katholiken langsam und kalt sind, wenn es darum geht, sich ihnen zu widersetzen und vorzugehen, wie Ihre Hoheit aus anderen meiner Briefe lesen konnte, über die gemachten Tätigkeiten in Wallis und in Graubünden; gestern sagten die drei Schweizer Herren, die zu mir kamen, dass der Bischof von Chur und der Abt von Pfäfers in dem genannten Ort Pfäfers den Schultheiß Sonebergh gebeten haben, also einen der drei Schweizer katholischen Herren, dass die Bitte an Graubünden gerichtet werden sollte, exemplarisch gegen einen Prediger vorzugehen, der in Zizers seit zehn Jahren vor dem Volk und gegen alle Kleriker herablassend spricht, beginnend mit dem Papst, und absteigend zu allen anderen niedrigeren Ordnungen, [...]. ${ }^{172}$

Nuntius Lodovico di Sarego nennt die Schweizer nie als solche. Er benützt das Wort „suizzeri“ nie. Vielmehr beschreibt er die einzelnen Regionen („prouincia“) und teilt somit die Schweiz in verschiedene Teile auf. ${ }^{173}$

Über seinen Einsatz schreibt Nuntius Sarego aus Altdorf am 14. Oktober 1615 in einem Brief nach Rom:

Der glühende Eifer der Verbreitung des Glaubens und der katholischen Religion und des Erwerbs von Seelen drängt mich frohen Mutes, diesen Gedanken von mir an Ihre Hochwürden zu schreiben. Da nun die Kronen von Frankreich und Spanien durch die gegenseitige Ehe verbunden sind, was zum gegenseitigen Wohlwollen beiträgt; und da nun bekannt wurde, wie man hört, diese Abhandlung der Berner mit dem unzufriedenen Fürsten und mit den Hugenotten von Frankreich gegen den König; und da nun aus vielen Gründen gesehen wurde, dass der Herzog von Savoyen kriegerische Vorhaben hatte, und nun versucht, das wiederherzustellen, was er beansprucht, und für eine Erweiterung seines Staates eintritt: Da scheint es mir, dass ich nicht dorthin kommen konnte, wo die beste Konjunktion der Gegenwart ist, um sie zu verbreiten, unsere liebe Religion, [...] $]^{174}$

171 Segreteria Stato, Svizzera Volume 10A, f. 83.

172 Segreteria Stato, Svizzera Volume 10A, f. 168.

173 Vgl. Segreteria Stato, Svizzera Volume 10A, f. 207 (St. Gallen), f. 215 (Graubünden), f. 223 (Wallis), f. 255-256 (Kloster Einsiedeln).

174 Segreteria Stato, Svizzera Volume 10A, f. 251. 
Das Verhältnis zum Bischof von Konstanz war wie bei den anderen Nuntien schwierig. In einem Brief vom 5. Dezember 1615 schreibt Sarego aus Altdorf nach Rom:

Wie bei meiner ersten Ankunft, und im Gespräch mit dem besagten Bischof [von Konstanz], entdeckte ich ihn als kalt in kirchlichen Dingen, und mit wenig Zuneigung für die Nuntien, die in diesem Land waren: Als ich mich von ihm verabschiedete und wegging, schien er mir so erwärmt, was seine Funktionen und Dienste betrifft, und so wohlwollend gegenüber Nuntien und allgemein über die Diener Unseres Herrn und des Heiligen Stuhls für die Zukunft zu sein, dass man sagen könnte, dass wir in seiner Person und durch sein Beispiel in noch anderem sehr vorangekommen sind: Daraufhin glaube ich, dass wir sicherstellen könnten, dass wir alles in allem viel verdient hätten, wenn wir auf die Fürsprache unseres Herrn hin einen Gewinn daraus ziehen könnten. Die bereits erflehte Gottes Gnade möge die Einnahmen aus jener Kirche für einige Jahre auf diese Kirche in Erweiterung ihrer vielen Schulden und Interessen angewendet werden. ${ }^{175}$

Der Nuntius stellte auch das fest, was in allen Instruktionen und vielen Briefen immer wieder hervorgehoben wird: Die Schweizer sind ein geteiltes Volk. In einem Brief aus Altdorf vom 23. Oktober 1616 schrieb Sarego nach Rom:

Diese Schweizer sind in ihren Überlegungen so geteilt, dass man da nicht mit Sicherheit etwas sagen kann. Es wurde in den bisherigen Briefen geschrieben, dass die ketzerischen Kantone beschlossen hatten, ihnen keine Menschen an den Botschafter von Frankreich zu übergeben; und jetzt heißt es, dass jeder dazu beiträgt, ihnen etwas zu gewähren, und ihn fast darum bittet, aber dass sie nichts anderes tun wollen. Die 4000 Männer, die die Katholiken gegeben haben, marschieren jedoch, und die von Altdorf sind bereits gegangen; aber es ist sehr schwierig, Soldaten zu gewinnen, sie werden gut bezahlt, und der Priester ist sehr zurückhaltend. Man sagt, dass sie Frankreich zugeneigt sind, dass hier der Botschafter der französischen Krone dies hier mitgeteilt habe, dass die Unruhen in dem Königreich vorüber sind und dass alle enthobenen Fürsten zurückgekehrt sind und dass Graubünden den Aufstand übt, [...], und dass diese Schweizer Soldaten, die gehen, in Garnisonen dienen und dort für lange Zeit bleiben müssen. ${ }^{176}$

Nuntius Sarego hatte alle Hände voll zu tun, vor allem mit dem Bischof von Konstanz, über den er in einem Brief vom Dezember 1616 (ohne genaueres Datum markiert) nach Rom schrieb:

Und es wurde nicht wenig getan: aus der Unterredung, die ich mit ihm hatte, dass er vor allem den Schweizer Teil seiner Diözese im Kopf hat, die in einem tragischen Zustand ist, und dass er nicht mehr daran denke, sie zu besuchen, und nichts anderes zu tun; ja, für die gewöhnliche Entfremdung, die die Deutschen von den Schweizern haben, und umgekehrt; weil er sagte, nichts Gewinnbringendes zu erhalten, weder geistlich noch weltlich:

175 Segreteria Stato, Svizzera Volume 10A, f. 302-303.

176 Segreteria Stato, Svizzera Volume 10A, f. 429. 
wie er es bei einem Besuch erlebt hatte, und darüber hinaus auf eigene Kosten und ohne jegliche Gegenleistung, weil die Schweizer es nicht zugelassen haben. Sie haben ihn beobachtet, den Austausch beobachtet oder haben mit ihm gemachte Abmachungen verlassen, die ihm irgendeine legitime Vergütung zugelassen hätten, aufgrund der Tatsache, dass es dem Bistum wegen dieser Domäne zusteht. Aber nachdem ich ihm geantwortet habe, dass er aus diesem Grund jene Seelen für sein Amt weder verlassen kann noch muss, und für die Liebe, die man seinem Nächsten gewähren muss, mit Geduld und auf seine Rechte pochen soll, so soll er aber geduldig beobachten und reagieren etc. Und alle Nuntien vor mir haben versucht, seine Besuche zu ermöglichen und jene Herren zu überreden, ihn nicht daran zu hindern, aber auch dem Bischof ihre Hilfe anzubieten, und ihm den Weg aufzuzeigen, wie man hier mit wenig Aufwand und Geld viel erreichen kann. ${ }^{177}$

Was in den Beschreibungen der meisten Nuntien zu Anfang ihrer Amtszeit in der Eidgenossenschaft auffällt, ist ihre Beschreibung des Klimas. Es gibt viel Schnee in dem Land, ist eine allgemeine Bemerkung der Nuntien. So schrieb Nuntius Sarego am 2. Februar 1614 in einem Brief aus Luzern nach Rom:

Aber je mehr ich darauf dränge und ich danach trachte, desto mehr scheint es mir, den Himmel gegen mich zu haben, denn zusätzlich zu der Schwierigkeit und der gewöhnlichen Unsicherheit, Briefe zu verschicken und zu erstellen, sind in diesem Jahr doch so viele Schneeflocken gefallen, und es mangelt nicht an Eis, was den Weg undurchdringlich macht, und den Zugang zu diesem Land, noch wollte ich es dem gemeinen Ansinnen glauben, das besagt, was alle darüber sagen, was aber die Erfahrung mich jetzt gelehrt hat. ${ }^{178}$

In einem Brief vom 2. September 1614 schrieb Nuntius Sarego aus Luzern nach Rom über das Söldnerwesen:

Tatsächlich bedauern diese schweizerisch-katholischen Herren, die nicht ganz auf Geld bedacht sind, dass sie ihr Volk zu diesem Anlass entsenden müssen, nachdem sie bei der Tagsatzung zwischen ihnen Gegensätze gebildet und vorgeschlagen haben, dass sie ihre Botschafter zum Herzog von Savoyen und zum Gouverneur von Mailand schicken sollten, und flehen sie an, sie nicht zu zwingen, ihr Volk in diesem Fall zu schicken, in der sie sich wegen der Gefahr, dass sie gegeneinander antreten müssten, und deshalb entschlossen sind, sich am 10. September in Altdorf mit allen Abgeordneten zu treffen und diejenigen zu wählen, die zu einem und zum anderen dieser Herren gehen müssen, und ihnen die entsprechenden Anträge zu geben. Um die Wahrheit zu sagen, habe ich sie ermahnt, und es scheint mir, dass es dem Anliegen nicht schaden kann, geduldig zu sein; zumal hier große Hoffnung besteht, dass die Mission von Bischof Savello [...] erfolgreich sein wird, $\left[\ldots . .{ }^{179}\right.$

177 Segreteria Stato, Svizzera Volume 10A, f. 517.

178 Segreteria Stato, Svizzera Volume 10B, f. 11.

179 Segreteria Stato, Svizzera Volume 10B, f. 281. 
Nuntius Sarego wurde auch aktiv bei der „Bekämpfung“ der Ausbreitung des reformatorischen Gedankenguts. So schreibt er in einem Brief vom 23. September 1614 aus Luzern nach Rom:

Der Aufruhr der Bauern gegen die Österreicher, der von den Schweizer Vertretern geführt wurde, hat sich mit diesen Bedingungen endlich beruhigt: Dass die Bauern für 12 Jahre den bisherigen Beitrag von zwei Pfund pro Krug Wein in der Taverne bezahlen, für die Kosten der Dinge des Elsass anfallen.

Und noch mehr, wegen der Ausgaben, die sie mit diesem Aufstand gemacht haben, zahlen sie eine weitere Steuer für 4 Jahre.

Dass sie alle Waffen, die sie haben, mit Ausnahme des Schwertes, abgeben, und ich weiß nicht, wie viele Armbrüste, aber die müssen an einem öffentlichen Ort gesammelt werden und sind nur dazu bestimmt, auf die Zielscheibe für Übungen zu schießen.

Dass die Köpfe des Aufruhrs den Ministern der Österreicher in die Hand gegeben werden, die sie in jeder Hinsicht festhalten wollten, aber es wurde abgemacht, dass sie sie 15 Tage im Gefängnis halten, unter Brot und Wasser, mit Strafen belegen usw...

Die Prediger und die ketzerischen Minister, die predigen, schärfen ein und übertreiben diese Verbindung der Völker, die ihnen zuhören: Und wenn man uns fragt, weshalb sie uns so sehr unter Druck setzen; haben sie geantwortet, dass sie sich eine so schöne Gelegenheit zur Erweiterung unserer Religion nicht entgehen lassen wollen. ${ }^{180}$

\section{Ein schwieriges Unterfangen für Nuntius Sarego waren die Verhandlungen zwi- schen den Kantonen im internationalen Kontext. In einem Brief aus Luzern nach Rom vom 21. April 1617 schrieb er:}

... nachdem sie in die Schweiz zurückkehren mussten, um den Walliser Pass zu stoppen, und andere, um dem Transit und ihren Unterkünften die entsprechenden Befehle zu erteilen. Die höchsten, die die ketzerischen Kantone, vor allem die Zürcher, ausrufen, jagen und bedrohen, dass sie sie nicht gehen lassen würden. Zumindest haben die Ketzer am 10. dieses Monats in Aarau einen Landtag abgehalten. Und die Zürcher haben an alle katholischen Kantone geschrieben, dass diese Menschen sie nicht gehen lassen werden, und dass sie nicht zulassen werden, dass sie durch Orte gehen werden, an denen sie teilnehmen in der Herrschaft und in der Regierung mit Katholiken.

Daraufhin haben die Katholiken am 13. dieses Monats in Luzern einen Landtag abgehalten: in dem sie angeordnet haben, dass geantwortet wird, dass jene Menschen, die aus Flandern nach Italien kommen, ohne Schaden, weder Belästigung an irgendeinem Ort noch an irgendeiner Person, weitergegeben werden und dass es nicht möglich war, zurückzufahren. ${ }^{181}$

Zwischen 1617 und 1618 werden die Schweizer Kantone immer mehr zu „Spielbällen“ der europäischen Mächte, wie es auch Nuntius Sarego feststellt. So schrieb er in einem Brief vom 23. Dezember 1617 nach Rom:

180 Segreteria Stato, Svizzera Volume 10B, f. 322.

181 Segreteria Stato, Svizzera Volume 10C, f. 76-77. 
Wiederum ist in diesen Gebieten nichts Neues zu mir angekommen, außer dass die SchlieBung des Passes in Graubünden bestätigt wird. Aber es scheint, dass es keinen Nutzen bringt, außer für das fremde Volk; denn sie stehen im Dienst der venezianischen Fürsten, und zwar viele von ihnen. Und es wird gesagt, dass wenn die venezianischen Fürsten jetzt für die Liga mit ihnen einstehen würden, dann würden sie Graubünden leicht bekommen; aber dass sie Graubünden nicht wollen, wenn die Leute dort keinen offenen Pass auch für Ausländer gewähren. ${ }^{182}$

Während Venedig sich vor allem für Graubünden als Zugangsort interessierte, gab es auf einer anderen Front die französische Seite, die sich als „Verbündeter der Katholiken“ präsentierte, wie Sarego in einem Brief vom 13. Januar 1618 feststellte:

In diesen Tagen schickte ich Herrn Hans Jakob Dieteli, meinen Dolmetscher in Solothurn, mit meinen Briefen und der Botschaft, Herrn von Minn als neuen Botschafter Frankreichs in diesen Gebieten zu begrüßen; um ihn zu ermahnen, unseren Heiligen Katholischen Glauben und seine Bekenner in diesen Ländern zu unterstützen, zu schützen und zu fördern; mit mir in allen guten und frommen Werken vereint zu sein und mich und meine Fähigkeiten in allem zu nutzen, was der breiten Öffentlichkeit, aber auch dem Allerchristlichsten König und Frankreich zugutekommen könnte, in dem Wissen, wie groß die Heiligkeit unseres Herrn in Zuneigung und Schutz ist ...

Die Dinge der Katholiken in diesen Gebieten werden gut laufen, denn es gibt (die französische, Anm. d. Autors) Autorität, die mächtig ist. Und ich werde es nicht versäumen, ihm vorzuschlagen, was gebraucht wird, und seine Hilfe dort zu suchen, wo ich sie brauche. ${ }^{183}$

In einem Brief vom 14. Dezember 1618 beschrieb Nuntius Sarego, wie der Vertreter der Katholiken in der Schweiz sich bei ihm für die Unterstützung bedankt habe. Der Brief des Nuntius wurde von Lugano aus geschickt. Der Inhalt besteht aus mehreren Punkten:

Seiner Seligkeit wurde im Allgemeinen für seine väterliche Zuneigung gegenüber ihnen gedankt; und insbesondere für zwei kürzlich erhaltene Gnaden; dass das Untertanengebiet von Ascona in die Hand der Jesuiten gegeben wird. Der andere Teil der Gewährung besteht darin, zwei Kantonen die Kanoniker von Bischofszell [...] zu gewähren.

[...]

3. Da der Bischof von Konstanz von Schulden und Interessen erdrückt ist, ist davon zu wissen, dass der Bischof im Kirchenkapitel, bei den Säkularen, wie er Ratschläge erteilen soll [...].

4. Da die Häretiker jedes Jahr Neuheiten in den Dingen der Religion bringen, und mit den Katholiken über diese Herrschaften von Weinfeld und den Wein im Thurgau sich absprechen müssen, und da sie (die Häretiker, Anm. d. Autors) immer überlegen sein wollen,

182 Segreteria Stato, Svizzera Volume 10C, f. 132.

183 Segreteria Stato, Svizzera Volume 10C, f. 173. 
also mächtiger; doch den Katholiken stehen nicht für das gleiche Anliegen dieselben Kräfte zur Verfügung, deshalb drohen sie zu zerbrechen: Seine Heiligkeit soll sich darüber erfreuen, ihnen zu versichern, dass die Katholiken angemessene Hilfe erhalten und dann dies mit einer guten Geldsumme auf einer Obstbank aufzubauen, [...] sich in anderer Verwendung erfreuen, als für den Krieg gegen Ketzer.

[...]

6. Was Seine Seligkeit geben soll, ist die Gewährung für das Bistum Konstanz, in gradibus prohibitis matrimonialibus, noch weiter als gewöhnlich zu vergeben, als dies den Nuntien gewährt wird: Vor allem für den Kanton Glarus, und anderen ähnlichen Orten, wo es mehr Häretiker als Katholiken gibt [...].

Ich bin sicher, dass Sie all das tun werden, wofür all dieser Nation der Schweizer Katholiken dankbar sein werden, und es wie immer bevorzugen werden, sowohl als Minister als auch als ihr Diener des Glaubens in diesen Gebieten gut gesehen und verstanden werden, und deshalb freundlich empfangen, einführen und ermutigen; [...]. ${ }^{184}$

In seinen Erläuterungen über die Lage in der Schweiz ging Nuntius Sarego auf ganz konkrete Fälle ein.

Kurz gesagt, in diesen Gebieten ist es notwendig, dass der Nuntius auch als Prokurator Eurer Majestätischen Heiligkeit dient. Durch mich ist der Bischof von Sitten benachrichtigt worden, dass der Abt von Saint Maurice gewählt wurde und durch unserem Herrn die apostolischen Bestätigungen erhalten hat [...]. ${ }^{185}$

Er kehrte am 24. September 1622 nach Hause zurück und trat als Bischof zurück. Sarego starb am 5. August 1625.

Saregos Nuntiatur reihte sich in jener zweiten Phase ein, die Verallo und d'Aquino vor ihm eingeläutet hatten. Doch unter Sarego kehrte wieder die Strategie ein, die Borromäus vorgegeben hatte: defensiv gegen häretische Vorstöße vorzugehen. So erhielt Sarego 1613 die Anweisung aus Rom, die Bibliotheken in dem ihm anvertrauten Gebiet zu „reinigen“. ${ }^{186}$ Es ging der römischen Kurie darum, die Protestanten nicht nur theologisch, sondern auch in gesellschaftlichen und politischen Ein- und Vorstellungen als Gegenpart darzustellen. In Saregos Zeit wurde nicht nur ein konfessioneller Gegensatz hervorgehoben, sondern auch ein grundlegendes Feindbild geschaffen. Damit wurde nicht nur eine Selbstvergewisserung bestätigt, es wurde auch versucht, die Katholiken in der Schweiz für eine gemeinsame Identität einzubinden. Das führte aber auch zur Annahme in Rom, dass die Protestanten ihrerseits die katholische Seite als Feinde betrachteten und bestrebt seien, dem Heiligen Stuhl zu schaden. Es ging

184 Segreteria Stato, Svizzera Volume 10C, f. 249-250.

185 Segreteria Stato, Svizzera Volume 10C, f. 271.

186 Vgl. Instruktion an Sarego (Anhang) 
um einen Gegensatz zwischen Gut und Böse. Die jeweiligen Seiten waren klar benannt. ${ }^{187}$

Die Resultate Saregos fielen aber nicht sonderlich gut aus. Snell schreibt sogar, dass „bittere Früchte“ erzeugt wurden. Unter Sarego gab es Konflikte zwischen der geistlichen und weltlichen Macht, was zu einer allgemeinen Schwächung der Bischöfe in der Schweiz führte. Religionshass und Intoleranz seien weitere Folgen der römischen Strategie gewesen, urteilt Snell. ${ }^{188}$

\subsubsection{Alessandro Scappi (1621-1628)}

Mit Alessandro Scappi haben wir es mit einem Norditaliener zu tun. Er ist um 1572 geboren und war der Sohn eines wichtigen Kurienmitarbeiters, und so erklomm auch Alessandro Scappi die Karriereleiter der Kurie, allerdings als Priester, obwohl man nicht weiß, wann er genau ordiniert wurde. Er studierte Kirchenrecht und wurde 1618 zum Bischof von Campagna und Satriano in Süditalien ernannt. Der frisch gewählte Papst Gregor V. ernannte ihn zum Nuntius in Luzern, wo er bis 1628 blieb.

Sein Anfang war wie bei vielen seiner Vorgänger - und auch Nachfolger mit Schwierigkeiten verbunden. So schrieb er am 13. September 1623 aus Rho nach Rom:

Seit Samstag [...] bin ich hier mit ein wenig Fieber; so raten mir die Ärzte davon ab, vorerst nach Freiburg zu reisen, da die Reise ohne Pause zehn Tage dauern würde, [...] $]^{190}$

Scappi war Nuntius zu einer Zeit, in der sich die katholischen Kantone auf der einen Seite und die protestantischen Kantone auf der anderen Seite in einer „politischen Krise“ gegenüberstanden, da sie sich auf internationaler Ebene als Söldner auf verschiedenen Seiten schlugen. ${ }^{191}$

Diese katholischen Kantone haben eine sehr klare Meinung darüber, dass die Venezianer den Bund mit den Wallisern praktizieren sollen, was auch bei der letzten Tagsatzung besprochen wurde, die dieselben Kantone in Vechs [sic!] hielten. Deren Meinung halte ich

187 Vgl. Stichwort „Ludovico di Sarego“, in: https://hls-dhs-dss.ch/de/articles/017918/201101-24/ (31. Dezember 2020).

188 Vgl. Christian Wilhelm von Glück, Ludwig Snell: Geschichte der Einführung in die Schweiz und ihre dargelegte Politik, S. LXII.

189 Vgl. Caspar Wirz: Bullen und Breven aus Italienischen Archiven, S. XXXIX.

190 Segreteria Stato, Svizzera Volume 12, f. 25 [oben rechts 19 markiert].

191 Vgl. Briefe von Nuntius Scappi vom 10. Oktober 1623; Segreteria Stato, Svizzera Volume 12, f. $63 / 57$. 
für wenig stichfest, doch dachte ich, dass ich Ihnen nicht dieses Treffen vorenthalten sollte, damit ich mir auch selbst versichere, dass diese Meinung wahr ist, und ich so die Ämter zugunsten oder gegen den Gedanken der Venezianer verlegen kann, wie es der Heiligkeit unseres Herrn gefallen wird [...]. ${ }^{192}$

Der Nuntius verfolgte mit großer Aufmerksamkeit, wie sich die protestantische Seite in diplomatischen Angelegenheiten verhielt. So schrieb er in einem Brief von November 1623 (genaues Datum unbekannt):

Da die Genfer große Bedenken gegenüber dem Herzog von Savoyen hatten und behaupteten, einem Vertrag mit Nachteilen für ihr Land gegenüberzustehen, schrieben sie an die Kantone Zürich, Glarus, Schaffhausen, Solothurn und Appenzell ihre Eindrücke, da diese die Vermittler waren, und griffen beim letzten Abkommen ein, der zwischen ihnen und Ihrer Hoheit von Savoyen zustande kam. Ich glaube, das war im Jahr 1603, um Ihre Hoheit an die Einhaltung dieses Vertrages zu erinnern. Darüber hinaus haben einige derselben Kantone darüber nachgedacht, dafür einen Landtag einzuberufen, aber die anderen haben mehrheitlich entschieden, dass der Kanton Zürich ohne viel Verwirrung zu stiften, in ihren Briefen an den erwähnten Herrn Herzog, nichts zum Nachteil des Genfer erbeten sollten, was den bereits erwähnten Vertrag betrifft, [...]. ${ }^{193}$

Interessant bei Nuntius Scappi ist, dass er sich nicht scheut, sich mit dem Botschafter Frankreichs auszutauschen. Die Nuntien in der Eidgenossenschaft hatten immer wieder Kontakte mit anderen Diplomaten. So schreibt Scappi in einem Brief vom November 1623 (ohne genaues Datum):

Die Bemerkung, die unter anderem im beigefügten Blatt vermerkt ist, in der steht, dass die Niederländer mit den Bernern einen Bund gründen wollen, wird von mir für wahr gehalten, denn als ich von meiner Rückkehr aus Freiburg in Solothurn vorbei kam, stellte ich fest, dass der französische Botschafter, Herr Myrron, auch Wind davon bekam; und es ist sicher, dass deswegen nach Bern einer aus den Niederlanden geschickt wurde. [... $]^{194}$

Ein besonderes Augenmerk legte der Nuntius auf die Lage in Graubünden. So schreibt er in einem Brief vom 27. November 1623 aus Disentis nach Rom:

Ich kam gestern in diesem Kloster Disentis an, das umgangssprachlich edler Tisitis (Disentis, Anm. d. Autors) genannt wird, und es ist alt, aber zerstört durch die vergangenen Kriege in Rätien, und alles hat sich verändert durch die gierige Klosterdisziplin im Benediktinerkloster, was zum schlechten Leben und die zu laschen Bräuche des Abtes und einiger Mönche führte, die dort leben. Deshalb werde ich jede meiner Tätigkeiten darauf verwenden, um nicht zu leiden, wenn ich nicht zuerst eine stabile Reform durchsetzen kann, wie ich hoffe ... und weil seit Gedenken kein Apostolischer Nuntius mehr in dieses Land ge-

192 Segreteria Stato, Svizzera Volume 12, f. 69/63.

193 Segreteria Stato, Svizzera Volume 12, f. 100/93.

194 Segreteria Stato, Svizzera Volume 12, f. 106/98. 
kommen war, [...] da die Huldigung und die Hingabe, die sie alle mit äußeren Handlungen zeigen, dem Heiligen Stuhl und Ihrem Dienst gegenüber, meine Erwartungen weit übertreffen; und wenn sie tatsächlich den Worten entsprechen werden, die ich für sinnvoll erachte und die ich von diesen Dorfbewohnern verlangen würde, und zwar, die Rechte dieses Klosters wiederzuerlangen, dann wird das für mich alles sein, was ich von ihnen verlange $[. .$.$] . { }^{195}$

Um 1624 war der Nuntius in der Eidgenossenschaft mit der Veltliner Frage beschäftigt, die eine internationale Bedeutung hatte. In einem Brief aus Luzern nach Rom vom 30. Juli 1624, der am 15. August 1624 in Rom dechiffriert wurde, schrieb Nuntius Scappi:

Ich höre, dass in den vier demokratischen katholischen Kantonen die französische Fraktion alles unternimmt mit ihren Bemühungen und Versprechungen, und mit der Gabe von gutem Getränk, sowie auch mit Geld, um andere im Sinne des Marquis von Coeure zu gewinnen, der auf nichts anderes wartet, als auf das Versprechen der Schweizer nach der Kapitulation von Madrid, [...].

und weil es nicht für unsere eigenen Überlegungen festgestellt werden kann, ob sie die genannten Volkskantone („Cantoni popolari“), die größtenteils ihren eigenen gegenwärtigen Interesse folgen, und offensichtlich nicht den Bestimmungen der Vernunft und des öffentlichen Dienstes folgen, deshalb verzichte ich darauf, Eurer Majestätischer Hochwürden das Konzept zu sagen, dass ich in mir mittrage, aber ich bekräftige sehr, dass ich mich nie selbst davon überzeugen werde, dass diese anderen katholischen aristokratischen Kantone das gewähren, was Coeure behauptet, [...]. ${ }^{196}$

Die Auseinandersetzung zwischen Katholiken und Protestanten in der Schweiz verfolgte der Nuntius mit besonderem Augenmerk, wie er in einem chiffrierten Brief vom 4. August 1624 (dechiffriert am 26. August 1624) schrieb:

Sicherlich sind einige Zürcher Senatoren, bzw. die beiden Bürgermeister, und viele ihrer Bewohner gut gegenüber der katholischen Religion gewogen, aber ich weiß nicht, wie wir jetzt hoffen können, dass der Kalvinismus vielleicht nicht ausgestorben, aber zumindest nicht die katholische Armee in jene Kantone einrücken müssten: weil die Minister bei diesen „Völkchen“ (Popolacci) zu viel Anerkennung dafür haben und weil sie zu böse geneigt sind gegenüber Katholiken, vertrauen sie sich gegenseitig nicht, dass sie miteinander sprechen, und bezweifeln, dass sie nicht als Anwälte der Katholiken angeprangert werden und dass sie ihres Ranges enthoben und ihres Eigentums beraubt werden, und des Vaterlandes ausgewiesen, wenn nicht des Lebens selbst. Die Mittel, die die Venezianer bei den Zürchern einsetzen wollen, scheinen mir nicht im Verhältnis zu der Notwendigkeit zu stehen, denn da die Republik eine solche Entscheidung nicht ohne Wissen treffen kann und ohne die Zustimmung vieler, unter denen sie nicht geben kann, ohne dass sie es nicht leichter finden sollten, sich von staatlichen Erwägungen überzeugen zu las-

195 Segreteria Stato, Svizzera Volume 12, f. 130/123.

196 Segreteria Stato, Svizzera Volume 13, f. f. 11/5. 
sen, als von der geistigen Frucht, die sich aus der Einführung der katholischen Religion in Zürich ergeben würde; entweder sind sie glaubwürdig, oder sie kommen nicht weit, oder die Zürcher erringen zuerst den Sieg, [...].

und es scheint, dass die katholischen Kantone einmal beschlossen haben, ernsthaft gegen die Ketzer vorzugehen, von denen sie jederzeit Schaden und empfindliche Beleidigungen erhalten, aber das bedeutet, dass sie unter den gegenwärtigen Umständen, in denen die Schweizer auf alle ausländischen Potentaten neidisch sind, immer noch sehr große Schwierigkeiten haben; deshalb sehe ich nicht, wie wir jetzt alle sicheren und wirksamen Mittel einsetzen können, zur Ausführung des heiligen Gedankens, die sie haben und die mir diese Kapuziner vorgeschlagen haben. ${ }^{197}$

In der Korrespondenz des Nuntius kann man sowohl zwischen den Zeilen als auch explizit nachlesen, wie er vor Ort mit Einheimischen Kontakt pflegte. Auf diese Weise erhielt er viele Informationen, festigte aber auch das Bild, welches er von den Schweizern hatte. So schrieb der Nuntius in einem Brief vom 4. August 1624 aus Luzern nach Rom:

\begin{abstract}
Als die Kapuziner-Versammlung dieser Provinz hier in Luzern vor ein paar Monate war, haben mir ihr Provinzial und der Pater Guardian von Konstanz in größter Geheimhaltung anvertraut, dass zwei Schweizer Katholiken, die mich genannt haben und mir wohlbekannt sind und als eifrige und nicht unkluge Menschen geschätzt werden, kurz vor der Durchfahrt durch Zürich mit einigen jener Senatoren sprachen, die Begriffe benutzt hatten, die über den üblichen Stil des Landes hinausgehen, und sie anflehten, sich bei den katholischen Kantonen einzusetzen, damit sie mit ihnen eine echte Bruderschaft und Freundschaft aufbauen könnten, und um den Zusammenhalt dieser Helvetischen Republik zu fördern, da sie mit der Mischung aus Katholiken und Ketzern in ihrer Freiheit nicht leicht zu halten ist, gegen die Pläne und Angriffe jeglicher ausländischer Truppen, von denen die meisten Österreicher und Deutsche sind, da sie große Eifersucht nach Zürich gebracht haben, indem sie sich auch denselben Zürchern anboten, dass sie, wenn sie sich dazu erklärten und die katholischen Kantone verpflichteten, ihnen die Möglichkeit gaben, darüber nachzudenken, was dieselben Katholiken von ihnen in Fragen der Religion gewünscht hätten. Da die oben genannten guten Kapuziner zusammen mit den beiden Vorrednern Hoffnung schufen, dass es in diesem Sachverhalt möglich sein würde, die Armee unserer Heiligen Religion in Zürich einzuführen, vor allem, wenn sie zu diesem Zweck ihre Ämter effektiv verlagern würden, dann würden die Zürcher dem christlichen König und der Republik Venedig wohl folgen; sie kamen also, um die Gebiete meines Dienstbereiches anzuflehen, [...]. ${ }^{198}$
\end{abstract}

Für den Nuntius war in dieser Phase klar: Die Katholiken sind immer zu unterstützen, die „Häretiker“ (Protestanten) hingegen soll man auf jeden Fall benachteiligen. Doch in der Auseinandersetzung musste er auch feststellen, dass

197 Segreteria Stato, Svizzera Volume 13, f. 13/7-14/8.

198 Segreteria Stato, Svizzera Volume 13, f. 14/8-15/9. 
die „andere Seite“ durchaus auch „gute Menschen“ vorzuweisen hatte, wie er beispielsweise in einem Brief vom 24. September 1624 schrieb:

Der Sekretär von Chur, der zwar ein Häretiker ist, aber einen guten Verstand in Staatsfragen hat, erklärt, dass sie bei den Infanteristen, die sich in diesen Gebieten angehäuft haben, nichts anderes zu tun hätten, als die Pässe in Graubünden und insbesondere von Steigh $^{199}$ zu schließen. $^{200}$

Die meisten Briefe behandeln die Kriegsvorbereitungen für das Veltlin. Der Nuntius beschrieb dann die Einzelheiten zu den Positionen der Schweizer (Katholiken) sowie der Franzosen und Spanier. So schrieb der Nuntius in einem Brief vom 27. Oktober 1624 nach Rom:

Die katholischen Kantone hatten bei dieser Gelegenheit daran gedacht, Unseren Lieben Herrn um finanzielle Unterstützung zu bitten, aber ich habe mich recht amüsiert. Aber sie sprechen sehr frei von ihrem Wunsch, dass die Schweizer Prälaten und die Kirchenleute ihren Beitrag leisten, wenn in diesen Gebieten Krieg geführt wird. Da erinnerte ich sie daran, nichts ohne die Zustimmung Unseres Lieben Herrn zu versuchen, der mir umso gnädiger erscheint, als der Klerus selbst es uns freiwillig erlauben wird. [... $]^{201}$

Der Nuntius schrieb am 2. August 1625 nach Rom:

Ich verspreche im Übrigen, in aller Verschwiegenheit, wie der Herr Kardinal mir befiehlt, dass die Franzosen das Veltlin nicht mit diesen katholischen Kantonen vereinen sollen, was aber bereits vor langer Zeit passiert ist, durch die allgemeine Meinung, die die Franzosen haben, dass diese katholischen Kantone mehr Spanier als Schweizer sind; aber wie ich den französischen Ministern oft gesagt habe, sehe ich hier nicht, warum die Franzosen dem Glauben der katholischen Schweizer in dieser Tatsache misstrauen sollten, während es neben vielen anderen Gründen diese katholischen Kantone sind, die sich so sehr für Frankreich einsetzen, und für die hohen Kredite, die sie von dieser Krone haben, und für den großen Sold, den sie jedes Jahr erhalten, was, wie mir scheint, eine große Sicherheit für die genannten Schweizer sein sollte, die von Seiner Majestät unterstützt werden $[. . .]^{202}$

Nuntius Scappi war vor allem mit der Veltliner Frage beschäftigt. Seine Korrespondenz nach Rom ist davon sehr stark geprägt und somit auch sein Bild über die Schweizer und deren Rolle. Er unterscheidet zwischen den Katholiken, die durchaus dem Ansinnen aus Rom folgen, und den Protestanten (,eretici“), die zwar religiös betrachtet eine gegnerische Seite bilden, doch als politischer Fak-

199 Hier ist sehr wahrscheinlich der Pass von St. Luzsteig gemeint.

200 Segreteria Stato, Svizzera Volume 13, f. 31/25.

201 Segreteria Stato, Svizzera Volume 13, f. 36/30.

202 Segreteria Stato, Svizzera Volume 13, f. 109/104. 
tor im geopolitischen Kontext in der Alpenregion eine ernstzunehmende Rolle aus Sicht des Papstgesandten einnehmen. ${ }^{203}$

Nuntius Scappi versuchte sich als Stratege einzusetzen, doch merkte er auch, dass Geld jenes Mittel ist, was auch in der Eidgenossenschaft - und nicht nur dort - die Dinge zum Rollen bringt. In einem Brief vom 9. Februar 1625 schrieb er nach Rom:

Das eine der großen Ärgernisse, die ich in dieser Nuntiatur hatte, bestand darin, mehrere ausgezeichnete Prälaten vor diesen weltlichen Richtern zu verteidigen, die von ihnen die Konten der Verwaltung ihrer Klöster verlangten, was besonders vorgeschlagen wurde von diesem Schultheiß Ambrino im Juli letzten Jahres bei der Tagsatzung von Baden, und ich widersetzte mich so effektiv, dass ich verwirrt wurde. So hat er von Anfang an das Gleiche auf das Feld gesetzt und anderen Geistlichen so viele Dinge angetan, und durch so viele Käufe hat er sie verarmen lassen, und kein anderer aus der säkularen Welt konnte mit seinem Geld mithalten, da sie es auch nicht zur Verfügung hatten; deshalb konnten die Geistlichen es nicht zu einem hohen Preis kaufen. Daraufhin sagte ich dem Schultheiß, und ich sagte es danach all denen, die mit mir über diese Angelegenheit gesprochen haben, dass sie, wenn sie ein vernünftiges und begründetes Interesse daran hätten, mir mitteilen sollten, damit ich es demütig zur Vorlage an Unseren Herrn vertreten kann, aber dass sie sehr vorsichtig sein sollten, keine ihrer eigenen Autoritäten für die Zensur und andere Unannehmlichkeiten, in denen sie auslaufen würden, zu erlassen, [...]. ${ }^{204}$

Scappi äußert sich jeweils sehr direkt und unmissverständlich. Auf diese Weise kann er beweisen, dass er die Lage vor Ort gut kennt und sie ernst nimmt. Am 8. Februar 1625 schrieb der Nuntius aus Luzern nach Rom:

Leider ist es sicher, dass es unter einigen dieser katholischen Kantone sehr ernsthafte Vortäuschungen gibt, ja, viele Feindschaften unter den Hauptfeinden eines bestimmten Kantons, und dass daher die Dinge dieser katholischen Republik nicht in einer Weise gedeihen, doch zumindest die Stärke der protestantischen Kantone nicht fürchtet; vor dieser letzten Tagsatzung dachte ich an meinen Vorschlag, sie zur Vereinigung aufzurufen, in dem nicht nur von einigen guten Ordensleuten, sondern auch von einigen der weiseren Senatoren von Luzern bestätigt wurde, ich ging darin im ersten Punkt meines Vorschlags ein. $[\ldots]^{205}$

Vom Glauben der Katholiken war der Nuntius so überzeugt, dass er jenen, die zum Heiligen Jahr nicht nach Rom pilgern konnten, Dispensen schenkte. ${ }^{206}$

203 Vgl. Segreteria Stato, Svizzera Volume 14, f. 77, 80, 110.

204 Segreteria Stato, Svizzera Volume 14, f. 120.

205 Segreteria Stato, Svizzera Volume 14, f. 145.

206 Vgl. Segreteria Stato, Svizzera Volume 14, f. 188. 
Auch von den „,richtigen Bündnissen“ der Katholiken und ihrer Aufrichtigkeit war er überzeugt. ${ }^{207}$

Dennoch hatten ihn auch viele Fälle dazu geführt, sein Bild im Laufe der Zeit zu ändern, wie er in einem Brief vom 24. Februar 1625 nach Rom festhielt:

Es scheint mir auf sichere Weise, dass hier die finstere Meinung eingebracht wird, welche einige wegen ihrer Leidenschaften und Interessen versucht haben, die einfachsten Seelen gegen die aufrichtigsten Taten Unseres Herrn aufzubringen, und da ich dabei sehr betroffen war, da ohne Grund verletzt wurde, was hingegen sehr bewundert werden muss, $\left[\ldots . .{ }^{208}\right.$

Der Nuntius machte auf die „Verführungsversuche“ der Franzosen aufmerksam. Dazu muss man die politische Situation beachten: die Auseinandersetzung zwischen Frankreich und Spanien sowie die damit verbundene Rolle Graubündens. ${ }^{209}$

So schrieb der Nuntius in einem Brief vom 20. März 1625 nach Rom:

... der Marquis [von Ogliani zu den Herren von Luzern] scheint hart in dem Stil gewesen zu sein, in dem die Gespräche geführt wurden, denn es war auch von einigen gesandten Senatoren in übertriebener Stimme mit hohen und fast bedrohlichen Worten eingebracht wurden, was ihn dann aber sehr verärgert hat und er sich an mich wandte, und ich konnte ihm zur Tröstung nichts anderes sagen konnte, als das, was ich ihm an Ort und Stelle gesagt habe, und zwar dass es eklig war, und bei seiner Ankunft wurde ihm gesagt, dass wir uns in dem Land befinden, wo wir uns anpassen müssen, um Beleidigungen zu empfangen, und dass man dies noch wohlwollend annehmen muss. Und weil heute Morgen der große Rat gehalten wird, um über seinen Vorschlag besser zu beraten, werde ich alles in meiner Macht Stehende tun, damit dieser Punkt die betreffenden Anführer [...] erreichen wird. 210

In den weiteren Briefen des Nuntius geht es um politische Strategien betreffend Graubünden und Veltlin sowie die Rolle der Eidgenossen und der Franzosen. Es gibt auch Kopien der Briefe zwischen dem Nuntius und dem französischen Botschafter Miron. ${ }^{211}$

So schreibt der Nuntius am 28. März 1626 nach Rom:

207 Vgl. Segreteria Stato, Svizzera Volume 14, f. 191.

208 Segreteria Stato, Svizzera Volume 14, f. 239. Vgl. auch Segreteria Stato, Svizzera Volume 14, f. 266.

209 Vgl. Segreteria Stato, Svizzera Volume 14, f. 347. Es handelt sich um einen Brief vom 22. April 1625, in der der Nuntius sich darüber beschwert, wie die Franzosen die Stellung des Heiligen Stuhls falsch einschätzen.

210 Segreteria Stato, Svizzera Volume 14, f. 291.

211 Vgl. Segreteria Stato, Svizzera, Volume 15. 
Mein Dolmetscher, den ich für diese katholischen Kantone geschickt habe, um die Wirkung zu erfahren, die der Brief Unseres Herrn auf sie ausübt, sagt mir, dass er in Uri noch nicht gelesen wurde; ich bin nicht überrascht, denn obwohl der Kanton an Frankreich gebunden ist, das sie jedoch nicht lieben, ist so viel von diesem Brief bekannt. In Schwyz, Zug und Unterwalden wurde der Brief gut gelesen, aber so falsch interpretiert, dass es tatsächlich den Sinnen der Kantone und der Verbündeten zu entsprechen scheint, dass es der Herr von Reding von Schwyz mit so viel Gereiztheit sät, dass viele der hier einfacheren Schwyzer Dorfbewohner es ständig glauben ... ${ }^{212}$

Band $16^{213}$ und 16A beinhalten vorwiegend Briefe und Kopien über ,politische Angelegenheiten“, die in der Tagsatzung behandelt werden müssen. Der Nuntius engagiert sich vor allem um die Lage im Wallis, wie er in einem Brief vom 9. Februar 1627 nach Rom schreibt:

Die katholischen Kantone werden jubeln, wenn ich sie vom fürsorglichen Gedanken informiere, den Unser Herr und Seine Allerheiligste Majestät dazu bringt, die Ruhe im Wallis und das geäußerte Versprechen zu bewahren, das ich gebe, um den Herrn Bischof von Sitten davon zu überzeugen, seine Kirche nicht aufzugeben. ${ }^{214}$

Dem Nuntius sind auch die Verhältnisse innerhalb der Eidgenossenschaft bekannt. So schreibt er am 6. Juli 1627 nach Rom:

\begin{abstract}
Auch die alten Zwistigkeiten zwischen den Herren von Freiburg und den Bernern werden wieder ins Spiel gebracht, wenn nicht gar, um sie zu ärgern und zu beseitigen, was vorerst nicht zu hoffen ist, zumindest um den Bernern selbst einen weiteren Grund für ihre Bewaffnung zu geben, sowie für die Aufstellung von Wachen und anderer militärische Aufgaben, die ihre Nachbarn immer neidischer machen, also die genannten Leute von Freiburg.

In einer Thurgauer Ortschaft namens Adorffo ${ }^{215}$ [sic!], wo bisher keine andere Armee war, als jene gottlose von Calvin, und nun wurden durch die Gnade Gottes mehr als hundert katholische Seelen entdeckt, die verlangen, dass hier eine Kirche für die katholische Ausübung gebaut werden soll; sie brachten unseren Abgeordneten den Befehl, sich ihnen anzuschließen, [...].“

Und weil ich mehrmals beobachtet habe, dass die katholischen Kantone in einigen Dokumenten die Protestanten mit dem Titel Evangelische nennen, habe ich einige meiner engsten Vertrauten in den katholischen Kantonen darüber nachdenken lassen, wie schlecht dieser Titel im Mund zugunsten der Protestanten ist; so bin ich nicht hoffnungslos, dass man nicht darüber hinausgehen wird, sich darüber in dieser Tagsatzung zu befassen, so dass diese Bezeichnung in Zukunft überhaupt nicht mehr oder zumindest so gemildert
\end{abstract}

212 Segreteria Stato, Svizzera, Volume 15, f. 161.

213 Segreteria Stato, Svizzera, Volume 16.

214 Segreteria Stato, Svizzera, Volume 16, f. 147.

215 Der Nuntius bezieht sich höchstwahrscheinlich auf die Ortschaft Aadorf. 
vorkommen wird und so bezeichnet werden, wie sie in Frankreich bezeichnet werden, und zwar als Reformierte. ${ }^{216}$

In Konstanz, von wo aus er die Lage in dem Gastland verfolgte, zählte er die Probleme auf, die vor allem im Süden des Landes festzustellen sind, wie er in einem Brief vom 4. Januar 1628 schrieb:

Die Nachrichten, die mich hier zu den Angelegenheiten, die das Wallis betreffen, erreichen, sind sehr ekelhaft. ${ }^{217}$

Die große Schwierigkeit bestand für ihn auch betreffs der Korrespondenzwege nach Rom. Wie der Nuntius in seinem ersten Brief aus Luzern am 11. Januar 1628 feststellte, gab es durchaus Schwierigkeiten beim Postversand:

Ich bin am 5. dieses Monats von Konstanz weggegangen und bin gestern hier in Luzern angekommen, da ich einen Tag mehr auf dem Reiseweg wegen Wind und Regen verbracht hatte, und der Neumond hat uns die gefährlichsten und stolzesten Männer gebracht, die in dieser Gegend sind. Hier hatte ich die Ehre, die beiden gnädigsten Briefe Eurer Majestät vom 11. und 19 des vergangenen Monats zu finden, aus denen ich das Unglück erfahren habe, das meine Botschaften erleiden, die nicht rechtzeitig Euer Ehren erreichten; so freue ich mich zu hören, dass sie kopiert geschickt werden, wie es auch bei diesen beiden letzten Briefen der Fall war, die ich vor einer Stunde von Eurer Majestät erhalten habe; und doch von vielen Teilen Italiens gewarnt wurde, dass meine Briefe vom 23. und 30. November auf dem Weg waren, so hoffe ich bei den nächsten Briefen, die ich von Ihnen erwarte, dass diese Antwortbriefe auch an Euch geschickt werden können, [...]. ${ }^{218}$

Es wird aber nicht erklärt, worin die Schwierigkeiten des Versands bestanden und wer daran schuld sei. Da die Briefe aus Rom ankamen, kann man annehmen, dass der Nuntius die Probleme eher in der Eidgenossenschaft sah.

Dass es turbulente Zeiten waren, stellt man auch beim Übergang zwischen den beiden Nuntiaturen fest. So schrieb Giovanni Scappi, Neffe von Nuntius Scappi, in einem Brief vom 1. Februar 1628:

Mein Onkel, Monsignore Nuntius, wurde am vergangenen Freitag beim Verlassen des Rates mit diesen Schweizer Katholiken von einem Fieberanfall befallen; aber er nahm es mit Leichtigkeit, sodass er es nicht ernst nahm; nach dem Mittagessen tat er nichts dagegen, und hatte sogar mit einigen der Schweizer verhandelt; und wichtiger noch, dass er am folgenden Samstag in den Rat zurückkehrte, wo er, nachdem er eine lange und durchgreifende Argumentation mit denselben Schweizern geführt hatte, gebeten wurde, zufrieden zu sein, dass die Abgeordneten von Wallis auch dort genannt wurden, [...]. ${ }^{219}$

216 Segreteria Stato, Svizzera, Volume 16A, f. 57-58.

217 Segreteria Stato, Svizzera, Volume 17, f. 11.

218 Segreteria Stato, Svizzera, Volume 17, f. 18.

219 Segreteria Stato, Svizzera, Volume 17, f. 53. 
Unter den Briefen aus der Eidgenossenschaft wurde über den Gotthardpass erstmals 1628 etwas darüber geschrieben, und zwar in einem Brief, in dem es um den Zugang zum Pass geht, der verschneit war. ${ }^{220}$

Der Nuntius hielt von der katholischen Seite in der Eidgenossenschaft sehr viel, so schrieb er im Januar 1628 nach Rom:

Die Schweizer Katholiken sollten sehr mächtig sein, denn der Bund, den sie mit den Wallisern haben, gründet sich auf die katholische Religion, die das Ziel hat, den Wallis zu erhalten, deshalb müssten sie als Schweizer Katholiken aus Staatsgründen ihre Macht ausüben, um die Berner zu bitten, sich nicht im Interesse dieser zu vermischen. [...] $]^{221}$

Die Jahre dieser Nuntiatur waren von Konflikten wie dem Dreißigjährigen Krieg geprägt, bei denen die Söldner aus der Eidgenossenschaft sehr beliebt waren. So geht es um eine Anfrage des kaiserlichen Gesandten Wolfgang von Mansfeld (1575-1638), ${ }^{222}$ der in einem Brief des Nuntius vom 4. April 1628 erwähnt wird:

\begin{abstract}
Es geht um den Brief, den die Kantone an den General von Mansfeld geschrieben haben, um die Absicht Seiner Kaiserlichen Majestät gegenüber ihnen so klar wie möglich zu machen, bezüglich der vielen Soldaten, die in der Nähe ihrer Grenzen standen, ... Und da diesen Herren von Luzern der Brief sehr vernünftig und nach einer reifen Überlegung würdig erschien und bevor sie richtig antworteten, wie er es kategorisch verlangte; deshalb trafen sie sich, um mit Rat und Tat der anderen katholischen Kantone, aber auch der Appenzeller Katholiken und des Fürstabtes von St. Gallen, ihrer Eidgenossen, zu beraten und zuzustimmen; sie alle luden ihn ab heute für acht Tage zum Landtag hier in Luzern ein. Und sie hören nicht auf, solange die Zürcher Abfall und Eifersucht auf den Geist Seiner Kaiserlichen Majestät säen; und solange sie diejenigen sind, die 8000 dieser aus Eisen hergestellte Stöcke gebracht haben, von denen der Brief von Mansfeld spricht, ähnlich denen, die sie bei ihrem letzten Aufstand in Graubünden benutzt haben; und die zusammen mit den Bernern einige Konzepte der Rebellion gegen die kaiserlichen Mandate in einigen Reichsstädten eingeflößt haben, [....]. 223
\end{abstract}

Der Nuntius stellte die schwierigen Verhandlungsabläufe in der Eidgenossenschaft fest und versuchte deshalb, die verschiedenen Seiten auch gegenseitig auszuspielen, wie er im Brief vom 13. April 1628 nach Rom schrieb:

Dieses verschämte indiskrete und barbarische Schweigen der Walliser war Gegenstand der Tagsatzung; und die Kantone haben einige ablehnende Haltung gezeigt. Daraufhin habe ich den Abgeordneten nicht sagen lassen, dass sie mich getroffen haben, da sie, nachdem sie bei denselben Kantonen so viel Zustimmung gefunden haben, nicht verwun-

220 Segreteria Stato, Svizzera, Volume 17, f. 89. Der Brief ist vom 9. März 1628.

221 Segreteria Stato, Svizzera, Volume 18, f. 15.

222 Vgl. Diethelm Klippel, Kai Lohsträter, Jutta Nowosadtko: Militär und Recht vom 16. bis 19. Jahrhundert, S. $214 \mathrm{f}$.

223 Segreteria Stato, Svizzera, Volume 17, f. 128. 
dert, ob sie auch dies missbrauchen werden; und dass sie jedoch, nachdem sie mit so viel Bequemlichkeit und Geduld auf ihn gewartet haben, eine Antwort erhalten haben, [...]. ${ }^{224}$

Und weiter beschrieb der Nuntius die Lage der Schweiz in einem Brief vom selben Tag nach Rom:

In der vergangenen Woche sollte in dieser Stadt ein großer Aufruhr herrschen, weil einige den Mut hatten zu sagen, dass es notwendig sei, weil die Armeen des Reiches gegen die Schweizer - wenn auch Häretiker - eindringen, und deshalb solle man schnell jene gute Bürger beseitigen, die der katholischen Religion glühend folgen, diesen Pfarrer in den See werfen, die Jesuiten aus Luzern wegschicken, wie es etliche ihnen eingeschärft haben, und sich allgemein in diesen Angelegenheiten nicht so sehr die häretischen Kantone verärgern. Da diese Androhungen in diesem Staatsrat eingebracht wurden, wurden dieselben Bürger, die es erlitten und gehört hatten, unter Eid zitiert und untersucht, und nachdem sie die Wahrheit gestanden hatten, wollten die Urheber, die davon Wind bekommen haben, diese mit Waffen angreifen, wenn nicht der Oberst [...] sie verhindert hätte. [...] Es geht darum, auch um zu sehen, was das gemeinsame Verständnis dieses Volkes betreffend der Zugehörigkeit zu den protestantischen Kantonen ist oder nicht, falls sie von den kaiserlichen Waffen angegriffen würden, [...]. ${ }^{225}$

Und im weiteren Teil des Briefes geht er auch auf das Verhältnis zwischen Venedig und den katholischen Kantonen ein:

Es ist so, dass die Venezianer sehr schlechte Aufträge und viel Geld unter den katholischen Kantonen gegen das Kaiserreich und seine heiligen Pläne verbreiten. Was nicht alles ist, denn wir wissen, dass durch die Herren von Schwyz viele Kisten mit Goldmünzen an den Sekretär der Republik Venedig mit Sitz in Zürich überbracht wurden, [...] Und es ist auch wahr, dass sechzig Schweizer aus Uri und anderen katholischen Kantonen nach Italien gebracht wurden, um den Fürstenherzog von Mantua zu bewachen. ${ }^{226}$

In einem chiffrierten Brief vom 18. April 1628 nannte der Nuntius auch namentlich einen Protagonisten, den er mit klaren Anschuldigungen beschreibt. Es handelt sich um den Schwyzer Heinrich Reding. ${ }^{227}$

224 Segreteria Stato, Svizzera, Volume 17, f. 154.

225 Segreteria Stato, Svizzera, Volume 18, f. 70.

226 Segreteria Stato, Svizzera, Volume 18, f. 71-72.

227 Heinrich Reding wurde 1562 in Schwyz geboren und starb am 19. Dezember 1634 in Paris. Er war ein katholischer Landmann von Schwyz. Sohn des Rudolf Reding und Bruder von Ital und Rudolf. Heinrich Reding war Ratsherr zu Schwyz, 1607 bis 1609 Landvogt in Baden, 161034 mehrfach Tagsatzungsgesandter, um 1610-34 Bannerherr, 1612-14, 1616-18, 1628-30 Landammann in Schwyz. Kurze Zeit war er auch in savoyischen Diensten, 1620 Gardehauptmann und Oberst in französischen Diensten. Er war einer der wichtigsten Gesandten und Vermittler der katholischen Eidgenossenschaft für die Solddienste in Frankreich, Savoyen und dem spanischen Mailand sowie zur Erhaltung der katholischen Religion im Wallis und während des 
Anlässlich des hier abgehaltenen Landtages entdeckte ich, dass der Reding von Schwyz mit den Dorfbewohnern dieses Kantons sehr mit viel Geld umgeht, sodass die Landesführung als Landammann, die sich in drei Wochen ändern wird, in seine eigene Person fällt; aber weil er einer von denen ist, die unter den katholischen Kantonen den Protestanten $\mathrm{zu}$ sehr verbunden ist und die immer im Widerspruch zu allen unserer Interessen stehen..., wäre seine Wahl schädlicher, als die Angelegenheiten des Bistums Sion und von Como mit der Präfektur Lugano, von denen ich weiß, was der Reding damit zu tun hat. $[\ldots]^{228}$

Der Austausch mit den anderen Papstgesandten in der „Region“ gehörte zu einem der Kerngeschäfte des Nuntius, der gleichzeitig auch mit den „Herren in Luzern“ klarkommen musste, wie aus dem Brief nach Rom vom 6. Mai 1628 ersichtlich ist:

Indem ich diesen Herren von Luzern die größte Sorge um das Böse, das Italien wieder einmal bedroht, zeigte, erläuterte ich ihnen die Wirksamkeit der geistlichen und weltlichen Heilmittel, die mit dem höchsten und eifrigsten Studium der Schriften Seiner Heiligkeit unseres Herrn verbunden sind. Es geht um die Bedeutung des Allerheiligsten Jubiläums (Heilige Jahr, Anm. d. Autors) und der Missionen der beiden außergewöhnlichen Nuntien an den Höfe des Kaiserreichs und des katholischen Landes (Frankreich, Anm. d. Autors) sowie um Herrn Giovanni Francesco Sacchetti beim Herzog von Savoyen und Herrn Don Gonzalo aus Spanien. ${ }^{229}$

So schrieb der Nuntius in der Eidgenossenschaft dem Nuntius beim Deutschen Reich am 11. März 1628:

Diese Schweizer sind sehr besorgt über die Waffen aus dem Reich, die an ihren Grenzen immer mehr anwachsen. Die einen stellen sich vor, dass Seine Majestät darüber nachdenkt, Helvetien wieder dem Haus Österreich zu unterwerfen, während andere glauben, dass dieser Sturm nur auf die protestantischen Kantone fallen sollte. [.... $]^{230}$

Das Verhältnis zu den protestantischen Kantonen wurde aber in jener Zeit immer schwieriger, wie der Nuntius in dem Brief vom 12. Mai 1628 nach Rom schrieb:

Ich wurde von guter Seite beraten, dass die protestantischen Kantone verlangen, die festen Güter, über die mehrere dieser Klöster und andere Geistliche in ihren Gebieten verfügen, schätzen zu lassen, um ihnen einen gewissen Beitrag zur Bezahlung der Soldaten, die kürzlich diese Protestanten erworben haben, und im Thurgau unter dem Vorwand

Dreißigjährigen Kriegs in Graubünden. Vgl. Stichwort „Heinrich Reding“, in: http://www.hlsdhs-dss.ch/textes/d/D19014.php (31. Dezember 2020).

228 Segreteria Stato, Svizzera, Volume 18, f. 82.

229 Segreteria Stato, Svizzera, Volume 17, f. 231.

230 Segreteria Stato, Svizzera, Volume 18, f. 45. 
schickten, um diese Provinz und ganz Helvetien vor den kaiserlichen Waffen zu schützen. Wenn das wahr ist, muss mich derselbe Klerus warnen; an einige dieser Prälaten habe ich geschrieben, um alle Besonderheiten zu kennen. ${ }^{231}$

Scappi war bereits seit 1627 nicht mehr in Luzern, sondern residierte in der Diözese von Piacenza. Er starb am 20. Juni 1653. ${ }^{232}$

\subsubsection{Ciriaco Rocci (1628-1630) ${ }^{233}$}

Wiederum kommt ein Römer nach Luzern: Ciriaco Rocci ist am 8. August 1582 in der Ewigen Stadt geboren. Sein Vater war ein aus Cremona stammender Händler. Ciriaco Roccis Onkel war Kardinal Pompeo Arrigoni, und so trat auch Ciriaco Rocci in die kirchliche Hierarchie ein. Wie die meisten seiner Vorgänger und Nachfolger war auch er ein Kirchenrechtler. Er wurde offiziell am 13. Mai 1628 zum Nuntius in Luzern ernannt. Das Schreiben dazu erhielt er erst zwei Wochen später von Kardinal Giulio Cesare Sacchetti in Ferrara ausgehändigt. Am 29. Mai wurde Ciriaco Rocci zum Titularerzbischof von Patrasso ernannt und am 14. Juni zum Priester geweiht, was darauf hinweist, dass seine Ernennung wichtiger war als das Bischofsamt als Voraussetzung für die Nuntiaturstelle. Er traf am 19. August 1628 in Luzern ein. ${ }^{234}$

Am 24. August 1628 ging Scappis Nachfolger Ciriaco Rocci als Erzbischof von Patras brieflich auf seine Ankunft in der Eidgenossenschaft ein:

Als ich in Luzern ankam, sah ich einen Haufen von Dispensen für Eheschließungen aus den Diözesen Basel, Konstanz und Sion betreffend den dritten und vierten Grad an Blutsverwandtschaft und Zugehörigkeit, wie der Bereich beschränkt ist, den mir Seine Seligkeit gewährt hat, da einige von ihnen nicht nur unwissend die Ehe geschlossen haben, sondern dort jahrelang so gelebt haben und Kinder hatten und andere schließlich Ehepartner unter Vertrag genommen haben. Wegen der Nähe, die sie zu den Ketzern haben, ist es für einige gefährlich, dorthin zu gehen und sich mit ihnen zu verheiraten. Ich habe jedoch die Zweckmäßigkeit beurteilt, Ihrer Allerheiligsten Majestät die beigefügte begrenzte Anzahl von neun Dispensationen in diesen Klassen zu schicken, und aus den Gründen, die dort dafür angegeben werden, [.... . $^{235}$

231 Segreteria Stato, Svizzera, Volume 17, f. 234.

232 Vgl. Stichwort „Alessandro Scappi“, in: https://hls-dhs-dss.ch/de/articles/016966/201102-21/ (31. Dezember 2020).

233 Caspar Wirz: Bullen und Breven aus Italienischen Archiven, S. XXXIX.

234 Urban Fink: Die Luzerner Nuntiatur 1586-1873.

235 Segreteria Stato, Svizzera, Volume 17, f. 378. 
Der neue Nuntius ist sehr kritisch mit seinem Vorgänger und wie dieser die katholische Seite in der Eidgenossenschaft gestützt hat. So schreibt er in einem Brief vom 5. September 1628 nach Rom:

\begin{abstract}
Und in Übereinstimmung mit dem, was mir Monsignore Bischof von di Piacenza ${ }^{236}$ gesagt hat, werde ich sehen, dass der Bischof ein Mann der Güte ist, aber dass er bei diesen Völkern auch in vielen Dingen mit wenig Umsicht regiert hat. Wenn man diese Kirche für lange Zeit ohne Hirte lässt, kann man der Gerichtsbarkeit des geistlichen Hauses viel Schaden zufügen, so zeitweilig wie tatsächlich geschehen, da diese Völker im katholischen Glauben nicht sehr gefestigt sind, und Priester, die gute Ordensleute sind, die sie lehren können; wie ich ihn, so wie ich fortfahren will, angewiesen habe, sich damit zufrieden zu geben, vier Kapuzinerprediger dieser Provinz Helvetiens zu empfangen, von denen ich hoffe, dass sie gute Fortschritte durch ihre Predigt erzeugen werden,[...].

Ich habe die Absicht kundgetan, dies so schnell wie möglich zu tun, indem sie sich zu erkennen geben, dass es besser ist als früher, denn Eure Hoheit wird vom Rückzug der Tagsatzung erfahren, bei der sie ${ }^{237}$ erneut ausdrücklich erklärt haben, dass sie im wahren katholischen und apostolischen römischen Glauben leben und sterben wollen, und dass sie nicht zulassen werden, dass weder ihre Länder aufgeben noch die neue Religion eingeführt werden, im Gegenteil, sie werden alle Ketzer vertreiben. [...] Doch sie werden von den benachbarten Bernern ständig provoziert, den katholischen Glauben zu verlassen und sich mit ihrer Sekte zu vereinen; und deshalb sind es diese Völker, die am meisten geistliche Hilfe brauchen, [...]. ${ }^{238}$
\end{abstract}

In jener Zeit gab es auch die sogenannte „Borromäische Pest“ (1629-1630), die der Nuntius von Altdorf aus „,beobachtete“. Während dieser Zeit war der heutige Südschweizer Kanton auch zwischen den Mailändern, Spaniern und den Eidgenossen umstritten. In einem Brief vom 14. Februar 1629 schreibt der Nuntius von Altdorf nach Rom:

Der Neid, den diese Schweizer gegenüber der Mailänder Regierung betreffend die drei Festungen von Bellinzona hegten, hat zugenommen, nachdem man ihnen kurz und knapp gesagt hat, dass zwei als Mönche verkleidete Ingenieure die Festungen begutachtet haben, und so haben sie bereits eine neue Garnison von 50 Soldaten aufgestellt, ohne alle andere Sorgfalt zu vergessen, um das Vorhaben der Spanier zu beobachten. 239

Dem Nuntius sind auch die Schwächen der Eidgenossenschaft bekannt, und zwar vor allem im Bereich der Ressourcen, so schreibt er in einem Brief vom 1. Januar 1630 in Luzern nach Rom:

236 Damit ist Nuntius Scappi gemeint.

237 Damit sind die Katholiken gemeint.

238 Segreteria Stato, Svizzera, Volume 17, f. 409-409.

239 Segreteria Stato, Svizzera, Volume 18, f. 197. 
... und während die Schweizer sich den Franzosen anschließen, glauben sie, dass es eine ausgezeichnete Möglichkeit war, den Frieden in Italien zu erleichtern: Aber ich sehe, was sie vor Angst zurückhält, dass sie nämlich aus dem Haus Österreich keine Nahrung erhalten, weil dieses Land unfruchtbar ist, obwohl die Menschen nicht schlecht leben, und auch die Mitglieder der spanischen Fraktion, die die Mehrheit des Landes stellen, würden ihre Kredite nicht verlieren wollen. [.... $]^{240}$

Nuntius Rocci war sehr aktiv, aber er beschränkte sich vor allem aufs Beobachten, wie man es in dem Brief vom 9. Juni 1629 nachlesen kann, den er aus Luzern nach Rom sandte:

Diese Schweizer Kantone, um irgendwie sicher zu sein, dass die kaiserliche Armee nicht versuchen wird, die Pässe nach Bellinzona zu besetzen, sind ihnen gegenüber misstrauisch wegen des vom Kaiser verfassten Briefs, den ihnen zwei ihrer Botschafter, einer aus Schwyz und einer aus Zürich, nach Chur geschickt haben, also verhandelten sie mit den Anführern dieser Soldaten und so konnten sie erfahren, ob diesen die Einreise in das Land der Schweizer befohlen wurde, [...]..$^{241}$

\section{Als Beobachter war er vor allem am Verhältnis zwischen Katholiken und Protes- tanten interessiert, wie er im Brief vom 26. Juni 1629 aus Luzern nach Rom schreibt:}

Diese ketzerischen Kantone appellieren an die katholischen Kantone, zusammen zu gehen, um die kaiserlichen Soldaten von den besetzten Gebieten zu vertreiben, aber die katholischen Kantone halten sich vorerst nicht an diesen Gedanken und wollen zunächst auf die Beschlüsse warten, die der König zuerst bekanntgeben wird, um auf jeden Fall die Unterstützung Seiner Majestät zu haben, [...]. ${ }^{242}$

Die meiste Zeit aber widmete der Nuntius den kirchenrechtlichen Angelegenheiten in der Eidgenossenschaft, wie es im Band $19 \mathrm{zu}$ finden ist. ${ }^{243}$ Doch schaut der Nuntius immer wieder auf die politische Lage und merkt in einem Brief vom 21. März 1629 aus Altdorf nach Rom an:

240 Segreteria Stato, Svizzera, Volume 18, f. 423.

241 Segreteria Stato, Svizzera, Volume 18A, f 23. Dieser Band im Vatikanischen Geheimarchiv ist besonders, weil er, im Gegensatz zu den anderen Dokumenten, als Buch mit Titelseite zu finden ist. Der Titel lautet: „REGISTRO DI LETTERE di Monsig.(r) Rocci Nunzio alli Suizzeri, scritte al Sig.(r) Card.(l) Barberino Nipote di Vrbano VIII. con le sue risposte, dalli 22 luglio 1628 alli 20 settembre 1630; Tomo Primo“. Viele Briefe waren bereits im vorhergehenden Band zu finden. Der zweite Teil besteht aus Korrespondenzbriefen von Kardinal Barberini (vor allem an andere Nuntien wie in Frankreich und im Deutschen Reich).

242 Segreteria Stato, Svizzera, Volume 18A, f 26.

243 Vgl. Segreteria Stato, Svizzera, Volume 19. In diesem Band geht es - wie in den vorhergehenden Bänden - vor allem um „Bischofsangelegenheiten“, wie beispielsweise: f. 13 und f. 24. 
Die vier häretischen Kantone Zürich, Basel, Bern und Schaffhausen bilden in Zürich einen Landtag, in dem besprochen wird, dass sie sich damit befassen wollen, untereinander eine ewige Abwehrliga gegen die Eindringlinge der oben genannten Kantone mit der Verpflichtung zur Bildung einer Armee mit viertausend bezahlten Infanteristen, und das tun sie aus Angst, dass die Berner ihre Waffen der kaiserlichen Majestät oder dem Allerchristlichsten König zur Verfügung stellen.

[...]

Die fünf katholischen Kantone halten in Luzern einen Landtag ab, auf dem es darum geht, dass die Gesundheitskommissare von Mailand den Pass freigeben, der auf Bertonico führt, im Staat der Schweizer Herren, wegen der Ansteckungsgefahr, da derzeit dank der Gnade Gottes niemand gestorben ist, und wenn sie es nicht wollen, so ziehen sie sich zusammen gegen den Staat Mailand. ${ }^{244}$

Um 1629 gab es aber etliche Schwierigkeiten für den Nuntius, Briefe nach Italien zu schicken und umgekehrt aus Italien zu erhalten, wie er in mehreren Briefen nach Süden schreibt. ${ }^{245}$ Auch fällt in dieser Zeit sein Engagement für den Seligund Heiligsprechungsprozess für Nikolaus von Flüe auf, wie er in einem Brief vom 21. August 1629 nach Rom schreibt:

Die Herren des Kantons Unterwalden haben mich dringend gebeten, Ihre Hoheit mit meinen Briefen zu bitten, dass Sie als Beschützer Helvetiens gerne Ihre Macht in die Heilige Ritenkongregation zur Seligsprechung von Bruder Nikolaus von Flüe stellen, ihrem Landsmann, und sie baten mich, dass bald der notwendige Prozess in Rom abgeschlossen sein wird, damit die Kongregation ihn seligspricht. [... $]^{246}$

Nuntius Rocci geht am Ende seiner Amtszeit auf seinen Nachfolger ein und schreibt in einem Brief aus Luzern am 25. Juni 1630 nach Rom:

In zwei bis drei Tagen erwarte ich Monsignore Scotto, den neuen Nuntius, nachdem ich kürzlich seine Briefe erhalten habe, in denen er mich hinweist, ihn in Locarno zu treffen, und nachdem ich dort ankomme, werde ich es nicht unterlassen, ihm alle genauen Informationen über alle Angelegenheiten und Strömungen dieser Nuntiatur sowie die Qualitäten und Bräuche dieser Schweizer Herren zu geben, damit er durch seine Tugend einen ausgezeichneten Dienst in seinem Amt verrichten kann. [.... $]^{247}$

Eine der letzten Amtshandlungen von Nuntius Rocci betraf die Lage im Wallis. In einem seiner letzten dienstlichen Briefe aus Luzern als Nuntius in der Eidgenossenschaft schreibt er am 11. September 1629: ${ }^{248}$

244 Segreteria Stato, Svizzera, Volume 19, f. 77.

245 Vgl. Segreteria Stato, Svizzera, Volume 19, f. 147, 174.

246 Segreteria Stato, Svizzera, Volume 19, f. 228.

247 Segreteria Stato, Svizzera, Volume 19, f. 139. 
Es waren nicht viele Tage vergangen, seitdem der Landvogt aus dem Generalrat von Wallis mir einen Brief geschrieben hatte, in dem er mich bat, Unseren Herrn zu bitten, die Rückkehr ihres Bischofs zu unterstützen, und er sagte mir auch, dass es für diesen fast unmöglich sei, in seine Residenz zurückzukehren; Da das Volk sich von diesem beleidigt fühlt, nicht nur wegen der Streitigkeiten und Differenzen, sondern weil er kürzlich eine Erklärung einiger Vorwürfe an die Presse geschickt hat, in der er sich verteidigt und die Angriffe gegen seine Kirche und seine Person nennt, indem er die wichtigsten anti-katholischen Ankläger offen benennt; und wenn ich ihnen viele Male geschrieben habe und diesen Herren der katholischen Kantone angedeutet habe, dass sie sich mit ihrem Hirten wiedervereinigen sollten, da in keiner Weise die Rückkehr verhindert werden kann ... ${ }^{249}$

Im April 1630 besuchte er verschiedene Benediktinerklöster im Gebiet der Nuntiatur, und zwar in den katholischen Kantonen sowie in den Diözesen von Konstanz und Basel, also auch jene Klöster, die im süddeutschen Raum außerhalb der Eidgenossenschaft lagen. Ein halbes Jahr zuvor, am 19. November 1629, hatte ihn Papst Urban VIII. zum Kardinal in pectore kreiert. Und kurz darauf wurde er mit Hilfe seines Bruders Antonio Rocci zum Nuntius in Paris ernannt. Doch stattdessen wurde er im April 1630 zum Reichshof nach Wien entsandt. Die Veröffentlichung seiner Aufnahme in das Kardinalskollegium am 28. November 1633 setzte seinem diplomatischen Werdegang ein Ende. Er nahm am Konklave von 1644 teil, bei dem Innozenz X. gewählt wurde. Ciriaco Rocci starb am 25. September 1651 und wurde in Rom begraben. ${ }^{250}$

\subsubsection{Ranuccio Scotti (1630-1639) $)^{251}$}

Der am 19. Juli 1597 in Parma geborene Ranuccio Scotti gehörte einer Adelsfamilie an und wurde mit 30 Jahren Bischof von Borgo San Donnini, dem heutigen Ort Fidenza. 1630 entsandte ihn Urban VIII. nach Luzern, wo er fast ein Jahrzehnt lang Nuntius war. ${ }^{252}$

Wie seine Vorgänger war er mit der großen Herausforderung, in Graubünden den Konflikt zwischen Katholiken und Protestanten zu entschärfen, beschäftigt. Der neue Nuntius versuchte bereits zu Beginn seines Amtes, aktiv zu

248 Es handelt sich um eine der letzten Amtshandlungen, auch wenn er noch ein halbes Jahr in der Eidgenossenschaft residierte, wie im vorherigen Brief, der 1630 verfasst wurde, nachzulesen ist.

249 Segreteria Stato, Svizzera, Volume 19, f. 176.

250 Vgl. Stichwort „Ciriaco Rocci“, in: http://www.treccani.it/enciclopedia/ciriaco-rocci_(Dizionario-Biografico)/ (31. Dezember 2020).

251 Vgl. Caspar Wirz: Bullen und Breven aus Italienischen Archiven, S. XXXIX.

252 Vgl. Stichwort „Ranuccio Scotti“, in: https://hls-dhs-dss.ch/de/articles/017919/2011-11-17/ (31. Dezember 2020). 
sein und direkt $\mathrm{zu}$ handeln. Er ging wohl davon aus, dass er die Katholiken direkt und ohne große Schwierigkeiten „anführen“ könne, wie er in einem Brief vom 25. Februar 1631 nach Rom schreibt:

Die Tagsatzung der fünf katholischen Kantone, die diese Woche in Luzern durchgeführt werden sollte, um die Antworten, die den Zürcher Protestanten gegeben werden sollten, zu beschließen, hat sich bis zur nächsten verlängert, und da selbst diejenigen Angelegenheiten oft schwere Folgen in der Nation hervorrufen, die große Nachteile für die katholische Religion mit sich bringen, hielt ich es für gut, selbst diese Tagsatzung zu leiten, und in der Hoffnung, dass die Angelegenheit in dieser Form von Eurer Eminenz geschätzt werden kann, [...]..$^{253}$

Der Nuntius, der an der Tagsatzung in Baden teilnahm, berichtet am 22. Februar 1631 nach Rom:

Es wird wieder über einen Bund der katholischen Kantone mit Spanien gesprochen, der wieder in Gang sein soll, aber zunächst wird eine große Geldzahlung für die vergangenen Dienste verlangt. In der Zwischenzeit wollen die Katholiken einen Krieg mit den Protestanten anfangen, damit sie Geld von irgendeinem Prinzen einnehmen können, ohne zu wissen, wie man es auf andere Weise bekommt.

[...]

Bei dem Treffen sagte mir der Vertreter von Venedig, der mir alle Interessen der Republik anvertraut, dass er nach Venedig geschrieben habe, wie unnütz die Geldsumme von achttausend Talern sei, die von den Protestanten und anderen gegeben wird, um einen Agenten zu halten. Es sei wie weggeworfenes Geld, während sie die Pässe der verbündeten Bündner so sehr vernachlässigen. ${ }^{254}$

Auch er reist viel herum in der Eidgenossenschaft - wie seine Vorgänger -, um die Lage vor Ort besser zu verstehen und einzugreifen. Darüber berichtet er dann nach Rom, wie beispielsweise im Brief vom 14. März 1631:

Am Samstag bin ich nach Konstanz und Ravensburg, von wo aus ich gestern ohne Zeitverlust hierher zurückgekehrt bin, nachdem ich die Reise in sechs Tagen hinter mir gebracht habe, denke ich, dass ich am Montag nach Luzern zurückkehren werde, um nicht in diesen sehr sicheren Orten zu bleiben, falls diese Kantone den Krieg auslösen würden, denn es wäre der erste Angriff: Um sich den Zürchern mit den Bernern anzuschließen und auch um die Katholiken, die bisher fest in ihren Vorsätzen waren, in Erinnerung zu rufen; aber die von Basel, Schaffhausen und Bern ließen zu verstehen geben, dass sie den Zürchern in keiner Weise zustimmen werden; Inzwischen bewaffnen sie sich nicht offen, aber sie machen geheime Sachen. [...] $]^{255}$

253 Segreteria Stato, Svizzera, Volume 21, f. 30.

254 Segreteria Stato, Svizzera, Volume 23, f. 31.

255 Segreteria Stato, Svizzera, Volume 21, f. 54. 
Nuntius Scotti wollte alles besser als seine Vorgänger machen und wusste gut Bescheid, wie es vor seiner Amtszeit in der Eidgenossenschaft aussah. Vor allem war es ihm ein Anliegen, die kirchenstrukturelle Ordnung zu wahren, wie er in einem Brief vom 18. April 1631 nach Rom schrieb:

In den Provinzen dieser Nuntiatur sieht es seit mindestens der Zeit des Bischofs von Piacenza so aus, dass bei der Nachfolge der Bischofsstühle oder der fixen Äbte, die Kapitel bis zur Wahl des Nachfolgers ohne die Hilfe des Apostolischen Nuntius nicht auskommen. Auch wenn man weiß, dass man dies vermeiden sollte, wie es der Monsignore von Piacenza mit dem Konstanzer Kapitel tat und im Fall von Basel mit dem Monsignore von Patras. Doch da die Nuntien immer auf die kirchlichen Einwände eingingen und auch einige Proteste der Kapitel annahmen, wurde immer alles erfolgreich überwunden, [...] $]^{256}$

\section{Am selben Tag, aber in einem chiffrierten Brief, schrieb der Nuntius nach Rom:}

Der Landammann Tanner ${ }^{257}$ von Altdorf war einer der ersten, der nach Luzern kam, um die Interessen zu erläutern, die sie mit den Protestanten verfolgen, und war an mich herangetreten, um mir zu sagen, dass von seinem Kanton und von den anderen gedacht wurde, Unseren Herrn um etwas Geld vom Apostolischen Stuhl zu bitten, zusätzlich zum Beitrag der Klöster, um den Katholiken zu helfen, bevor die Dinge zerbrechen würden, in der Hoffnung, nicht weniger zu bekommen als in anderen Zeiten von früheren Päpsten. Ich antwortete ihm, dass Seine Heiligkeit in gutem Willen niemandem nachgegeben habe, sondern dass die Apostolische Kammer durch die großen Kosten erschöpft sei, da es für die Erhaltung des Kirchenstaates zweckmäßig sei und die alten und neuen Festungen und Soldaten, erschien es mir ausreichend zu sein, daher war ich jetzt gegen eine solche Bitte der katholischen Kantone, da ich glaube, dass trotz so viel Lärm kein Krieg folgen wird, dennoch wollte ich bei allem guten Respekt Ihrer Eminenz demütig alles vortragen. 258

Am 28. April 1631 schrieb der Nuntius über einen Vorfall nach Rom, bei dem sich Katholiken und Protestanten in der Schweiz in die Haare gerieten:

In diesen Tagen trafen sich unweit von Baden sieben unbewaffnete Katholiken mit sechzig Zürcher Untertanen, die mit Schwertern bewaffnete Ketzer waren, um in den Tavernen trinken zu gehen, und dort angekommen, waren sie in einer Kapelle, die mit Marienbildern bemalt war und auch mit Heiligen, sodass die Ketzer Steine nahmen und mit ihren Schwertern begannen, die Glasscheibe zu zerstören und die Figuren kaputt zu schlagen. Als die wenigen Katholiken das sahen und eine solche Handlung nicht ertragen konnten, obwohl sie keine Waffen bei sich hatten, nahmen sie Holz aus einem Wald und begannen

256 Segreteria Stato, Svizzera, Volume 21, f. 93.

257 Sehr wahrscheinlich bezieht sich der Nuntius auf Johann Jakob Tanner, der allerdings zu jener Zeit gar nicht Landamman von Uri war, sondern von 1623 bis 1625.1630 war es Heinrich Sebastian Tresch bzw. Karl Emanuel von Roll. Vgl. den Artikel in http://www.urikon.ch/UR_Behoerden/BEH_RR_LA.aspx (31. Dezember 2020).

258 Segreteria Stato, Svizzera, Volume 23, f. 56. 
so, auf die Ketzer einzuschlagen, und es kamen plötzlich weitere vier Katholiken hinzu, die die Schwerter der Ketzer wegnahmen, und von den 60 Beteiligten wurden 40 verwundet und einer starb. Auf diese Weise meldeten sie neben der Scham auch den Schaden, die Zürcher haben jedoch dazu nichts geäußert; in der Erwartung, dass die Landsgemeinde in Baden diese Angelegenheit behandelt: [... $]^{259}$

Der Nuntius bemerkte wie seine Vorgänger, dass die Eidgenossenschaft eine aus geopolitischer Sicht strategische Position in Europa innehatte. Dabei spielten die Bündner eine besondere Rolle, wie er in einem Brief vom 30. Mai 1631 nach Rom schrieb:

Trotz des Friedens, den wir heute in Italien auch in den Gebieten der Spanier haben, bezweifeln diese Kantone, dass Graubünden - ihr Verbündeter - nicht nur nicht ihre Freiheit erlangen, sondern dass dieselben Spanier behaupten, in diesem Land voranzuschreiten, und all dieser Zweifel wird durch Briefe aus Frankreich verursacht, [...]. ${ }^{260}$

\section{Am 14. Juli 1631 ging er nochmals auf die Abstände zwischen Katholiken und Protestanten ein und schrieb nach Rom:}

Es wurde beschlossen, dass nächste Woche ein Landtag stattfinden soll, an der nicht nur alle 9 Kantone teilnehmen werden, sondern auch die katholischen Bundesgenossen aus dem Wallis, der Bischof von Basel und der Abt von St. Gallen; es geht darum, da Graubünden nicht sehr viel mit den Ketzern anzufangen weiß, sich darin mit der Art und Weise zu befassen, wie man sich vor ausländischen Feinden und im Inland zu verteidigen hat; und inzwischen können die Protestanten aus diesem Grund selbst niemandem trauen und keine Zeit verlieren, um alles zu verpassen [...]. Die Stadt Konstanz hingegen sieht den Feind in ihrer Nähe, und schon ist der Rat dort entschlossen, da sie sich von den Erzherzögen verlassen und von den Schweizern wegen ihrer Zwietracht nicht geholfen fühlt, deshalb wendet sie sich in erster Linie dem Schweden zu, [...]. ${ }^{261}$

Der Nuntius verfolgte dann das weitere Vorgehen in Bezug auf die Kontrolle über den Kanton Thurgau und schrieb am 29. August 1631 aus Luzern nach Rom:

Diese katholischen Kantone warten jedoch auf die Antwort der Zürcher, ob sie gemeinsam den Thurgau teilen wollen, denn sie bekennen sich dazu, nicht zu den Beschlüssen der Mehrheit der Stimmen zugunsten des Bischofs von Konstanz und der Äbte von St. Gallen in jener Provinz stehen zu wollen, aber wenn die Antwort zu spät kommt, dann wird es als ein Zeichen dafür betrachtet, dass sie aufgeben wollen, weil die Häretiker nichts weniger als von einer Teilung hören wollen ... Inzwischen bereiten sich die Katholiken auf jeglichen Versuch vor, nachdem sie von ihren Untertanen außerhalb von Monti in Italien ei-

259 Segreteria Stato, Svizzera, Volume 21, f. 99.

260 Segreteria Stato, Svizzera, Volume 21, f. 135.

261 Segreteria Stato, Svizzera, Volume 21, f. 198. 
ne Antwort erhalten haben, dass sie mit Geld und Menschen trotz allem zu ihren Gunsten bereitet sein werden, obwohl sie den protestantischen Kantonen unterstellt sind, [...]. ${ }^{262}$

Kritisch betrachtete der Nuntius die Einstellung der Katholiken, die seiner Meinung nach die Franzosen nicht in genügender Weise mit Söldner unterstützten, wie dies für die Spanier geschehe, wie er in einem Brief vom 5. März 1632 nach Rom schrieb:

Diese katholischen Kantone sind sehr unentschlossen, was die Entsendung von Söldnern an die Franzosen betrifft; die Fraktionen sind auf dem Feld zu finden, einige sind Anhänger Spaniens, die ihnen Söldner gewähren, weil sie ihren Lohn von der Mailänder Regierung erhalten, [...] Die vier Kantone in der Nähe des Fußstapfens zum St. Gotthard sind die demokratischen Räte, also das Volk, in großer Verwirrung, als ob es ein großes Aufgebot geben sollte; [... $]^{263}$

Der Nuntius sah mit Argwohn, wie die Katholiken trotz religiöser Differenzen weiterhin mit den Protestanten im Bund blieben, und wunderte sich, dass sie nicht stattdessen mit anderen „Partnern“ im deutschsprachigen Raum paktierten, wie er in einem Brief vom 16. Mai 1632 nach Rom schrieb:

Die Vereinbarungen, die zwischen den Rittern von Malta aus Deutschen und Schweizern bestanden, schienen 1626 sehr korrekt zu sein; in der Tat gibt es von Seiner Heiligkeit ein Breve dazu, in der die entsprechenden Seiten zwischen diesen beiden Nationen verstärkt werden; damit die Schweizer mit anderen deutschsprachigen Rittern wetteifern könnten; einige bekennen sich jedoch dazu, sie abzulehnen; aber während die Kantone in ihrem Land viele Aufträge erhalten und sie weiterhin mit den Protestanten im Bund bleiben, wenn auch eifrige Katholiken zu Recht Gnade erwarten; [...] $]^{264}$

Der Nuntius sah die Schweizer als zu nachgiebig und nicht resolut in ihrer Haltung an, wie er in einem Brief vom 23. April 1632 festhielt:

Die Schweizer sehen sich von Spaniern verspottet, von denen sie nur Worte erhalten, aber nicht weniger von Franzosen, die nicht mehr über Regimenter sprechen, wie es ihnen ein gewöhnlicher Botschafter tun würde. ${ }^{265}$

262 Segreteria Stato, Svizzera, Volume 21, f. 255. In f. 261 ist ein weiterer Brief mit demselben Datum zu finden, in dem präzisiert wird, dass sich „Zürich“ nicht rührt, und deshalb sei alles „festgefahren“.

263 Segreteria Stato, Svizzera, Volume 22, f. 69. Eine Tagsatzung unter protestantischen Kantonen, die sich mit dem Vertreter Schwedens trafen, wurde vom Nuntius mit Sorge beobachtet. Das schreibt er in einem Brief vom 23. April 1632, Segreteria Stato, Svizzera, Volume 22, f. 113. 264 Segreteria Stato, Svizzera, Volume 22, f. 145. 265 Segreteria Stato, Svizzera, Volume 23, f. 116. 
Doch andersrum zeigt der Nuntius auch Verständnis, so zumindest schreibt er das, für die Haltung der Katholiken, die wegen fehlender Zahlungen zurückhaltend sind. Dazu schreibt der Nuntius am 29. April 1632 nach Rom:

Die protestantischen Kantone, um die Abmachungen mit dem Schweden zu entschuldigen, sagen, dass Katholiken nicht miteinander klarkommen sollten, wie sie es tun, und zwar mit den Spaniern, die eine Unmenge von Soldaten aus Italien kommen lassen, aber es ist schwierig, dass dies geschieht, wenn sie nicht zumindest einen Teil des Lohnes erhalten, [...]. ${ }^{266}$

Die Abmachungen über das Söldnerwesen prägten die 1630er Jahre, und der Nuntius versuchte sich immer wieder als „Söldner-Agent“ einzubringen, wie er beispielsweise in einem Brief vom 11. April 1634 schrieb:

Ohne andere Überlegung als für gute Zwecke geschieht es, dass oft in diesen Gebieten die Meinungen oder Beschwerden nicht sehr beliebt sind, wie beispielsweise der Kanton Unterwalden, der einen Erlass veröffentlicht hat, bei der jeder, ob kirchlich oder weltlich, bis $\mathrm{zu}$ einem gewissen Ansatz dazu beitragen musste, einen Teil des Geldes zu geben, um jenes, das aus der Schatzkammer ausgegeben wurde, das sie in diesem Sommer gegen Ketzer oder Ungläubige brauchten, und da sie viel Bereitschaft bei den Priestern fanden, die ihrem Wunsch zustimmten und ihnen das Geld geben würden; Aber als ich davon erfuhr, rief ich die Abgeordneten zu mir, die im Landtag waren, und machte sie darauf aufmerksam, dass sie mich nicht dazu veranlassen dürfen, ihnen in diesem Geschäft beizustehen, und so stellte ich ihnen als Stellvertreter einen Priester vor, der als Kommissar und Steuereintreiber wirken sollte, um die Summe, die sie im laufenden Jahr einnehmen wollten, mit einer Erklärung einzusammeln, die für die Kosten der Soldaten gedacht ist, für jene, die wegen der eigenen Verteidigung gegen Ketzer eingesetzt werden; sie haben daher diese Absicht geäußert, keinen Lärm zu verursachen, und ich hoffe, dass sie sie in den anderen drei Kantonen, denen ich meine Sicht für die gleichen Dekrete erlassen haben, auch einbringen können; [... $]^{267}$

Die Lage der Katholiken in vielen Gebieten der Eidgenossenschaft sah der Nuntius von den „häretischen“ Protestanten bedroht. Vor allem hatte er Sorge um jene Gebiete, die „zu nahe“ an den protestantischen Kernlanden Zürich und Bern lagen. So beschrieb er in einem Brief vom 22. August 1634, wie er die Katholiken im Gebiet von Baden unterstützte, und wunderte sich, dass auch ,ältere Katholiken“ vieles über den Glauben nicht wussten:

Da Baden seit jeher ganz katholisch geblieben ist, aber nicht in der Grafschaft, da es in allen Teilen des Gebiets und Dörfern mit häretischen Teilen vermischt vorkommt, die von Zürchern und Bernern umgeben sind; und da in zwanzig Jahren die Bischöfe von Kon-

266 Segreteria Stato, Svizzera, Volume 23, f. 125. Der Brief wurde am 19. Mai 1632 in Rom dechiffriert.

267 Segreteria Stato, Svizzera, Volume 24-31, f. 7. 
stanz nicht zu sehen waren, weiß ich, dass Ihre Eminenz spirituell erfreut sein wird zu sehen, dass ich an Christi Himmelfahrt allein und ohne Begleitung der anderen die Heilige Firmung an fünftausend Menschen gespendet habe, die aus diesen von Ketzern geprägten Orten stammten, und es gab viele 60Jährige, die nicht wussten, was die Firmung ist, und die Menge des Volkes war so groß, dass etliche sich daran erstickt haben. [...] $]^{268}$

Die Angelegenheit mit Spanien beschäftige den Nuntius sehr, wie er in mehreren Briefen im Jahr 1635 schrieb, wie beispielsweise am 18. April 1635, einem dechiffrierten Brief:

Das Eintreten der Schweizer Katholiken für Spanien erhält keine Unterstützung von dieser Einrichtung, wie es der Botschafter glaubte, da sie selbst energisch dies bekämpfen; die Kantone sind gespalten; drei sind dafür, die anderen, wie Luzern und Schwyz, welche auch einen der Pässe nach Italien kontrollieren, wollen nicht die Neutralität brechen und deshalb meiden sie die Resolution und listig wollen sie zuerst das Anliegen des Botschafters von Frankreich abwarten. Geld wird auch nicht aus Mailand gesehen und es werden auch keine Vorurteile noch Argumente für den Umgang mit einer Söldnerentsendung entdeckt, und deshalb bleibt das Ganze unsicher. ${ }^{269}$

Die geostrategische Lage der Zentralschweiz war ein großes Anliegen während des Dreißigjährigen Krieges, und so versuchte der Nuntius, die Passzugänge für die „katholische Seite“ zu fördern. In einem Brief vom 5. August 1635 schrieb er nach Rom:

Von der gemeinsamen Erklärung oder dem Umkehrschreiben des Kantons Uri, der den wichtigsten Pass nach Italien darstellt, zunächst an den König Frankreichs und dann an den Botschafter durch die den anderen Verbündeten, da sie unmittelbar neben Schwyz sind, so wird Ihre Eminenz sehen, dass der Bund mit Frankreich bleibt, und das Umkehrungschreiben, das den Schweizer Katholiken von König Heinrich gegeben wurde und in dem erwähnt wird, dass sie nicht den Feinden Seiner Majestät den Pass nach Mailand und Savoyen überlassen sollten; und das ist der größte Ekel, den die Spanier hier im Sinn haben, während sie den in dem Bündnis des vergangenen Jahres geleisteten Eid mit dem Kardinal-Infant widerrufen. [...] $]^{270}$

Als Nuntius wirkte er auch als Zwischenstelle zwischen dem Metropolitanbischof von Konstanz und den dazugehörigen katholischen Gebieten des damaligen Bistums Konstanz. So gelang es ihm, dass zumindest die Suffraganbischöfe in der Eidgenossenschaft die Sakramente spenden konnten (Firmung), was nicht einfach war, da die Bischöfe durch protestantische Gebiete reisen mussten

268 Segreteria Stato, Svizzera, Volume 24-31, f. 54.

269 Segreteria Stato, Svizzera, Volume 32, f. 19.

270 Segreteria Stato, Svizzera, Volume 24-31, f. 123. 
und oft dabei gehindert wurden. Deshalb berichtete der Nuntius am 5. August 1635 voll Freude nach Rom:

Die Tatsache, dass dieses Gebiet von fünf benachbarten katholischen Kantonen seit 29 Jahren der Anwesenheit der Konstanzer Bischöfe beraubt war und es auch keine Möglichkeit gegeben hatte, dass dieser sie persönlich besuchen konnte, so weiß ich, dass Eure Eminenz dankbar sein werden zu hören, dass nach mindestens 17 Jahren, in denen es nicht einmal einen Besuch eines Suffraganbischofs gegeben hat, um die grundlegenden Dienste zu erfüllen, endlich auf meine Bitte hin die Aufforderung des gegenwärtigen Bischofs durch die Hände des Titularbischofs von Tiberia, seinem Suffraganbischof ausgeführt wird, der hart gearbeitet und alles mit großer Zufriedenheit beendet hat, und die Freude dieser Menschen war inbrünstig, [...] $]^{271}$

Nuntius Scotti sah die spanische Seite als Störenfried an, wie er in einem dechiffrierten Brief vom 8. Mai 1635 nach Rom schrieb:

Auch hier sind vorurteilsvolle Stimmen aus dem Veltlin angekommen, die besagen, dass die Katholische Religion durch die Ketzerpredigten angegriffen worden sei, aber ich habe, um Krallen zu zeigen und den Herzog von Rohan für die Anwerbung zu gewinnen, keine Bestätigung darüber, was wahr ist, und selbst ich würde von denen wissen, die mir die Warnungen dort geben [...] Ich halte daher fest, dass es sich um Erfindungen der Spanier handelt, von denen diese katholischen Kantone am ehesten benutzt werden, um sie zu entfremden und gegenüber Frankreich hasserfüllt zu halten, [.....$^{272}$

Der Nuntius bemerkte aber auch, dass hinter den „religiösen Ideologien“ durchaus „Realpolitik“ zu finden ist. So geht er davon aus, dass die protestantischen Kantone zwar lautstark ihre Positionen verkünden, doch durchaus milde vorgehen, wenn es in ihrem Interesse ist, wie beispielsweise die Haltung Zürichs gegenüber den katholischen Kantonen in Sachen Zufahrtsgewährung durch die Alpenpässe, die im katholischen Teil der Eidgenossenschaft liegen. Das geht beispielsweise aus dem Brief vom 2. Dezember 1635 hervor:

Auch wenn die Zürcher mit den anderen protestantischen Kantonen in der Aarauer Tagsatzung einen Beschluss gefasst haben, die Katholiken wegen der Pass-Vergabe an die Alemannen erzürnt anzuschreiben, wird dies nichts ändern, sondern es wird zum Schweigen gebracht und es wird weiter zugelassen, um das Haus Österreich nicht zu irritieren. $[\ldots]^{273}$

Die Lage in der Eidgenossenschaft wurde immer schwieriger. Neben dem Krieg im benachbarten Deutschen Reich wurden in den 1630er Jahren die Gebiete der

271 Segreteria Stato, Svizzera, Volume 24-31, f. 124.

272 Segreteria Stato, Svizzera, Volume 32, f. 21.

273 Segreteria Stato, Svizzera, Volume 24-31, f. 174. 
Eidgenossenschaft auch von Katastrophen heimgesucht, die die Bevölkerung in Mitleidenschaft zog, wie es in einem Brief vom 13. Januar 1636 benannt wird:

Das Desaster der Ansteckung zusammen mit den Folgen des Krieges in diesen Nachbarschaften, verursachen den Mangel an dem einen und dem anderen Geschlecht, und mit ihr die Notwendigkeit, die Gnade Unseres Herrn für Ehedispensen in Anspruch zu nehmen, da die armen Oratorien im beigefügten Folio beschrieben sind, [...]. ${ }^{274}$

Die Haltung der Schweizer gegenüber dem Geld war dem Nuntius auch oft aufgefallen, wie beispielsweise bei der Söldnerentsendung aus Uri. So schrieb Nuntius Scotti in einem dechiffrierten Brief vom 16. Januar 1636 nach Rom:

Der Schweizer Kanton Uri, der von dem größeren Geldbetrag hörte, den er von den Spaniern erhalten würde, nahm den Brief zugunsten Frankreichs wieder zurück, wobei eine Gegenleistung darin enthalten war, sodass Uri verpflichtet war, von dem spanischen Bund abzusehen, da der Kanton bereits 20000 Franken verbraucht hatte. [... $]^{275}$

Der Nuntius wehrte sich gegen Vorwürfe aus dem Ausland, allen voran vom Nuntius in Spanien, die ihn beschuldigten, die Schweizer Katholiken nicht in genügender Weise für die katholischen Interessen einzunehmen. In einem Brief vom 23. Januar 1636 schrieb der Nuntius darüber nach Rom:

Diejenigen, die Verleumdungen gegen mich erfinden, sollten auch daran denken, sie zu beweisen; aber geblendet von ihrer eigenen Leidenschaft, glauben sie, die Gnade des katholischen Königs entgegen allem gerechten Sinnen Seiner Heiligkeit und Seiner Nuntien zu nutzen, haben sie (wenn es diese Minister sind, wie ich glaube) immer nicht nur gegen mich, sondern auch gegen meine Vorgänger sich eingesetzt, um das genaue Gegenteil von dem zu tun, was in Mailand geschieht. So geschah es, während ich hier 4 Jahre lang einen Bund anregte, der den Forderungen des Kaisers an Seine Heiligkeit nach der Verteidigung Italiens gegenüber dem Schweden nachkommt, und von Fürsten, die dort Staaten wie insbesondere den katholischen König hatten, waren umgekehrt sofort in Mailand vertreten, das heißt die den Bund gegen das Haus Österreich nutzten; und gleichzeitig ermutigen sie, wie es aus den Vorschlägen in den Schriften in den Tagsatzungen hervorgeht, die Schweizer Katholiken, nicht nur nicht mit dem Schweden in einen Bund einzutreten, sondern nicht einmal die Neutralität untereinander annehmen. [...]

Das dritte ist das Schreiben von Monsignore Nuntius von Spanien an Eure Eminenz, das ebenso lächerlich wie unwahrscheinlich ist; denn ohne Glauben an die Schriften kann man von ganz Helvetien wissen, ob der Provinzialpater der Kapuziner entfernt wird oder nicht, oder ob er seit zwei Jahren derselbe ist: Aber noch mehr, als von seinen Patres gegen den Aufstieg Frankreichs gepredigt wurde, befand ich mich damals in Wil, fast 3 Tage entfernt und 3 Monate lang; ich konnte aber auch nicht von denen wissen, die hier waren, auch wenn es Briefe gegeben hätte. Aber ich bin vor allem überrascht, dass dieselben

274 Segreteria Stato, Svizzera, Volume 24-31, f. 204.

275 Segreteria Stato, Svizzera, Volume 32, f. 53. 
Menschen, die in Mailand oder in Spanien ähnliche Dinge tun, schweigen, weil sie bei jeder Gelegenheit immer mit ihnen vereint sind, weil sie nicht Offiziale sind, wie Kommandant Bilia und unzählige andere, [...]. . $^{276}$

Das Jahr 1636 war geprägt vom Krieg und von der prekären Gesundheitsversorgung, sodass der Nuntius sich vor allen Dingen um Ehedispense kümmern musste, wie er in einem Brief vom 17. Februar 1636 nach Rom schrieb:

Zunehmend werden die Bedürfnisse und Mängel in diesen Nachbarprovinzen zu Schwaben und dem Elsass entdeckt, die dieser Nuntiatur aus dem langen Krieg unterstellt und durch Krankheitsansteckungen geprägt sind. Es sind die Städte, die sie nicht schützen, und Dörfer, die größtenteils ohne Männer und Frauen sind, weil beide Geschlechter fehlen und sie mittlerweile nur auswärtig finden, um zu heiraten. Deshalb kommt es häufiger vor, dass um Ehedispense gebeten wird, auch unter sehr engen familiären Graden. Dennoch weiche ich bei diesen universellen Klagen nicht von den verwendeten Vorgaben ab, wie Eure Eminenz an dem hier gemeinsamen Folio der Armen sehen wird, die um Dispens bitten, [....]. ${ }^{277}$

Für die bisherigen Nuntien waren drei Gebiete in der Eidgenossenschaft ein Dauerthema: Das Wallis wurde zwar mit der Zeit ein „ruhiger Ort“, während Graubünden weiterhin Anlass zu sprechen gab. Das Veltlin war ebenfalls ein „Unruheort“, vor allem aus konfessionellen Gründen. Im Wallis und Graubünden ging es hauptsächlich um den Zugang nach Italien sowie um die Rolle und Machtstellung des jeweiligen Bischofs in Sion bzw. Chur. Betreffend der Zugänge nach Italien spielte auch der Gotthard - und somit die Zentralschweiz - eine Schlüsselrolle. Es scheint aber, dass diese Gebiete den Nuntien sehr entsprachen und in diesem Sinne weniger Probleme darstellten.

$\mathrm{Zu}$ den Nuntienbriefen ist noch hinzuzufügen, dass die Briefe sich nicht nur in der Länge und Ausführlichkeit unterscheiden. Inhaltlich lassen sich bisher vier Arten von Schriften unterscheiden: die Beschreibungsbriefe zu Tagsatzungen und anderen Begebenheiten, kurze Schriftstücke zu Ereignissen seines Alltags (Gesundheitszustand, Beschreibung der Pass-Zugänge usw.), Dispense (mit beigelegten Listen) und Korrespondenzbriefe (internationaler Schriftverkehr).

In einem Brief vom 27. April 1636 geht der Nuntius auf die schwierige Lage der Bevölkerung in der Eidgenossenschaft ein, die vom Krieg in den benachbarten Ländern und durch Krankheiten geplagt war:

In einem Dorf, das etwa eine Stunde von hier aus entfernt liegt, wurde ein Haus geschlossen, weil dort bereits zum dritten Mal einer krank wurde, nach dem Tod zweier Männer dort, die bereits vor einem Monat eine Ansteckung hatten, aber hoffentlich kommt es

276 Segreteria Stato, Svizzera, Volume 24-31, f. 212.

277 Segreteria Stato, Svizzera, Volume 24-31, f. 244. 
nicht mehr vor, da in dieser Provinz und in den Nachbarländern wie dem Elsass, Schwaben, Rätien und Tirol ein solches Übel sicher vorkommt; es kommt vor, dass das ungarische Fieber kommt und zwar wird es durch eine außergewöhnliche Hitze verursacht, außerhalb der Jahreszeit; die Kälte lässt nach und das macht die Luft gesünder und dauert wohl bis Mai,[...] Da Menschen vor allem im Elsass und in Schwaben aus reiner Not fehlen und diejenigen, die in Helvetien ankommen, um Schutz zu suchen, ist die Bevölkerung stark reduziert und scheint ein Schatten ihrer selbst, da wenige übrig bleiben, sodass viele auf ihren Höfen sterben. [... $]^{278}$

\section{Am 31. August 1636 schrieb der Nuntius aus Luzern nach Rom:}

Ich bat diese Herren der Kantone, wo der Kardinalgesandte vorbeikommen wird, die größten Ehren vorzubereiten; es besteht kein Zweifel, dass sie als Befürworter des Heiligen Stuhls ihm diese ehrwürdige Ehrerbietung und die Zuneigung verleihen werden; und um einige Beispiele zu nennen, so habe die ich eine bedeckte Gondel in den See stellen lassen, die in diesen Gebieten nicht mehr zu sehen ist, sodass man ihn treffen kann, und ihn in Luzern in meinem Haus untergebracht; da hier mit sehr viel unterschiedlicheren Gebräuchen als in jedem anderen Land umgegangen wird, denn jede Persönlichkeit muss die üblichen Einrichtungen besuchen, also die Tavernen, wo der Fremde sich an den Ort anpassen und allen Wein ausgeben kann. Der Kanoniker Thomas Henrici, Pfarrer von Basel, den Sie kennen, hat mich gebeten, Ihre Eminenz zu bitten, ihn in den Dienst des Kardinals zu stellen, und so Mitglied des Gesandten zu sein, ohne sich um irgendeine Bestimmung zu kümmern; und er ist mit fünf Sprachen ausgestattet, Deutsch, Flämisch, Französisch, Latein und Italienisch. Ich habe geantwortet, dass ich dieses Anliegen weitergeben werde, aber dass ich glaube, dass es zu spät sein wird. [...] $]^{279}$

Doch auch mit Skandalen musste sich der Nuntius auseinandersetzen, wie es beispielsweise im Laufe des Jahres 1636 geschah. Dazu schrieb der Nuntius ausführlich in einem Brief vom 31. August 1636 nach Rom:

Bei diesen Katholiken ist es versehentlich zu einem traurigen Geschehnis gekommen und zu einem Skandal, da plötzlich Bruder Hadrian unter dem Abt von Sankt Blasien, einem Kloster des heiligen Franziskus, vom Glauben abgefallen ist, und umso ernster ist es, da er Beichtvater dieses ganzen Klosters in Luzern war und als solcher große Anerkennung genoss. Am Tag des heiligen Festes der Aufnahme Mariens in den Himmel wurde er nicht mehr aufgefunden, noch wusste man, wo er war, zufällig konnte durch Briefe, die vom Wächter abgefangen wurden, festgestellt werden, dass er in Zürich gut aufgenommen und von diesen Protestanten weltlich gekleidet wurde. Das schrieb er an einen Freund nach Luzern, da er eine edle junge Frau davon überzeugen wollte, ihn zu besuchen, damit sie getröstet werde, und weil er nun erkannt haben soll, dass es keinen anderen Weg des Heils gebe, als einzig das Vertrauen in Gott, und dass alle Geistlichen ins Verderben gelangen. Der Brief wurde nicht weitergereicht, sondern zurückgehalten; und sofort wurde den Richtern diese Angelegenheit vermittelt und auch mit jenen in Zürich sowie durch

278 Segreteria Stato, Svizzera, Volume 24-31, f. 308.

279 Segreteria Stato, Svizzera, Volume 24-31, f. 384. 
mich dem Vertreter Venedigs, und durch denselben Wächter wurde ein Brief verschickt, um dem Abtrünnigen in meinem Namen zu erklären, ob man zu ihm sprechen darf, denn wenn er sich wiedereinfinden will, wird es keine Strafe geben und ihm würde dann alle Gnade erwiesen werden; und gleichzeitig wird darum gebeten, zumindest die Rückgabe des Ordenshabits zu erwirken, damit es kein Sakrileg gibt. Ich vertrete gegenüber Eurer Eminenz den Fall in diesem Sinne, den Ihr Euch vorstellen könnt und der Ihnen gehören wird, und ich grüße Sie demütig. ${ }^{280}$

Zum genannten Fall gibt es vom 12. Oktober 1636 eine Erläuterung, die aufzeigt, dass es für den Nuntius gar nicht so einfach ist, sich damit auseinanderzusetzen, und zwar aus Zuständigkeitsgründen, da das Kloster St. Blasien nicht eindeutig zur Eidgenossenschaft gehört, wie er im Brief festhielt:

Es kam von jenen Protestanten von Zürich zur Kunst von Bottero eine Antwort; und auch von Katholiken hier wird dies geringgeschätzt und dutzendfach als verlustreich betrachtet, da es zum Glaubensabfall führt. Nun, da ich von Eurer Eminenz am vergangenen 20. den Auftrag erhalten habe, werde ich Sie über diese Angelegenheit informieren, und sehr demütig antworte ich nur mit dem Zusatz, dass sich die Abtei St. Blasius, wo der Apostat geboren wurde, auf dieser Seite hier und über den Rhein hinaus erstreckt, also mit seiner Zuständigkeit Teil des Deutschen Reiches und Teil Helvetiens ist. [...] $]^{281}$

Doch auch die Krankheiten und Seuchen prägten seinen Alltag, wie der Nuntius in einem Brief vom 9. November 1636 nach Rom schrieb:

In Luzern findet die Ansteckung keine Opfer und nur ein Haus bleibt geschlossen; in Altdorf hingegen hat sie vom Kanton Uri aus Richtung St. Gotthard und Italien wieder angefangen zu wüten, und Böses verursacht, da sie nicht für beide Länder jenseits der Berge aufgehört zu wirken, und im Veltlin verursacht sie ein großes Massaker. Im Rest Helvetiens hört man nichts dergleichen, wie in Rätien und im Schwabenland und auch nicht in Ländern wie dem Elsass beim Rhein. [.... $]^{282}$

Im Laufe seiner Amtszeit stellte Nuntius Scotti auch fest, wie weit er in seinem Vorhaben gekommen war, die Katholiken für sich zu gewinnen, wie er in einem chiffrierten Brief vom 22. Februar 1637 nach Rom schrieb:

Da es für die Nuntien in diesen Gebieten notwendig ist, dass sie die Seelen der Schweizer vor den Ketzern gewinnen, damit diese Seelen dem Heiligen Stuhl zugewandt sind, und als solche dem Eifer nachgehen können, den Seine Heiligkeit und Eure Eminenz haben, damit sie zum größeren Anstieg der katholischen Religion beitragen können. Seit zwei Jahren kämpfe ich darum, mich wohlwollend zu verhalten gegenüber Herrn Schuhmacher, der Schultheiß von Luzern war, und nach vielen Schwierigkeiten, die wegen des

280 Segreteria Stato, Svizzera, Volume 24-31, f. 385.

281 Segreteria Stato, Svizzera, Volume 24-31, f. 415.

282 Segreteria Stato, Svizzera, Volume 24-31, f. 438. 
Eindrucks entstanden sind, weil einige ein unheilvolles Bild der Dinge Roms genährt haben, so habe ich sie endlich alle hingebungsvoll oder zumindest teilweise dazu gebracht; $[\ldots]^{283}$

Der Nuntius sah es als Problem an, dass man in den protestantischen Kantonen keine katholische Messe feiern durfte. Er plante, Zürich von einer Erlaubnis zu überzeugen, damit sie dann auch in anderen protestantischen Kantonen eingeführt werde, wie er in dem Brief vom 22. April 1637 schrieb:

Bis zur Ankunft des Provinzials der Kapuziner dieser Provinz wartend, wurde die Vertretung Eurer Eminenz mit ihren Mitteln abgewartet, ebenso wie der Wunsch einiger bedeutender und innigster Schweizer Katholiken, einmal in der Stadt Zürich eine Kirche oder Privatkapelle zu sehen, die für die Feier der Messe geöffnet ist, damit dann die anderen Kantone Bern, Basel und Schaffhausen am Beispiel des ersten protestantischen Kantons dasselbe tun, doch die Häretiker scheinen dem eine große Hartnäckigkeit entgegenzubringen, denn nicht einmal den Botschaftern und Bürgern der Katholischen Fürsten ist es erlaubt, einen solchen spirituellen Trost zu erhalten; Franzosen und Venezianer müssen deshalb bei Hochfesten ohne Gottesdienste auskommen oder jedes Mal weit reisen, um an der Heiligen Messe teilzunehmen, und zwar außerhalb ihres juristisch zugewiesenen Amtsterritoriums. Was den Betroffenen sehr misslich erscheint und nicht zuletzt den vielen ausländischen Gästen sehr ungelegen vorkommt, während es in allen Städten Deutschlands die freie Ausübung der katholischen Religion gibt; aber da dies im Handumdrehen sehr schwer zu bekommen wäre, würde man jetzt nur von dem oben genannten ausgehen wollen, d.h. von der Feier einer täglichen Messe wie in England unter dem Titel des Fürstenministers und der Ausländer. [.... $]^{284}$

Briefe über die Schweizergarde sind von den Nuntien wenige zu finden. Eine besondere Korrespondenzführung betraf den Fall der Ehefrau eines Gardisten, die der Nuntius in einem Brief vom 1. Mai 1637 nannte:

Frau Agnese de Crudi hat den Wunsch geäußert, da sie mit Herrn Pfiffer, Leutnant der Schweizergarde Seiner Heiligkeit, verheiratet ist, dass wenn sie nach Rom kommt, ich für sie fürsprechen soll und ihre Familie mit Eurer Eminenz als großen Beschützer rechnen kann. Aber ich gehe diese Anfrage, die ich annehmen muss, mit so viel Gefühl an, da, wie ich um Ihrer Freundlichkeit zu begegnen weiß, die Sie gegenüber der Schweizer Nation hegen, von der sie auch als Beschützer gelten. Ohne zu verschweigen, dass von mir einige Gefallen an fast alle alten Schweizer Familien gemacht wurden, so finde ich, dass es für die genannte Frau Agnese unter den wichtigsten zählt, da sie als Fremde aus dem Kanton Schaffhausen stammt, da ihre Familie nicht zur calvinistischen Sekte beitreten wollte, wie es andere Kantone getan haben, so blieb die Familie Crudi der katholischen Kirche treu, und um dies $\mathrm{zu}$ erhalten, da waren sie bereit, das Heimatland zu verlassen und zogen nach Rheinau um; und hinzu kommt noch ein weiteres besonderes Verdienst gegenüber

283 Segreteria Stato, Svizzera, Volume 32, f. 90.

284 Segreteria Stato, Svizzera, Volume 24-31, f. 503. 
dem Heiligen Stuhl, da einer ihrer Vorfahren namens Christoph der beliebte Geheimkellner von Papst Julius II. war. [.... $]^{285}$

Der Nuntius sah vor allem die Einmischung der weltlichen Institutionen in den katholischen Gebieten nicht gern, da er für eine strikte Trennung der Machtbefugnisse eintrat, wie er im Beispiel des Kantons Uri in einem Brief vom 9. August 1637 aus Wil nach Rom schrieb:

Die Schweizer des Kantons Uri, die unter anderem am entschlossensten gegen die kirchliche Immunität vorgehen, sind der Meinung, dass sie seit ihren Vorfahren die Herren des einen und des anderen Forums waren; In diesen vier Monaten haben sie es getan und haben im Rat beschlossen, acht Kirchenkapitel zu veröffentlichen, die die Freiheit von zwei Nonnenklöstern in ihrem Land Altdorf beeinträchtigen, und als ich davon erfuhr, dachte ich daran, wie man dies wieder rückgängig machen kann, in der Hoffnung, nach und nach die Gemüter zu gewinnen. Nun, nachdem ich es glücklicherweise geschafft habe, in einem weiteren Rat der gleichen 60 Mitglieder dies zu erreichen, hegte ich die Absicht, dass sie sich in kirchliche Angelegenheit nicht mehr einmischen sollten, aber dass sie ihre Gründe durch drei Abgeordnete mitteilen können, und so beschließen sie in Übereinstimmung, was ich als mehr Gewinn für diese Klöster schätzen würde; $[. . .]^{286}$

Auch im Falle von Schwyz nannte der Nuntius die - aus seiner Sicht - falsche Einstellung in Bezug auf das Kloster Einsiedeln, wie er in einem Brief vom 30. August 1637 aus Wil nach Rom schrieb:

Damit Eure Eminenz ständig darüber informiert wird, werde ich es nicht versäumen, in diesen Gebieten um Ruhe bei den Schweizer Herren zu sorgen, vor allem mit dem Abt der Einsiedelei, da dieses Schweizer Volk nicht in der Lage ist, weil sie niemanden über sich haben wollen und als Herrscher der Gebiete des Klosters Einsiedeln und auch die anderen katholischen Kantone müssen zur Rechenschaft gezogen werden, auch weil der Abt viele gleichwertige Gründe vorzuweisen hat; Mit jeder größeren Demut sende ich Eurer Eminenz zu Ihrer Information die Antwort, die mir der letzte Landtag nach der von Schwyz erhaltenen Botschaft gegeben hat, in der die Absicht enthalten ist, zur Beseitigung der Ungerechtigkeit zu schreiten, wie es der Abt wollte; es wurde darauf hingewiesen, dass die Zuständigkeit der Gebiete vom Reich abhängt. Denn sonst kann es durchaus geschehen, dass, wenn die Dinge nicht gütlich geregelt werden, Beleidigungen für die Kirche und das Kloster folgen würden; [...] $]^{287}$

Nuntius Scotti war es auch ein Anliegen, jene Katholiken zu unterstützen, die es seiner Meinung nach verdienten, so schrieb er in einem Brief vom 13. September 1637 aus Wil nach Rom:

285 Segreteria Stato, Svizzera, Volume 24-31, f. 539.

286 Segreteria Stato, Svizzera, Volume 24-31, f. 559.

287 Segreteria Stato, Svizzera, Volume 24-31, f. 589. 
Unter den wichtigsten Schweizern, die sich gezeigt haben, und den Fürsprechern des Heiligen Stuhls, gibt es im Kanton Schwyz Herrn Anastasio Kyd, der mittels der Güte Eurer Eminenz wünscht, ohne jegliche Ausgaben von Seiner Heiligkeit die Gnade der aus Gold bestehenden Ehrzuweisung für Herrn Hans Kyd erhalten, also seinen Sohn, um bei allen anderen Gelegenheiten Ihnen mehr Ehrerweisung aufzeigen zu können, indem ich demütig mein Flehen im Namen derselben Ihnen anbiete. ${ }^{288}$

Einen besonderen Bezug hatte Nuntius Scotti zur Abtei von St. Gallen, wie er in einem Brief vom 4. Oktober 1637 aus Rorschach nach Rom schrieb:

Ich weiß, dass Ihre Eminenz sich freuen wird, in dem Brief zu erfahren, dass ich nach meiner Rückkehr nach Luzern den frommen Pater Abt von St. Gallen getroffen habe, der dem Heiligen Apostolischen Stuhl sehr ergeben ist, und einer Gruppe seiner Vorgängeräbte, die in gleicher Weise das Verdienst für die Erhaltung und Einstellung der katholischen Religion aufgezeigt haben, die mit großem Eifer in ihrem Staat dies bewahrt haben, und ebenso jedes kirchliche Fest, das allein in den Gottesämtern der Kirche von St. Gallen über viertausend Katholiken, die auch außerhalb der Stadt leben, empfangen haben; auch wenn es in der Umgebung so ketzerisch sein mag, wird die Macht der Äbte benötigt, damit sie ihre Arbeit in allen Funktionen der Kirche verrichten können, wobei sie mit höchster Hingabe das tun, insbesondere in der christlichen Lehre. Vor allem wegen des Schatzes vieler Reliquien, die in Statuen und Silbergehäusen aufbewahrt werden, und der antiken Bücher, die mehr als tausend Jahre alt sind und dem großen Teil der Handschriften, die berühmt sind und sich dort befinden als Erinnerungen an verschiedene bedeutende Päpste und Kaiser, die die Abtei begünstigten. Um jedoch auch dort die Erinnerung an Seine Heiligkeit zu bewahren, habe ich ihnen sein exaktes Porträt gegeben und sie waren sehr dankbar dafür. Ich habe diese besondere Begebenheit geschrieben, in dem Wissen, dass Ihre Eminenz bei allen Gelegenheiten die Äbte und Klosterinstanzen mit der Freundlichkeit schützen wird, die ihr gebührt; [...]. ${ }^{289}$

Der Nuntius kam wieder auf den Streit zwischen den Schwyzern und dem Kloster Einsiedeln zurück, als er in einem Brief vom 15. November 1637 von Luzern nach Rom schrieb:

Die volkstümliche Gewalt des Kantons Schwyz gegen den Abt von Einsiedeln, dessen Bruder sie im Hass auf die katholischen Kantone mit der Konfiszierung seines Vermögen und Hausverbot auf ihrem Territorium verurteilt haben, in dem sie das Land Einsiedeln als ihre eigene beanspruchte Gerichtsbarkeit verstanden haben wollen. Das Ganze schreitet immer weiter voran, auch wenn ganz klar ist, dass die Äbte immer die Herrschaft über ihr Land hatten und sie die Schwyzer nur als ihre Anwälte und Verteidiger hatten; Entschlossen, in dieser letzten Tagsatzung der Katholiken mit dem Vorschlag, den Ihre Eminenz die Ehren haben wird zu sehen, in der Hoffnung, dass der Vorschlag von Ihrer großen Umsicht gut gefunden wird, um den Abt zu unterstützen, und nicht weniger auch den kaiserlichen Kommissar, der sich der Vereinigung dieses Vorschlags anschließt, da dieser Fall

288 Segreteria Stato, Svizzera, Volume 24-31, f. 594.

289 Segreteria Stato, Svizzera, Volume 24-31, f. 602. 
der Zuständigkeit des Kaisers unterliegt, und nicht an Seine Heiligkeit, außer es wird um Hilfe gebeten, und so wurde beschlossen, den Abt zu unterstützen, sowie ich das kann, und so habe ich die Häupter des Aufstandes hier in meinem Haus angesprochen und ihnen erklären lassen, dass sie zusammen mit mir mit den katholischen Kantonen vereint sind und es ihnen überlassen wird, zu verlieren, und dass das Volk sich wie auf einer Welle befindet, die sich wendet und sich allen Banden stellt, am Ende aber werden dieselben Leute ihre Autoren entdecken, und über die wird alles Böse fallen, und doch es ist gut, dass sie selbst Abhilfe schaffen; Deshalb habe ich auch an die Kantone Freiburg und Solothurn zu Gunsten des Abtes selbst geschrieben. [... $]^{290}$

In einem Brief, den Nuntius Scotti direkt an die Teilnehmer der Tagsatzung der katholischen Orte richtete, ging er am 15. November 1637 auf seine Stellung ein:

\begin{abstract}
Majestätische und mächtige Herren,
Der Grund, weshalb ich nicht persönlich erschienen bin oder gar selten vor Ihren Majestätischsten Herrschaften in der Tagsatzung erschienen bin, war erstens, weil die von mir unantastbar bewahrte Neutralität vom ersten Tag meiner Ankunft in Helvetien wichtig war. Es sind nun acht Jahre vergangen, seit ich hier bin. Und zweitens habe ich mich bis heute nie in die Politik eingemischt, wie es all Ihren Majestätischen Herren durch Ihre Klugheit und Wachsamkeit bekannt ist, die Ihre Herrschaften immer hatten, um in Ihren eigenen Staaten einen Frieden zu bewahren, der von Gott, unserem Herrn, kommt, der mit der weltweit anerkannten Herrlichkeit die Schweiz gesegnet hat; Drittens habe ich die einzigartige Frömmigkeit in der Fortsetzung der Ergebenheit Ihrer würdigen Vorfahren gefördert, indem ich in meiner Amtszeit den Klöstern die Ehre erwiesen habe, und den Ordensleuten, die heute in einem heiligen Zustand leben; alle diese Punkte, an die Ihr mich heute Morgen erinnert habt, führen mich dazu, mich mit Euren Majestätischen Herrschaften und mit der von mir so viel geliebten Gruppe zu freuen.

Aber weil dieser oben erwähnte Frieden durch den neuen Streit, den die Herren von Schwyz mit dem Abt der Einsiedelei haben, leicht gestört werden dürfte, habe ich meine einzigartige Zuneigung zu Seiner Heiligkeit genutzt, um Ihn zu erinnern, dass sie, da sie bereitwillig die Einmischung für das Gemeinsame aufgeben, besser nicht folgen können. Ich für meinen Teil und das Amt, das ich im Namen Seiner Heiligkeit und in Übereinstimmung mit dem rechtschaffenen Sinnen des Heiligen Stuhles führe, die mir wiederholt das rechtschaffenste Sinnen des Heiligen erklärt haben und die mir wiederholt in dieser Angelegenheit erklärt haben, biete ich noch einmal meine Vereinigung mit Ihren Herrschaften an, für eine so gute Lösung zusammenzuarbeiten, [.....$^{291}$
\end{abstract}

Am Ende seiner Amtszeit hatte Nuntius Scotti noch mit Streitigkeiten zu tun, bei denen es um seine Machtstellung in der Eidgenossenschaft ging. So schrieb er in einem Brief an die Luzerner Behörden im Falle eines Testaments zugunsten der Kirche am 23. September 1638:

290 Segreteria Stato, Svizzera, Volume 24-31, f. 626.

291 Segreteria Stato, Svizzera, Volume 24-31, f. 627. 
Ich empfinde große Bewunderung dafür, dass Ihre Majestätischen Herrschaften in einem großen Rat der Hundert bedauern, über den Willen von Dorothea Schobingerin, die der Kirche wohlwollend gegenübersteht, ein endgültiges Urteil zu fällen über die $15000 \mathrm{Gul}$ den die sie ,pias causas‘ hinterlassen hat, und dass Ihre Herrschaften sich mit der Grundlage befassen, die nicht mit ihren Statuten und Gemeindegesetze übereinstimmen; aber ich, als Apostolischer Nuntius des Heiligen Stuhls in diesen Gebieten, bekenne, dass der Ehre Gottes und Seiner Kirche über allen weltlichen, zerbrechlichen und vorübergehenden Mächten Respekt gebührt und ich schätze es sehr, Herrn Oberst Bircher, den Schultheiß, anzuschreiben, damit sie das Statut und die kommunalen Gesetze der Laienfürsten beachten, welche die gewünschte Macht haben, doch was der Kirche zusteht, ist nicht zu leugnen, denn das ist nicht vom Papst genehmigt worden, und das Testament von Schobingerin ist zu beachten, das in seiner Form sehr gültig ist und vom Heiligen Apostolischen Stuhl genehmigt wurde. Deshalb kann dies nicht von den Herren genommen werden, $[. . .]^{292}$

Zum Ende seiner Dienstzeit ging Nuntius Scotti in einem Brief nach Rom auf seine letzte Tage in der Eidgenossenschaft ein und beschrieb am 5. Mai 1639:

Es befand sich in Luzern zum Zeitpunkt meiner Abreise, die am Dienstag am Mittag erfolgte, so viele Leute, dass die Straßen voll waren, und die Bürger mussten in ihren Häusern von den Fenstern zuschauen. Ich weiß, dass Ihre Eminenz Freude an einer solchen Nachricht über die Hingabe dieses Volkes haben wird, welche die Herzen der Schweizer Katholiken dem Heiligen Stuhl erweisen. Das Gleiche erlebte ich auf dem Reiseweg, als ich einen Richter aus Solothurn traf, der mich einen ganzen Tag lang davon aufhielt und nicht erlauben wollte, dass ich abreise, und der Herr Botschafter von Frankreich wollte in jeder Hinsicht, dass ich in seiner Unterkunft bleibe, die hervorragend ist und die Ordnung seines Königs aufzeigt, und ich finde diesen Diplomaten in seiner Klugheit und seinem Wert als wichtigsten Minister, den ich in diesen Gebieten getroffen habe. Ich werde nun meine Reise nach Bern und Freiburg fortsetzen, da ich den wiederholten Bitten dieser Kantone nicht widersprechen konnte, da dort die Katholiken das so stark ausgesprochen haben, dass ich dort eine Verlängerung des auf viele Jahre verbrachten Dienstes verbringen werde. Sie haben den Nuntius auch lange Zeit nicht gesehen gehabt, und die Freiburger mit den Solothurnern haben eine besondere Hingabe gegenüber dem Heiligen Stuhl unter Beweis gestellt, obwohl sie von so mächtigen bernischen Ketzern umgeben sind. [...] $]^{293}$

Scotti hatte im Laufe seiner Amtszeit mit vielen verschiedenen Streitigkeiten zu tun. Im Band 34 im Vatikanischen Archiv sind seine Briefe aus der Schweiz aufbewahrt wie f. 13 (30.12.1639), f. 17 (4.1.1640), f. 20 (6.1.1640), wo es um den Streit zwischen Schwyz und dem Kloster Einsiedeln geht. In anderen Briefen z. B. f. 30 (20.1.1640) - ging es um Territorialstreitigkeiten zwischen dem Bischof von Basel und den Reformierten. Im Brief vom 24. Februar 1640 schrieb Nuntius Scotti:

292 Segreteria Stato, Svizzera, Volume 33, f. 3-4.

293 Segreteria Stato, Svizzera, Volume 24-31, f. 837. 
In Ausführung der Vorgaben Eurer Eminenz arbeite ich mit ganzem Herzen daran, die Differenzen, die die Männer des Kantons Schwyz mit dem Abt und dem Kloster Einsiedeln haben, auszugleichen: Aber da die Volksregierung von Schwyz unvernünftig ist, muss ich dies langsam angehen und mich mit Geduld bemühen, sie zu überzeugen, ihre Ansprüche an die katholischen Kantone nicht zu gefährden, entsprechend der Vorgaben, die Eure Eminenz mit Ihren Briefen an sie gerichtet haben. Weil das rigorose und gewalttätige Verfahren in dieser Angelegenheit jedoch schlechte Auswirkungen haben könnte, so könnte auch Schweigsamkeit und das Zusammenleben nur ein Skandal sein, und ein sehr schlechtes Beispiel sowohl für die katholischen Kantone selbst als auch für ihren Umgang mit den Protestanten, die es wagen könnten (wie ich es Eurer Eminenz gegenüber schon mehrmals erwähnt habe), das Eigentum der Kirchen zu übernehmen; deshalb versuche ich immer, etwas dafür zu tun. Die Schwyzer hatten nie den Wunsch gehabt, jemandem ihre Gründe zu verraten oder zu zeigen. In der diesjährigen Karnevalszeit habe ich sie da$\mathrm{zu}$ veranlasst, sie an vier katholische Kantone weiterzugeben, die nun die Informationen des Klosters erhalten, so dass ich hoffe, auch Schwyz zu dem oben genannten Kompromiss zu bewegen. [.... $]^{294}$

Nuntius Scotti betonte, wie intensiv er an den diplomatischen Gesprächen beteiligt war und mit wem er darüber sprach, wie er in einem Brief vom 16. März 1640 nach Rom schrieb:

In meiner demütigen Antwort auf die gnadenvolle Antwort auf Ihre Eminenz des vergangenen 25. (Februar) bitte ich Sie zu glauben, dass ich es seit meiner Zeit in diesem Amt nie versäumt habe, jedes erdenkliche Amt als Vorsteher der katholischen Religion im Veltlin zu bestehen, wie in ganz Rätien. Ich habe an die Erzherzogin und an Graf Francesco Casati, Vertreter Spaniens in Chur, sowie an einige katholische Bündner Führer geschrieben. Sowohl mit dem Bischof von Chur als auch mit dem Bischof von Como halte ich ständige Korrespondenz; [...] $]^{295}$

Die Familie Casati gehörte spätestens seit den 1620er Jahren zu jenen, die die spanischen Interessen in der Schweiz vertraten. ${ }^{296}$ Die Mailänder Familie Casati hatte über 100 Jahre lang - und zwar von 1594 bis 1704 mit kurzen Unterbrechungen - die spanisch-mailändische Gesandtschaft in der katholischen Eidgenossenschaft vertreten. ${ }^{297}$

Ein Eklat gab es für Nuntius Scotti am Ende seiner Dienstzeit in der Eidgenossenschaft, als ein verhafteter Priester aus dem Tessin von den Eidgenossen nicht der kirchlichen Autorität überlassen wurde, was zu einem Kompetenzstreit zwischen staatlicher und kirchlicher Seite führte, wie er in einem Brief vom 28. Juni 1640 nach Rom schrieb:

294 Segreteria Stato, Svizzera, Volume 34, f. 45.

295 Segreteria Stato, Svizzera, Volume 34, f. 56.

296 Andreas Würgler: Verflechtung und Verfahren, S. 87.

297 Vgl. Rudolf Bolzern: Spanien, Mailand und die katholische Eidgenossenschaft, S. 38 ff. 
Mit einem meiner eigenen am 14. des jetzigen Monats vertrat ich demütig bei Eurer Eminenz die finsteren Eindrücke, die diese Schweizer Herrschaften gegen den Bischof von Como ausdrücken, und ihre Zurückhaltung, ihm den gefangenen Priester von Lugano nicht übergeben zu wollen, indem sie die kirchliche Immunität verletzen, statt auf die Gerechtigkeit zu vertrauen. [...] $]^{298}$

Während Nuntius Scotti sich um die Bündner Angelegenheiten kümmerte und sich intensiv mit den fünf katholischen Orten der Eidgenossenschaft auseinandersetzte, kann man dies nicht für die anderen, der Nuntiatur angehörenden Territorien sagen. Das lag wohl auch daran, dass seine Amtszeit in den Wirren des Dreißigjährigen Krieges lag. Seine Vermittlungskünste führten dazu, dass der Bischof von Sitten, Hildebrand Jost, wieder zu seinem Amtssitz zurückkehren konnte. Im Tessin sorgte er dafür, dass das Verhältnis zu den Zentralschweizer Kantonen einigermaßen friedlich fortgeführt werden konnte. Seine größten Niederlage, zumindest sah er das so, war das Akzeptieren der Gleichstellung der konfessionellen Gruppen im Thurgau und Rheintal. Diese verschiedenen Dimensionen hatten ihn so beeindruckt, dass er 1642 zwei Ausgaben über die Schweiz herausgab unter dem Titel: „Helvetia profana e sacra“. ${ }^{299}$ Darin erläutert er die politische Entwicklung der Kantone, und im zweiten Band schreibt er über die religiösen Aspekte in der Eidgenossenschaft.

In seiner Finalrelation über die Nuntiatur in der Eidgenossenschaft resümierte Scotti: „Es gibt keine schwierigere Nuntiatur als jene“. Er lieferte auch eine Begründung:

Denn die anderen [Nuntiaturen] bei den großen Höfen genügt es, wenn der Nuntius für den öffentlichen Dienst erreicht, dass ihm der Fürst und zwei oder drei Minister zugeneigt sind. In der Schweiz hingegen muss man mit einer Unmenge von Leuten verhandeln, von welchen die einen Parteigänger des Kaisers, die anderen Frankreichs oder Spaniens sind. ${ }^{300}$

Ähnliche Aussagen sind aber auch bei Gesandten anderer Länder zu finden. So weist Surchat darauf hin, dass auch von kaiserlich-mailändischen, französischen, toskanischen und spanischen Gesandten analoge Äußerungen überliefert sind. ${ }^{301}$

298 Segreteria Stato, Svizzera, Volume 34, f. 141.

299 Helvetia Sacra. Relatione de' vescovati, abbatie, et altre dignità subordinate alla Nuntiatura Helvetica fatta da Monsignor Scotti, vescovo del Borgo di S. Donino, governatore della Marca, Macerata 1647: https://books.google.it/books?id=TltBAAAAcAAJ\&hl=de\&source=gbs_book_other_versions (31. Dezember 2020).

300 Zit. nach Pierre Surchat: Das Corpus Helveticum im Urteil der Nuntien, S. 112.

301 Vgl. ebd. 
Nach Luzern wurde er Nuntius in Frankreich, dort blieb er bis 1641. 1643 wurde er Gouverneur der italienischen Region Marken. Er reichte seinen Amtsverzicht als Bischof von Borgo San Donnino am 5. August 1645 ein, und acht Jahre später wurde er „Kammerdiener Seiner Heiligkeit“. Ranuccio Scotti starb am 10. Mai 1659 in Piacenza, wobei einige Quellen das Todesjahr auf 1661 datieren. ${ }^{302}$

\subsubsection{Girolamo Farnese $(1639-1643)^{303}$}

Auch Girolamo Farnese stammte aus einer Adelsfamilie. Geboren am 3. September 1599 in Latera in der Nähe von Viterbo, wuchs er aber in Parma auf, wo er unter dem Schutz von Ranuccio Farnese stand. Seine kirchliche Karriere begann er am Hof von Papst Paul V. und führte seinen Werdegang unter Gregor XV. weiter. Am 11. April 1639 wurde er wie sein Vorgänger zum Titularbischof von Patrasso ernannt und daraufhin nach Luzern entsandt, wo er bis 1643 Nuntius war. $^{304}$

Im Bestand „Segreteria di Stato, Svizzera“ Band 32A im Vatikanischen Geheimarchiv sind nur Briefe an den Nuntius zu finden, und zwar aus Luzern und anderen eidgenössischen Orten. Die Orte bedankten sich für die Zusammenarbeit oder wollten etwas präzisieren. Das meiste ist auf Italienisch verfasst; einige Briefe sind aber auf Latein. ${ }^{305}$

Als neuer Nuntius machte Farnese an jenen Punkten weiter, die seine Vorgänger bereits erarbeitet hatten. So ging es auch in seiner Amtszeit um die bekannten Themen: das Söldnerwesen und dem Umgang mit den protestantischen Orten, wie er in einem Brief vom 19. Juli 1640 nach Rom schrieb:

Ich bezweifle nicht, dass ich auf Weisung des Heiligen Stuhls den gegenwärtigen Streit zugunsten der kirchlichen Immunität unterstützen kann, denn die sieben Kantone, die von Luzern und Altdorf angeführt sind, stehen auf unserer Seite. Zürich und Glarus werden aus den bekannten Gründen aus der Vergangenheit eher gegen uns sein, und auch, weil sie gegen Armee von General Horn sind, was der Grund für die Einführung einer Geldsteuer war; Die Äbte und alle beteiligten Geistlichen und die der französischen Fraktion werden noch angefragt werden; und mit all dem, weil es sich um ein sehr wichtiges

302 Vgl.Stichwort „Ranuccio Scotti“, in: https://hls-dhs-dss.ch/de/articles/017919/2011-11-17/ (31. Dezember 2020).

303 Vgl. Caspar Wirz: Bullen und Breven aus Italienischen Archiven, S. XL; Henri Biaudet, Les nonciatures apostoliques permanentes jusqu'en 1648, S. 269, 289, 317.

304 Vgl. Stichwort „Girolamo Farnese“, in: https://hls-dhs-dss.ch/de/articles/017901/200408-17/ (31. Dezember 2020).

305 Vgl. Segreteria Stato, Svizzera, Volume 32A. 
Anliegen handelt, das bereits im Gange ist, wird es auf der spanischen Seite auf einige Schwierigkeiten stoßen. ${ }^{306}$

Da er in der Zeit des Dreißigjährigen Krieges wirkte, ging es in seiner Amtszeit darum, die militärischen Hilfen zu verfolgen. Seine weiteren Anliegen betrafen vor allem auch die schwierige Lage im Bistum Sitten und Chur. Er wandte sich aber auch gegen die Schwyzer, die versuchten, die Autorität des Klosters Einsiedeln zu untergraben. Er reiste aber auch durch das Land und besuchte beispielsweise die Präpositur auf dem Großen Sankt Bernhard. Mit der Zusage Luzerns erreichte er es auch, dass die Jesuiten als Beichtväter in den Zisterzienserinnenklöstern in Eschenbach und Rathausen wirken konnten.

Mühe hatte Nuntius Farnese mit dem Bischof von Konstanz und den weltlichen Mächten in der Eidgenossenschaft, wie er in einem chiffrierten Brief vom 18. Januar 1641 aus Luzern nach Rom schrieb:

Ich habe mit anderen von mir gesendeten Briefen, die Kälte des Bischofs von Konstanz in seinem Hirtenamt und gleichzeitig die Hoffnung bekundet, dass er aufgrund seines ausgezeichneten Wesens und seiner Absicht die Erwärmung wiederfindet, wie Eure Eminenz es von mir erwartet hat. Nun habe ich aus dem Bericht des Generalvikars festgestellt, dass die ganze Unordnung in erster Linie von den Laien ausgeht, die das ganze Bistum frei verwalten und nur an weltliche Interessen denken; aber auch von den Jesuiten, die dem Bischof zur Wahrung seiner absoluten Autorität Konzepte vorschlagen, die eher politisch als geistlich sind; Was die Jesuiten betrifft, so bin ich auf sie zurückgekehrt, und zwar sowohl wegen des guten Eifers als auch auf Anregung ihres Rufes, so hoffe ich, dass sie etwas Gutes tun werden; aber was die Laienminister betrifft, so kann ich gegen sie kein Mittel anwenden, und ich glaube, dass es sehr stark um sie ging, $[. . .]^{307}$

Wie seine Vorgänger ging Nuntius Farnese so vor, die katholische Stellung gerade in protestantischen Gebieten zu beeinflussen. Die Streitigkeiten zwischen Frankreich und Spanien nutzte er diesbezüglich besonders stark aus, wie aus einem chiffrierten Brief vom 15. März 1641 aus Luzern nach Rom hervorgeht:

Nicht, weil ich verlangt hätte, dass der französische Bezirk Burgund sich innerhalb der Grenzen meiner Nuntiatur befinden sollte, sondern nur, um meinen Stil fortzusetzen, habe ich Ihrer Eminenz einen Teil der Bitten übergeben, die mir von einigen Burgundern gestellt wurden, wie sie durch das extreme Elend ihres Vaterlandes bewegt sind, am Glück der Schweizer teilhaben zu wollen und mit dieser Nation verbunden werden möchten, und weil es Gerüchte gibt, dass die Genannten aus dem Burgund, die vom König von Spanien aufgegeben wurden, Verhandlungen über eine Konföderation mit den Bernern führen, was der katholischen Religion einen großen Vorteil bereiten würde und was ich für die Benachrichtigung Ihrer Eminenz von Bedeutung hielt, dass der Bischof von Lau-

306 Segreteria Stato, Svizzera, Volume 33, f. 19.

307 Segreteria Stato, Svizzera, Volume 33, f. 27. 
sanne nach Mailand ging, mit der Absicht, zu Herrn Prinz Thomas überzusiedeln, der entsprechende Einladungsschreiben aufzeigt. ${ }^{308}$

In einem weiteren chiffrierten Brief vom 25. Januar 1641 ging Nuntius Farnese auf die schwierige Bildung von Allianzen ein:

Es wird von den Österreichern den Schweizern eine sehr weitläufige Parteinahme vorgeschlagen, um sie zur Verteidigung des Burgunds zu bewegen und sie von der Freundschaft Frankreichs zu trennen, d. h. ihnen die Verteidigung von Salines zu übergeben und ihnen die Einnahmen aus dem Salz für den Unterhalt der Soldaten zu übertragen; Das Geschäft wäre in Ordnung, wenn die Garnison aus den katholischen Kantonen wäre, aber es werden wohl die Zürcher, oder sogar die mächtigen Berner, oder die anderen Nachbarn bevorzugt und ich bezweifle, dass die Spanier den Platz verlieren werden, und die Völker die katholische Religion verlassen werden, so dass ich glaube, dass ich mich widersetzen muss, aber mit der gebotenen Vorsicht, um mich nicht in politische Angelegenheiten einzumischen. $^{309}$

Nuntius Farnese war mit der Lage unzufrieden und ging davon aus, dass nur durch Fehler von Seiten der Protestanten Vorteile für die katholische Seite zu holen seien, wie er in einem chiffrierten Brief vom 12. Juli 1641 aus Wettingen nach Rom schrieb:

Falls die Berner den Aufstand herbeirufen, so könnte man auf einen großen Nutzen für die katholische Religion hoffen. In der Zwischenzeit ist die vorgenommene Anpassung nicht dauerhaft, und es wird angenommen, dass die Anführer der Rebellion nicht sicher sein werden.

Ich habe keine Arbeiter, die herumlaufen; Jesuiten und deutsche Kapuziner machen mehr Politik als Religion, vor vielen Jahren gab es noch Italiener und Kardinal d'Aquino und die haben es mit viel Profit ausgenutzt. [... $]^{310}$

Die Antwort aus Rom war kurz und klar, wie es in dem Antwortbrief vom 31. August 1641 heißt:

Eure Herrschaft tut gut daran, alles zu beschaffen, was der katholischen Religion zugutekommt, und sie zu verteidigen, aber Ihre Arbeit soll mit Umsicht getätigt werden, die sich selbst davor schützt, in politische Dinge einzutreten, die Sie der Parteilichkeit verdächtig machen, und mit den notwendigen Warnungen, dass andere nicht versuchen werden, Sie über die Gefahr der Dinge stolpern zu lassen. ${ }^{311}$

308 Segreteria Stato, Svizzera, Volume 33, f. 29.

309 Segreteria Stato, Svizzera, Volume 33, f. 32.

310 Segreteria Stato, Svizzera, Volume 33, f. 33.

311 Segreteria Stato, Svizzera, Volume 33, f. 34. 
In einem längeren Brief erläuterte Nuntius Farnese, mit wie viel Hinterhalt und Risiken bei den Verhandlungen in der Eidgenossenschaft $\mathrm{zu}$ rechnen sei. So heißt es in dem Brief vom 24. Oktober 1641 nach Rom:

Für diese Kantone werden geheime Verhandlungen mit dem Herzog von Parma geführt, und es werden falsche Beziehungen wegen der Aufstellung der Armee Unseres Lieben Herrn angedeutet, deshalb ist es notwendig, dass ein französischer oder spanischer Minister den Einsatz zeigt, weil der Herzog sonst in diesen Gebieten keine Anhängerschaft gewinnt. Ich habe es als meine Schuld betrachtet, diese Informationspflicht den katholischen Kantonen gegenüber bei der Tagsatzung zu teilen. [...] $]^{312}$

Ich will Ihre Eminenz darauf aufmerksam machen, dass diese Menschen sehr geldgierig sind und dass sie derzeit keinen Dienst ausüben, weder in Mailand noch im Piemont, und einige, die in Frankreich sind, werden mit der nächsten Tagsatzung zurückgerufen werden, und wenn sie feststellen, dass sie nach Italien kommen dürfen, wird es für sie schwierig sein, das zu glauben, aber die Aufrechterhaltung dieser katholischen Kantone, die dem Heiligen Stuhl dienen, sowie das Aufsetzen eines Vertrags, könnten sehr hilfreich sein. ${ }^{313}$

Ein klares Bild von den Schweizern dokumentierte Nuntius Farnese in einem chiffrierten Brief vom 6. Dezember 1641 nach Rom:

Die Republik Schweiz besteht nicht aus einer, sondern aus vielen Republiken, die untereinander völlig gespalten und voneinander unabhängig sind. Denn jeder Kanton, bzw. jede Ortschaft eines Kantons - solange der Ort nicht unterworfen ist - kann selbst die Soldatentrommel rühren und denjenigen ihre Soldaten anbieten, die dafür Geld zahlen. Es stimmt jedoch, dass es angesichts der Enge des Territoriums eines jeden Kantons, insbesondere jenes der Katholiken, notwendig ist, bei großer Anfrage nach Söldnern auch in den Untertanengebieten wie Thurgau, Aargau, Baden, Sargans, Rheintal und anderen zu suchen: Da diese unter der Herrschaft von acht Kantonen stehen, die Mehrheit von ihnen die Anfrage stellen und ihre Zustimmung einholen. Dazu ist es notwendig, ja sogar auf eigene Kosten, viele Tagsatzungen einzuberufen, bei denen dann viele Hunderte eines jeden Kantons interessieren; und mehr, um ihnen die Vergütung einer Söldnertruppe zu gewähren, die sie für Dritte ausüben dürfen. Und schließlich ist es notwendig, die vielen Schwierigkeiten mit Hilfe von Geld zu überwinden, die von den erfahrensten Anführern solcher Geschäftshandlungen künstlich vorgeschlagen werden. Es ist wahr, dass diese Kantone in früheren Zeiten aus Notwendigkeit der Verteidigung ihrer Freiheit einen Bund untereinander bildeten und unter dem Titel der guten Freundschaft viele politische Interessen, insbesondere militärische, miteinander geteilt haben: Aber nach einer langen Friedenszeit und unüberwindbarer Glückseligkeit haben die Anführer jeder Republik sich sowohl dem Handel als auch der Besorgung der Soldatennahrung zugewandt, um Geld auf Zinsen zu geben, die Ketzerei eingeführt, Fraktionen gebildet, Neid gesät, Streitigkeiten und Meinungsverschiedenheiten wurden auf einen solchen Begriff gebracht, dass sie sich gegenseitig mehr Feinde nennen können, als Konföderierte. Die Tagsatzungen sind nichts

312 Segreteria Stato, Svizzera, Volume 33, f. 43.

313 Segreteria Stato, Svizzera, Volume 33, f. 44. 
anderes als eine Frage von monetärem Interesse, die sie zusammen mit den eidgenössischen Grundsätzen oder der Privatregierung jedes Kantons teilen. Sie wollen nicht zulassen, dass bei der Versammlung auf freundliche Weise darüber diskutiert wird, wegen der Eifersucht, niemandem unterworfen zu sein, und wegen des Mangels an Vertrauen, der untereinander besteht. [...] $]^{314}$

Die Lage war aber so kompliziert, dass Nuntius Farnese in einem chiffrierten Brief am 20. Dezember 1641 nach Rom schrieb:

Ich werde Eurer Eminenz demütig versichern, dass die vorliegenden Bedingungen sehr unterschiedlich sind im Vergleich zu denen in der Zeit von Julius II. und Leo X. ..., weil die Schweizer damals durch die Religion untereinander vereint waren, und sie waren auch mit Graubünden und dem Wallis gut verbunden, um einen sehr mächtigen Körper zu schaffen und dem Heiligen Stuhl gute Hilfe zu leisten; aber jetzt sind die Kräfte für Helvetien und zwischen den Katholiken in Graubünden, und die Walliser sind mit den Schweizern so uneins, dass sie kein Militär mehr unter einem Schweizer Oberst haben wollen, wie sie es zuvor taten. Es wurde von Paul IV. und Pius mit diesen fünf kleinen katholischen Kantonen ein Bündnis geschlossen, so dass es gut wäre, die Angelegenheit zu sehen, die dem gegenwärtigen Zustand besser entsprechen würde, und wenn Eure Eminenz sie nicht findet, so werde ich mich darum kümmern, denn der Heilige Stuhl kann Schweizer Soldaten aus Graubünden, Wallis und vom Staat des Abtes von St. Gallen haben, ohne ein Bündnis schließen zu müssen, [...]. ${ }^{315}$

Farnese kehrte danach zum Heiligen Stuhl nach Rom zurück und wurde Sekretär der Kongregation für die Bischöfe und Ordensleute. 1650 wurde er zum Gouverneur von Rom und 1655 zum Präfekten des Apostolischen Palastes sowie zum Gouverneur von Castel Gandolfo ernannt.

Beim Konsistorium am 9. April 1657 wurde er von Alexander VII. zum Kardinal in pectore kreiert. Er war von 1658 bis 1662 Legat in Bologna und danach Graf von Latera, seinem Geburtsort. Er nahm am Konklave von 1667 teil, bei dem Clemens IX. gewählt wurde, und zählte sogar zu den „Papabili“, musste aber mit einer vehementen Gegnerschaft rechnen. Er starb am 8. Februar 1668 und wurde in der römischen Kirche „Il Gesù“ begraben. ${ }^{316}$

314 Segreteria Stato, Svizzera, Volume 33, f. 49-50.

315 Segreteria Stato, Svizzera, Volume 33, f. 51. Die restlichen Texte in diesem Band sind Korrespondenzbriefe zwischen dem Nuntius und dem zuständigen Kardinal in Rom. Es geht vor allen Dingen um die Rekrutierung von Schweizer Soldaten (also Anzahl, Anwerbung usw.). 316 Vgl. Stichwort „Girolamo Farnese“, in: https://hls-dhs-dss.ch/de/articles/017901/200408-17/ (31. Dezember 2020). 


\subsubsection{Lorenzo Gavotti (1643-1646)}

Lorenzo Gavotti wurde 1595 in Savona geboren. Sein Vater Girolamo war ein Vertreter einer berühmten lokalen Familie, die 1626 dem genuesischen Patriziat zugeschrieben werden sollte. In jungen Jahren übersiedelte Lorenzo Gavotti nach Rom, wo einige seiner Verwandten bereits lebten. Dort studierte er, um an der Kurie zu arbeiten. 1617 legte er seine Gelübde ab, als er dem Orden der Theatiner beitrat. Nach seiner Ausbildung wurde er zum Priester geweiht und mit der Pfarrei Sant'Andrea della Valle in Rom betraut, die er bis 1633 leitete, als Papst Urban VIII. ihn bat, das Bistum Ventimiglia zu leiten. ${ }^{318}$

Er wurde von Giovanni Battista Scannaroli, Titularbischof von Sidone, zum Bischof geweiht. Am 2. Juli nahm er die Diözese in Besitz und blieb dort 17 Jahre lang. Während dieser Zeit unternahm er mehrere pastorale Besuche, hielt 1635, 1638 und 1642 drei Diözesansynoden ab, von denen die erste vom örtlichen Klerus betreut wurde. ${ }^{319}$

Am 28. Oktober 1643 schickte der Papst, besorgt über den weiter andauernden Krieg von Castro, Gavotti nach Luzern als Nuntius bei den katholischen Schweizer Kantonen, um den aus römischer Sicht wichtigen Weg durch die Täler für feindliche Truppen $\mathrm{zu}$ blockieren, die von der Familie Farnese in Deutschland eingestellt wurden, da sie dort militärisch tätig waren. Während seiner dreijährigen Nuntiatur fungierte er als erfolgloser Vermittler zwischen dem Bischof von Como, Lazzaro Carafino, und den Kantonen Uri, Schwyz und Unterwalden, die die Immunität und kirchliche Zuständigkeit der Tessiner Untertanengebiete einschränken bzw. beibehalten wollten. Im Gegensatz zu den pro-spanischen Kapuzinern versuchte er in den Konflikten, die während des Dreißigjährigen Krieges entstanden waren, zwischen Spanien und Frankreich neutral zu bleiben, um die Position der Katholiken in der Schweiz zu erhalten und im Bund zu stärken. In der schwierigen Situation, die in Graubünden entstanden war, blickte er misstrauisch auf die Aktivitäten des pro-französischen Bischofs von Chur, Johann Flugi von Aspermont, ohne jedoch Maßnahmen gegen ihn zu ergreifen. ${ }^{320}$

Nuntius Gavotti ging wie seine Vorgänger auf die komplizierte geopolitische Lage ein und versuchte ebenfalls, militärische Allianzen, die im Interesse der

317 Vgl. Dizionario biografico degli Italiani, Volume 52, S. 729-731; Caspar Wirz: Bullen und Breven aus Italienischen Archiven, S. XL.

318 Vgl. Stichwort „Lorenzo Gavotti“, in: https://hls-dhs-dss.ch/de/articles/017905/2006-1120/ (31. Dezember 2020).

319 Ebd.

320 Ebd. 
katholischen Kirche lagen, zu festigen, wie er in einem chiffrierten Brief vom 1. November 1644 nach Rom schrieb:

Die Übel, unter denen die katholische Religion im Elsass, Thurgau, Rätien und dem Bistum Basel zu leiden hat, stammen hauptsächlich aus der Hitze der französischen Waffen, die mit denen von Weimar ${ }^{321}$ vereint sind, angesichts der Korrespondenz, die zwischen den Ketzern dieser Orte verläuft; darüber hinaus wurde mehrmals auf die Krone Frankreichs zurückgegriffen, und von dort aus sind Briefe an die Minister zugunsten der Katholiken gegangen, aber bisher wurden keine Früchte erzielt. ${ }^{322}$

Wie sein Vorgänger Nuntius Farnese es in die Wege geleitet hatte, um den Druck auf den Bischof von Chur zu beseitigen, unterstützte Gavotti den Plan, die Schulden des Bischofs durch Geldeinnahmen von Benediktiner-Klöstern zu tilgen, wie in einem Brief vom 8. November 1644 geschrieben wird:

Um den Bischof von Chur von den Schulden zu befreien, da die Mehrheit der Gläubiger Häretiker ist, die kein anderes Ziel haben, als die Zinseinnahmen zu vervielfachen, um in kurzer Zeit in Besitz dieses Bistums zu gelangen, stellte Monsignore Farnese die Anordnung aus Rom fest, dass einige benediktinische Klöster durch die Auszahlung von 20 tausend Gulden, die für die Zwecke der Tilgung dieser Schulden verwendet werden sollen, von der Gerichtsbarkeit des Bischofs ausgenommen werden sollten: [... $]^{323}$

\section{In einem Brief vom 13. November 1644 heißt es aus Luzern:}

Als ich Rom für meinen Dienst verließ, hatte ich einen besonderen Auftrag erhalten und zwar, mich mit der Aussöhnung zwischen Monsignore Bischof von Como und den Herren der katholischen Kantone zu befassen, für die Bemächtigung durch einige von ihnen, die der Bischof in seinem Gebiet erlebt hat: Dieser Beschluss wurde mit den Stimmen der ketzerischen Kantone in der Tagsatzung angenommen, da sie Stellvertreter der Vollstrecker der Bemächtigung der Kantone Altdorf, Schwyz und Unterwalden waren, aber immer in allem die Kantone Luzern und Unterwalden zurückgewiesen haben.

Um diese Differenzen einvernehmlich zu beenden, bin ich auf der Reise, die ich unternommen habe, um hierher zu kommen, durch Como gefahren, wo ich mich mit dem Bischof traf, der, obwohl er sehr verärgert war, bereit war, das Richtige zu tun. [... $]^{324}$

Nuntius Gavotti befürchtete, dass sich die Katholiken in der Eidgenossenschaft von den Protestanten vereinnahmen lassen, wie er in einem chiffrierten Brief vom 27. Dezember 1644 nach Rom schrieb:

321 Vgl. Artikel über die Kriegsführung 1645, in: https://it.wikisource.org/wiki/Azioni_egregie_operate_in_guerra/1645 (31. Dezember 2020).

322 Segreteria Stato, Svizzera, Volume 36, f. 4.

323 Segreteria Stato, Svizzera, Volume 37, f. 13.

324 Segreteria Stato, Svizzera, Volume 37, f. 42. 
Der Grund, warum die große Tagsatzung, die die Ketzer für den kommenden 15. Januar bestellt hatten, verschoben wird, ist nichts anderes, als das, was mir dieser Herr Schultheiß anvertraut hat, da sich diese katholischen Herren nicht zu Recht aufstellen wollen, um mit Waffen für den Fall bereit zu sein, dass die Ketzer in der Tagsatzung auf ihren ungerechten Ansprüchen bestehen wollten. Aber alles, was zählt, ist, dass sich einige Katholiken nicht von dem Geld, das die größte Gefahr darstellt, das in diesen Ländern betrieben wird, beeinflussen lassen. Angesichts des genannten Verdachts und des Wunsches den sie nennen, und zwar den Frieden des Landes zu verteidigen, der hauptsächlich darin besteht, unsere Heilige Religion in dieser Provinz zu erhalten, haben sie mich gebeten, den Heiligen Vater zu bitten, dass er weiterhin durch seine väterliche Zuneigung diese Länder unterstützt und an den Herzog von Bayern schreibt, [...]. ${ }^{325}$

Nuntius Lorenzo Gavotti musste sich besonders zwei Angelegenheiten widmen: Die katholischen Orte hielten den Bischof von Como in ihrer Obhut (,sequestro"). Auch musste Gavotti sich um die Thurgau-Angelegenheit kümmern. Dieser Ort war von den katholischen Orten umstritten. ${ }^{326}$

Am 17. April 1645 schrieb Nuntius Gavotti aus Luzern in einem chiffrierten Brief:

Die Abneigung der drei Kantone Freiburg, Solothurn und Bern, wie sie es in ihrem Anliegen bekunden, betrifft die unterschiedlichen Haltungen zum Kanton Thurgau von Seiten der betroffenen katholischen Kantonen und des Kantons Zürich. Es geht darum, einen Ausgleich zu finden, wie dieser Herr Schultheiß Pircher sagte, [...]. Herr Schultheiß Flechtenstein bestätigt mir, dass der Botschafter Frankreichs Uneinigkeit zwischen den Kantonen hervorruft, doch sie wollen zu einem Ende ihrer Pläne betreffend Konstanz kommen, was dennoch allgemein überschätzt wird, [...]. ${ }^{327}$

Der Umgang mit der protestantischen Seite wurde in einem Brief vom 18. Juli 1645 folgendermaßen beschrieben:

Der Vertrag über den Verkauf des Vermögens der Protestanten des Veltlin war vor der Abreise der Vertreter kein brauchbares Instrument; da die Vertreter der genannten Protestanten nicht in Chiavenna erschienen waren, wie es vereinbart worden war: Da diese Katholiken jedoch Beschwerden gegen die genannten Vertreter geäußert hatten, hatten diese versprochen, auch wenn die Vertreter nicht erschienen sind, so soll die Absicht dieser Angelegenheit gemäß der Tagsatzung von Ilanz erreicht werden, von der ich unverzüglich über die Fortsetzung informieren werden. ${ }^{328}$

325 Segreteria Stato, Svizzera, Volume 36, f. 14.

326 Vgl. Segreteria Stato, Svizzera, Volume 37, f. 84; 355.

327 Segreteria Stato, Svizzera, Volume 37, f. 185.

328 Segreteria Stato, Svizzera, Volume 37, f. 326. 
In einem konkreten Fall geht der Nuntius auch auf den Fall einer nicht gestatten Beerdigung eines Protestanten ein, der auf einem katholischen Friedhof hätte bestattet werden sollen. So schrieb der Nuntius am 25. Juli 1645 nach Rom:

Ich kümmere mich darum, dass der Bischof von Chur und diese Katholiken dazu bewogen werden, dass sie bei jeder Gelegenheit der Angelegenheiten, die ihnen von überall her übermittelt werden, jene väterliche Sorge befolgen, die das Heilige Unseres Lieben Herrgottes in dieser Hinsicht vorgibt, wie es in dieser Gemeinschaft zuvor war, da die Not jedoch zur Versuchung führt, dass die Bündner Protestanten in der Tagsatzung von Ilanz dazu gebracht werden sollen, die Kapuziner aus dem Land zu vertreiben, da die schlechte Gewohnheit gegen die Ordensmänner zugenommen hat, weil sie aufgrund meines Befehls die Bestattung eines Protestanten auf dem Friedhof der Pfarrei nicht zugelassen haben, wie ich es dem Franziskanerpater von Vigevano mitteilte: hinzu kommt auch die grobe Art, wie der Bischof von Chur schreibt, dass Pater Deodato als Präfekt dieser Mission behandelt wird, im Übrigen ein guter Ordensmann, den ich seit Monaten davor warne, und jetzt melde ich dies erneut der Heiligen Kongregation Propaganda Fide. Es wurde alles für die Katholiken unternommen, damit die Protestanten keine Gründe zum Angreifen haben; und ich bitte Gott darum, dass daraus etwas Gutes folgt, [...]. ${ }^{329}$

Der Nuntius musste sich um den Fall eines flüchtigen Priesters aus Lugano kümmern, der in den katholischen Orten der Eidgenossenschaft für Aufsehen sorgte. ${ }^{330}$ Und deshalb schloss er daraus in einem Brief vom 29. August 1645:

(Angelegenheiten der Ordensleute und Pfarrer); aber diese verstehen manchmal weniger ähnliche Dinge als die Weltlichen selbst, was das Elend dieser Länder verstärkt. Ich habe bisher nicht gewusst, welche anderen Mittel nützlich sein könnten, denn ein öffentlicher Handel in den Räten, bestehend aus diesen in einigen Kantonen in Tausenden von Menschen aller Art, würde eine offensichtliche Gefahr großer Verwirrung mit sich bringen, ohne die Absicht zu erreichen. [.... $]^{331}$

Im Herbst 1645 musste sich Nuntius Gavotti dann um den Seligsprechungsprozess von Nikolaus von Flüe kümmern, wie es etliche Katholiken in der Eidgenossenschaft von ihm verlangten. ${ }^{332}$ Und auch um den Bau der ersten Marienkirche in der Schweiz, die dem italienischen Wallfahrtsort Loreto gewidmet ist. ${ }^{333}$ Dies zeigt, dass Gavotti sich auch - wie ein Diözesanbischof - um religiö-

329 Segreteria Stato, Svizzera, Volume 37, f. 335.

330 Vgl. Brief im Sommer 1645 in Segreteria Stato, Svizzera, Volume 37, f. 353-354, f. 355, f. 364, f. 370.

331 Segreteria Stato, Svizzera, Volume 37, f. 387.

332 Vgl. Segreteria Stato, Svizzera, Volume 37, f. 452.

333 Vgl. Segreteria Stato, Svizzera, Volume 37, f. 454. Die Kirche sollte im luzernischen Hergiswil erbaut werden. 
se „Geschäfte“ kümmern musste und nicht nur mit geopolitischen, diplomatischen oder wirtschaftlichen Bereichen zu tun hatte.

Nuntius Gavotti behandelte gemäß dem Band 38 der Nuntius-Korrespondenz vor allem die Debatte in den Tagsatzungen rund um die „Thurgauer Angelegenheit“ und das Vorhaben der Protestanten, die Kapuziner aus Graubünden zu vertreiben bzw. ihre Präsenz zu verbieten. ${ }^{334}$

Eine abschätzende Bemerkung sorgte bei Nuntius Gavotti für Unverständnis dafür, dass nicht alle Schweizer Katholiken auf seiner Seite standen und dies auch offen in der Tagsatzung kundtaten, wie er in einem Brief vom 22. August 1645 nach Rom schrieb:

Ich habe es nicht versäumt, Ihnen die Schwere des Verbrechens, das die weltlichen Behörden der Kirche und dem Kirchenmann angetan haben, darzulegen, indem ich mich auf das bezog, was über den Prozess bekannt ist, [...]. Es schien mir wenig hilfreich, mit allen möglichen Menschen zu tun zu haben, die nicht fähig sind, und vor allem, weil nur zwei Stimmen von Katholiken für die Mehrheit der Ketzer reichten, mit denen der eine Katholik bereits zuvor erklärt hatte, zur Vollstreckung der Gerechtigkeit gegen den Kleriker zu stimmen. ${ }^{335}$

Eine weitere Angelegenheit betraf die Wahl eines neuen Landrichters in Graubünden. Nuntius Gavotti war gegen die Wahl eines Protestanten. ${ }^{336}$ So schlussfolgert er, dass einzig durch eine gezielte Bildungspolitik in der Eidgenossenschaft dagegen vorgegangen werden kann, wie er in einem Brief vom 3. Juli 1646 schrieb:

In diesen Teilen wächst jedoch der Bedarf an einer guten Erziehung in der Jugend, vor allem wegen der außerordentlichen Wachsamkeit gegenüber den Ketzern bei der Verbreitung ihrer falschen Lehre; deshalb soll zwischen den Herren von Solothurn und den Jesuiten die Einrichtung eines Kollegs in diesem Kanton festgelegt werden und es sollen zu Beginn acht Ordensmänner dort anfangen. ${ }^{337}$

Die Lage in der Westschweiz schien dem Nuntius vor allem problematisch zu sein, wo die Mehrheit der Protestanten die katholische Minderheit - und vor allem den Bischof von Lausanne - unter Druck setzte. Dagegen wollte Gavotti konkret vorgehen und berichtete am 9. Oktober 1646 nach Rom:

Ich antwortete dem Bischof von Lausanne herzlich, wie ich Eurer Eminenz am 10. Juli bereits mitgeteilt hatte, letztendlich auf das große Bedürfnis, dass seine Diözese unter den

334 Vgl. Segreteria Stato, Svizzera, Volume 38.

335 Segreteria Stato, Svizzera, Volume 37, f. 370

336 Vgl. Segreteria Stato, Svizzera, Volume 38, f. 118.

337 Segreteria Stato, Svizzera, Volume 38, f. 280. 
Ketzern zu leiden hat und nach der ständigen Anwesenheit ihres Hirten lechzt; indem ich ihn darauf ansprach, um mir so schnell wie möglich zu antworten, beschloss er, dies zu tun: Nun bekam ich seine Antwort am 10. dieses Monats und darin dankte er mir für die Mitteilung, die er erhalten hatte, und versprach, gegen Ende dieses Monats nach Freiburg zurückzukehren, um genauer verhandeln zu können und um zu sehen, was getan werden kann, damit die gute Regierungsführung dieses Bistums verbessert werden kann. ${ }^{338}$

Den Unterlagen wird eine Bitte der katholischen Vertreter der eidgenössischen Orte beim Nuntius beigefügt. Es ist wahrscheinlich, dass ihre Bitte vom Nuntius mitverfasst wurde. Darin steht:

Geführt vom rechten Eifer, stellen die demütigsten Redner und gehorsamsten Kinder und Diener Eurer Heiligkeit den Mangel an gebildeten Menschen in dieser Provinz, mit der gefährlichen Lage ihrer Nähe zu den Ketzern, die mit all ihrer Macht bestrebt sind, ihre falsche Lehre zu erweitern, und weil sie (die Katholiken) meist arm sind, haben sie keine Möglichkeit, ihre Kinder ins Ausland zum Studium zu schicken, so dass sie zu Mauern gegen diese Feinde werden könnten. ${ }^{339}$

Im April 1646 bat Gavotti aus gesundheitlichen Gründen um die Rückführung. Der Antrag wurde am 7. November angenommen, so dass er Zeit hatte, ein Jesuitenkolleg in Solothurn und Bellinzona zu errichten, die Anwesenheit der Kapuziner in Chur zu verteidigen, die Residenz aller Schweizer Bischöfe auf ihren Sitzen zu beantragen und als Sprecher für den Seligsprechungsantrag von Bruder Klaus aus Unterwalden zu fungieren. Als er in Rom ankam, überreichte er dem Papst die Briefe der Räte der katholischen Kantone, die die Arbeit des Nuntius lobten und seine Beförderung auf eine höhere Ebene empfahlen.

Als er 1650 nach Italien zurückkehrte, ging er nach Rom und trat 1653 als Bischof von Ventimiglia zurück und erhielt ein Kanonikat in der Basilika Santa Maria Maggiore. Unter Alexander VII. übte Gavotti das Amt des Bischofsassistenten der Papstkapelle aus.

Am 2. Juli 1670 wurde er zum Erzbischof von Rhodos ernannt, insbesondere zum Erzbischof von Infidelium, einer rein ehrenamtlichen und wirtschaftlich bedeutenden Stelle, die es ihm ermöglichte, die letzten Jahre seines Lebens ohne große Sorgen zu verbringen.

Er starb am 9. August 1679 in Rom. Die Leiche wurde nach Genua gebracht, wo sie am 28. August in der von Pietro Berrettini da Cortona erbauten Familienkapelle in der Kirche San Nicola da Tolentino begraben wurde. ${ }^{340}$

338 Segreteria Stato, Svizzera, Volume 38, f. 386.

339 Segreteria Stato, Svizzera, Volume 38, f. 391.

340 Vgl. Stichwort „Lorenzo Gavotti“, in: https://hls-dhs-dss.ch/de/articles/017905/2006-1120/ (31. Dezember 2020). 


\subsubsection{Alfonso Sacrati (1646-1647)}

Geboren um 1585, also ein Jahr vor der Einführung der ständigen Nuntiatur in Luzern, war Alfonso Sacrati als Sohn eines Grafen und Neffe von Kardinal Francesco Sacrati ebenfalls ein aus dem Adel der Emilia Romagna stammender Kirchenmann. Aus seiner Biographie ist wenig bekannt. Paul V. ernannte ihn am 12. Juni 1617 zum Bischof von Comacchio. Neun Jahre später reichte aber Alfonso Sacrati seinen Rücktritt ein. Alfonso Scarati wurde am 27. März 1643 von Papst Urban VIII. zum Vizeregenten Roms ernannt. Diese Stelle hatte er bis zum 20. Oktober 1646 inne, um danach als Nuntius in Luzern zu wirken. Die Ernennung durch Papst Innozenz X. erfolgte am 7. November 1646. Er blieb in der Eidgenossenschaft bis zu seinem Tod am 14. September 1647.

Nuntius Sacrati begann seine Korrespondenz mit Rom, indem er die Reise in die Schweiz beschrieb und auf die „Hürden“ des Weges einging, wie er im Brief vom 6. Januar 1647 nach Rom schrieb:

Je mehr mir die Ehre zuteilwurde, die mir Seine Heiligkeit und die Freundlichkeit Eurer Eminenz, die mich begleitete, für die Reise nach Helvetien zu schenken; desto mehr wurden wir daran gehindert, dies zu tun, weil uns die schlammigen Straßen der Romagna und der Lombardei und danach das Eis und der Schnee, die die Berge überziehen, und vor allem der St. Gotthard, wo Italien seinen Namen und seine Sprache verliert, daran hinderten. In meiner Reise hatte ich nicht die Ehre, Kardinal Fachinetto und Kardinal Rossetti, den Brief unseres Herrn und die Breve Eurer Eminenz, sowie Kardinal Cibo und der Falkner, die den einen und den anderen mit allem gebührenden Respekt empfangen haben, entgegenbringen zu können. [... $]^{342}$

Dann ging ich an den Bergen vorbei, überwand dank Gottes Gnade den Schnee, das Eis und die Gefahren, und jetzt befinde ich mich in Luzern, gerade noch rechtzeitig, die im Kloster versammelten Vertreter der sieben katholischen Kantone, denen ich den Brief und das Schreiben Eurer Eminenz vorgelegt habe, und machte sie zu einem breiten Zeugnis der väterlichen Liebe, die ihnen Seine Heiligkeit fast mit Tränen in den Augen bringt, und mit liebevollen Worten zeigten sie das Innere der Seele, mit der sie sowohl die Gnade empfingen, als auch die Gnade, die mir auf dem vergangenen Weg widerfahren ist. [.... $]^{343}$

In seinen ersten Amtshandlungen musste er sich wie sein Vorgänger Gavotti mit der „feindlichen Einstellung“ der Bündner auseinandersetzen, die die Priester und Ordensleute aus ihrem Kanton verbannen wollten. ${ }^{344}$ Nuntius Sacrati kümmerte sich insbesondere um die Stadt Konstanz, die von den Eidgenossen

341 Vgl. Caspar Wirz: Bullen und Breven aus Italienischen Archiven, S. XL.

342 Segreteria Stato, Svizzera, Volume 39, f. 3.

343 Segreteria Stato, Svizzera, Volume 39, f. 4.

344 Vgl. Segreteria Stato, Svizzera, Volume 39, f. 6. 
kontrolliert wurde. ${ }^{345}$ So wies er aber auf die Gefahr hin, die aus der komplizierten Sachlage herrührte, wie er in einem Brief vom 30. April 1647 schrieb:

So haben Protestanten und Ketzer aus Graubünden die Gelegenheit genutzt, durch die Uneinigkeit der Katholiken für die Anwendung von einigen von ihnen im Dienste Frankreichs sowie bei anderen, die Spanien treu geblieben waren, um ihren bösen Geist zum Nachteil der katholischen Religion und mit engen Verhandlungen zwischen ihnen, und dem Marquis Salice, dem Botschafter Frankreichs, zu handeln. Der französische Botschafter ist aber ein Mann des wahren Gefühls für die Christen und der wegen der tödlichen Vergeltung, die er durch Seine Allerchristlichste Majestät zu fürchten hatte, hütete er sich wohl, eine zu positive Einstellung gegenüber den Häretikern zu zeigen, [...]. ${ }^{346}$

Nuntius Sacrati ging zunächst auf die Schwierigkeiten in der Westschweiz ein, wie er in dem Brief vom 28. Mai 1647 nach Rom schrieb:

Von Anfang an, als ich zur Nuntiatur kam, wurde ich unter anderem durch eine Anweisung, die mir in Rom gegeben wurde (durch Eure Eminenz), und durch einen Bericht von Monsignore Gavotti gewarnt, der den Bischof von Lausanne in einem altersschwachen Alter vorfand und da dieser nicht in der Lage war, die Diözese mit einem für sein Amt günstigen Anstand zu erhalten, weil er kein anderes Einkommen aus seiner Kirche hat, als die etwa 50 Doppel, die er seit vielen Jahren aus dem Burgund erhält, wo er geboren wurde, obwohl seine Diözese, wenn auch klein, wie jede andere Diözese, die ständige Unterstützung seines Hirten braucht, gerade weil sie von bernischen Ketzern umgeben ist. Deshalb war es mein Vorgänger, der den Bischof davor warnte, sich um die Herde um sich zu kümmern, da er verpflichtet ist, in seinem Haus zu bleiben, und dass es Strafen gibt, die die Päpste gegen diejenigen verhängen, die ohne Erlaubnis die Diözese verlassen. ${ }^{347}$

Auf der geographisch anderen Seite sorgte sich Nuntius Sacrati um die Zukunft des Bistums Chur, wie er im Brief vom 28. Mai 1647 schrieb:

Ich schrieb an den Bischof von Chur, dass eine gleichgültige und neutrale Haltung in diesen turbulenten Zeiten den Ämtern große Autorität verleiht, die weder für die Betroffenen auf der einen noch auf der anderen Seite verschwiegen werden können, was gerade die Merkmale der Kirchenmänner sind und derjenigen, die die Macht haben, deren gutes Urteil viel besser zu verstehen gibt, um sie zu unterstützen. [... $]^{348}$

Die Churer Frage war für Nuntius Sacrati nicht nur eine „lokale Angelegenheit“, er verstand sie auch im Kontext des Westfälischen Friedens bzw. der Verhandlungen, die dazu führten, den Dreißigjährigen Krieg zu beenden und somit die Konfessionsfrage zu lösen, wie er im Brief vom 4. Juni 1647 schrieb:

345 Vgl. Segreteria Stato, Svizzera, Volume 39, f. 16, 25, 46.

346 Segreteria Stato, Svizzera, Volume 39, f. 96.

347 Segreteria Stato, Svizzera, Volume 39, f. 133.

348 Segreteria Stato, Svizzera, Volume 39, f. 137. 
Der Churer Landtag versammelte sich hauptsächlich (wie ich in der Vergangenheit an Eure Eminenz geschrieben habe) wegen der Auseinandersetzung zu religiösen Fragen, die von Protestanten angeregt wurden, die durch ihre ständige Ungeduld, die Katholiken in Rätien betreffend, und sie wissen nichts anderes als unerbittlichen Hass gegen sie auszuüben, indem sie entweder die Katholiken zur Ausweisung bringen wollen, oder sie zur Ketzerei zu bewegen; die Protestanten hatten ja bereits in der Einrichtung einer dreifachen Ordnung den Mut gehabt, schismatische Artikel vorzuschlagen, die bereits veraltet waren, und zwar seit den Jahren 1524. 26 von 61 Punkten davon waren bereits angenommen, aber weder umgesetzt, noch akzeptiert, ja von denselben Protestanten widerrufen, zwar nicht mit Waffengewalt, wie sie sagen, sondern aus gutem und mit freiem Willen: [...]

Die Friedensverhandlungen in Münster betreffend die Religionsfrage scheinen Graubünden und den katholischen Kantonen sehr günstig und gut zu sein. [.... $]^{349}$

Doch eine Woche später musste die Nuntiatur in Luzern den plötzlichen Tod von Alfonso Sacrati vermelden. Danach wurde Giacomo Villani Internuntius. Villani schrieb am 11. Juni 1647 nach Rom:

Darauf folgte der Tod von Monsignore, meinem hochgeschätzten Nuntius, wie ich Eure Eminenz sofort mit einer separaten Mitteilung informierte; und am folgenden Tag, um 6 Uhr in der Früh, wurde die Leiche feierlich im Palast seiner Residenz aufgebahrt, und dann folgte eine Prozession in der Luzerner Stiftskirche, wo er begraben wurde, begleitet von zahlreichen Menschen, die alle in Braun gekleidet waren, wie von den Schultheißen befohlen, und die die Ausführung der Kondolenz nicht vernachlässigten, damit sie ihm auch jede Ehre der Würde des Prälaten bezeugten. ${ }^{350}$

Villani verfolgte die gleiche Linie wie Sacrati, und zwar ging es um die die Bündner Angelegenheit und insbesondere den dort herrschenden Religionskonflikt. ${ }^{351}$

Der Internuntius Villani schrieb in seinen Briefen auch, dass er eine volle Anerkennung des Heiligen Stuhls brauchte. ${ }^{352}$ Es war für ihn nicht einfach, da er in Konkurrenz zu anderen Bischöfen in der Eidgenossenschaft stand sowie von Seiten der Reformierten unter Druck gesetzt wurde. Auch Klöster waren nicht bereit, Villani anzuerkennen. ${ }^{353}$

349 Segreteria Stato, Svizzera, Volume 39, f. 155.

350 Segreteria Stato, Svizzera, Volume 39, f. 161.

351 Vgl. Segreteria Stato, Svizzera, Volume 39, f. 244, 253, 264, 279, 301,

352 Vgl. Segreteria Stato, Svizzera, Volume 39, f. 310.

353 Vgl. Vgl. Segreteria Stato, Svizzera, Volume 39, f. 318-319: Allen voran das Kloster St. Urban weigerte sich, ihn als Papstgesandten anzuerkennen. 


\subsubsection{Francesco Boccapaduli (1647-1652) ${ }^{354}$}

Auch Francesco Boccapaduli ${ }^{355}$ war ein Römer, geboren am 3. April 1600, stammte er aus einer römischen Adelsfamilie. Seine Mutter war Französin. Als Zwölfjähriger begann er seine Kirchenkarriere und kam unter den Schutz von Papst Paul V. Unter Urban VIII. wurde Boccapaduli Bischof von Valva und Sulmona, wo er dann auch residierte. Innozenz X. berief ihn am 28. Februar 1647 zum Bischof von Città di Castello. Er wurde am 14. September desselben Jahres zum Nuntius in Luzern ernannt. Anfangs November kam er in die Stadt am Vierwaldstättersee an. Nach dem plötzlichen Tod von Nuntius Sacrati und der interimistischen Leitung Villanis kam Boccapaduli in Luzern an, von wo er brieflich nach Rom seine Reise beschrieb bzw. die Etappen erläuterte. ${ }^{356}$

Vielleicht liegt es an den Begebenheiten jener Zeit, aber Nuntius Boccapaduli schreibt regelmäßig über den Stand der Dinge im Deutschen Reich (mehr als über die Eidgenossenschaft!).

Auch er kümmert sich zunächst um die Besserung der Lage der Katholiken in Graubünden, die weiterhin unter Druck stehen, und da scheint ihm der Seligsprechungsprozess für Nikolaus von der Flüe ein guter Anlass zu sein, wie er am 17. März 1648 nach Rom schrieb:

Ich will Eurer Eminenz die gute Nachricht überbringen, wie ich dies immer ehrfürchtig tue, indem ich die Gnade gemeinsam mit der ganzen Nation teile, und Sie werden die Ehren dieser ihrer Nation zu empfangen schätzen, da er bereits nicht nur bei den Katholiken auf große Verehrung zählen kann, sondern auch als Heiliger bei den Ketzern gilt, die ihn nicht verabscheuen. ${ }^{357}$

Und dann kommen auch noch „ungewöhnliche Anfragen“. So schrieb Nuntius Boccapaduli am 24. März 1648 nach Rom:

Ich erhalte eine Anfrage von diesem Kanton Altdorf, dass ich eine Lizenz bestätigen möge, die bereits in anderen Zeiten durch ein Schreiben dieses Staatssekretariats von Monsignore Sarego, ehemaliger Nuntius, erhalten wurde, dass nämlich die Waren, die von Deutschland nach Italien und von Italien nach Deutschland gelangen, die Reise in ihr Territorium auch an Feiertagen fortsetzen können, aber in Anbetracht der Tragweite des Schreibens, haben wir in Übereinstimmung mit dem beigefügten Exemplar gesehen, dass die Bestimmung nicht mit Ausnahme der Waren gilt, die aus den Niederlanden nach Italien kommen, und weil der Wunsch geäußert wird, dass nicht nur diejenigen davon betroffen sind,

354 Vgl. Caspar Wirz: Bullen und Breven aus Italienischen Archiven, S. XL.

355 Vgl. Stichwort „Francesco Boccapaduli“, in: https://hls-dhs-dss.ch/de/articles/017885/ 2004-06-04/ (31. Dezember 2020).

356 Vgl. Segreteria Stato, Svizzera, Volume 39, f. 358, 395.

357 Segreteria Stato, Svizzera, Volume 40, f. 105. 
die aus Deutschland kommen, sondern auch diejenigen, die auf dem Weg aus Italien mitgebracht werden, und ebenso die Esswaren, also die Bedürfnisse, die das Land hat, und dies wegen der Schwierigkeit des Passes des St. Gotthard-Gebirges, den man nicht immer überqueren kann, und deshalb habe ich aus Sicherheitsgründen geschätzt, dass ich alles Eurer Eminenz darstellen muss, um zu erfahren, wie weit ich gehen kann, ihnen die Güte der Gnaden unseres Herrn zu erteilen, während ich auf Ihre Antwort warten werde, $[\ldots . .]^{358}$

Auch Nuntius Boccapaduli musste sich wie der Internuntius Villani mit dem „Rebellen-Abt“ des Klosters St. Urban auseinandersetzen. ${ }^{359}$ Und ebenfalls oft musste Boccapaduli dem französischen Botschafter in der Eidgenossenschaft auf Anfragen antworten, die dieser ihm stellte. ${ }^{360}$

Sorgen bereitete Nuntius Boccapaduli die Haltung Venedigs, das weniger „religiös“ und mehr „wirtschaftlich“ dachte, wie der Nuntius zwischen den Zeilen in einem Brief vom 7. Juli 1648 nach Rom schrieb:

Da es abgemacht ist, dass mit dem Schweizer Volk, das im Dienste der Republik Venedig in Italien Fuß fassen wird, auch zwei Prediger mitgehen werden, habe ich es nicht versäumt, dem Gesandten derselben Republik in Zürich den Schaden für unsere Heilige Religion und den Nachteil, den vor allem ihr eigenes Land davon erhalten kann, zu erläutern, aber ich erhalte als Entschuldigung, dass es notwendig sei, wie Eure Eminenz aus der beigefügten Kopie erkennen kann, auch werde ich den Nuntius in Venedig informieren, damit er davor gewarnt werden kann. ${ }^{361}$

Die Angelegenheit mit dem Söldnerwesen beschäftigte Boccapaduli sehr, und er glaubte, dass etwas im Schilde geführt wurde, was der katholischen Kirche schaden könnte. Gerade den Treffen bei der Tagsatzung misstraute er sehr, wie er in einem Brief vom 21. Juli 1648 schrieb:

Soweit aus der Tagsatzung, in der allerdings weiterhin diese Kantone in Baden tagen, und da die Protestanten für die gemeinsamen Thurgauer Präfekturen die notwendigen Unterschiede in der Religion begründet haben, haben die Katholiken nach der Abmachung, die sie untereinander getroffen haben, zuerst versucht, ein privates Gespräch zwischen ihnen führen, und die Zürcher, die am meisten an diesem Thema interessiert sind, haben dann doch geantwortet, dass sie von ihren Obrigkeiten keine anderen präzisen Handlungsanweisungen erhalten haben, und man glaubt jedoch, dass in diesem Sinne demnächst neue Tagsatzungen einberufen werden. ${ }^{362}$

358 Segreteria Stato, Svizzera, Volume 40, f. 111.

359 Vgl. Segreteria Stato, Svizzera, Volume 40, f. 196-199, 226-228, 334-35, 428.

360 Vgl. Segreteria Stato, Svizzera, Volume 40, f. 250-251, 335, 542-545.

361 Segreteria Stato, Svizzera, Volume 40, f. 276.

362 Segreteria Stato, Svizzera, Volume 40, f. 306. 
Das Söldnerwesen war 1648 für die Schweiz in zweierlei Hinsicht negativ. Einerseits nahm mit dem Ende des Dreißigjährigen Krieges die Suche nach Soldaten rapide $a b$, und andererseits waren zum Ende der Kriege die beteiligten Mächte auch finanziell erschöpft. So schrieb Nuntius Boccapaduli am 22. Oktober 1648:

\begin{abstract}
Man hat jedoch große Schwierigkeiten, Geld in dem Land ${ }^{363} \mathrm{zu}$ finden, da es wegen der Dauer der Kriege außerordentlich erschöpft ist, aber man setzt alles daran, es zu suchen, wo man kann, damit sie sich auch für Helvetien interessieren, das, weil sie von den Unannehmlichkeiten der Kriege verschont blieb, eine größere Bequemlichkeit $\mathrm{zu}$ haben scheint, und in der Tat findet man dort eine sehr gute Übereinstimmung, weil die Menschen es sich leisten können, auch zu ihrem eigenen Vorteil einzustehen und die Waffen aus ihrer Nähe fernzuhalten. ${ }^{364}$
\end{abstract}

Und so sah er auch Gefahren für den Frieden, weil die Söldner nicht mehr bezahlt werden konnten. Er befürchtete sogar, dass sie neue Kriege entfachen könnten, wenn man ihnen nicht so rasch wie möglich die Löhne zukommen ließ. ${ }^{365}$

Boccapadulis größter Erfolg war die Nicht-Beteiligung der katholischen Kantone am Konflikt zwischen Frankreich und Österreich. Es war sein Verdienst, dass Frankreich sich nicht mehr in die Angelegenheiten der Katholiken in der Schweiz einmischte. Auch er unterstütze wie sein Vorgänger die Jesuiten, insbesondere im Tessin, wo der Orden eine Bildungseinrichtung in Bellinzona besaß.

Das folgende Jahr 1649 war dann für Nuntius Boccapaduli seinen Briefen nach vor allem vom Frieden im Deutschen Reich geprägt. Er verfolgte die Entwicklungen und beschrieb die Konsequenzen, die auch für die Schweiz wichtig waren. ${ }^{366}$

Der Nuntius hatte aber auch viel wegen der Klöster „um die Ohren“, wie beispielsweise die Abtswahl in Wettingen, die Probleme im Zisterzienserkloster in Rothenburg und ähnliches. In einer Instruktion wird P. Celestino Sfondrati (1644-1696) genannt, der Großneffe Papst Gregors XIV. ${ }^{367}$ Dieser schreibe viel aus der Schweiz, sodass er durchaus zum Kardinal erhoben werden könnte. Sfondrati wurde jedoch erst von Papst Innozenz XII. im Konsistorium vom 12. Dezember 1695 als Kardinalpriester in das Kardinalskollegium aufgenommen. Der Nuntius in Luzern sollte zum Fürstabt Sfondrati ein „gutes freundschaftliches Verhältnis“ aufbauen, insbesondere sei Sfondrati im Bereich des Lehram-

363 Damit ist das Deutsche Reich gemeint.

364 Segreteria Stato, Svizzera, Volume 40, f. 553.

365 Vgl. Segreteria Stato, Svizzera, Volume 40, f. 573.

366 Vgl. Segreteria Stato, Svizzera, Volume 41.

367 Vgl. Segreteria di Stato, Svizzera, Volume 233, f. 381. 
tes (Dottrina), des Umgangs (Galanteria) und des Verdienstes (Emerita) zu berücksichtigen, so die Instruktion weiter. ${ }^{368}$

Doch vor allem die Lage in Graubünden sorgte für viel Korrespondenz zwischen Luzern und Rom, und der Nuntius schien sich bestens auszukennen sowie direkte Kontakte vor Ort zu haben, wenn er sogar Einzelfälle kannte. So schrieb er in einem Brief vom 9. März 1649:

Man spürt, dass in Graubünden die Menschen zu einem Aufstand neigen, da es bereits einige Gemeinden gibt, die gegen ihre Regenten aufgebracht sind, und andererseits haben die Anführer begonnen, die Gegenbewegung zu verhindern, indem sie in Chur einige Kriegsmunition geholt haben, die in einem Tresor auf dem Land ein paar Stunden entfernt aufbewahrt wurde, [...]. ${ }^{369}$

Die Lage wurde nicht einfacher, als Söldner wieder in ihre Heimat zurückkehren wollten, und da gab es Schwierigkeiten, wie Nuntius Boccapaduli am 8. Januar 1650 schrieb:

Es begannen bei einigen ihrer Häuser die Leute der sechzehn Kompanien dieses Landes aufzutauchen, also von jenen, die aus dem Dienst Frankreichs entlassen wurden und von denen einige, die bereits fast drei Stunden unterwegs waren, um durch einen geheimen Weg an den Grenzen Burgunds nach Helvetien auf Berner Boden zurückzukehren, doch wurden sie von den Gouverneuren der nahegelegenen Orte der französischen Krone verhaftet, und der Waffen und des Gepäcks entledigt, und zwei Kapitäne, einer aus Zürich und der andere aus Schaffhausen, mussten zurückbleiben, der Rest durfte unbewaffnet passieren. Das Ganze wurde ohne Grund getan. Doch auf die Waffen verzichteten sie ohne Widerstand, denn es ist in dieser Nation Brauch, dass sie die Waffen von ihren Kapitänen und nicht von den Fürsten erhalten, denen sie dienen. Man hört auch, dass neben den sechzehn Kompanien auch weitere vierundzwanzig entlassen werden sollten. ${ }^{370}$

1650 wird das Verhältnis zwischen Nuntius Boccapaduli und dem Bischof von Konstanz, Franz Johann Vogt von Altensumerau und Prasberg, ${ }^{371}$ arg strapaziert. Es folgte ein harscher Briefwechsel zwischen dem Nuntius, dem Bischof

368 Vgl. Segreteria di Stato, Svizzera, Volume 233, f. 381.

369 Vgl. Segreteria Stato, Svizzera, Volume 41, f. 88.

370 Segreteria Stato, Svizzera, Volume 41, f. 16.

371 Franz Johann Vogt von Altensumerau und Prasberg (1611-1689) war Fürstbischof von Konstanz von 1645 bis 1689. Vgl. Artikel über ihn, in: https://hls-dhs-dss.ch/de/articles/ 026349/2012-09-27/ (31. Dezember 2020): „Wie seine Vorgänger wehrte sich auch V. gegen die Eingriffe in die bischöfliche Jurisdiktion. Um die Streitigkeiten zu beenden, schloss er 1652 mit dem Kloster St. Blasien, 1659 und 1682 mit der Deutschordensballei Elsass und 1659 mit jener von Franken sowie 1683 mit dem Kanton Luzern Verträge ab. Im Konflikt mit dem Nuntius in Luzern ersuchte der Bischof sogar den Kaiser als Protektor der Deutschen Nation um Hilfe.“ 
und Rom. So antwortete Nuntius Boccapaduli in einem Brief vom 24. Februar 1650:

Ich habe die Erzählung gelesen, wie es Eure Heiligste Herrschaft mir wohlwollend zugeschickt hat, was anlässlich des Besuchs geschehen sein soll, als mein Auditor zu dem Kloster Weißenau ${ }^{372} \mathrm{kam}$, und ich finde in Ihrem Beitrag ganz andere Besonderheiten als jene, die mir mein Auditor selbst und der Klosterpater, der ihn als Aktuar begleitet hatte, angegeben haben, und ich nehme an, dass es notgedrungen noch besser wäre, wenn man die Wahrheit zur Heiligkeit unseres Herrn bringen würde, [...]. ${ }^{373}$

Nuntius Boccapaduli sorgte sich auch um die Einführung von Treueschwüren für Kirchenleute, die bei Ernennungen $\mathrm{zu}$ ihm kommen sollen, um ihren Glauben $\mathrm{zu}$ bezeugen. ${ }^{374}$

Auch er war aber informiert, was in den katholischen Orten geschah, und so beschrieb er in einem Brief vom 9. Mai 1551 nach Rom:

Bei der Erneuerung der Ämter, wie es üblich ist in diesen Volkskantonen, geschah es Anfang Mai aber, dass in Schwyz das versammelte Volk einen der Ihren aus dem Gefängnis mit Tumult herauszog. Es handelte sich um einen, den der Ordentliche Rat der Anführer eingesperrt hatte, weil er sich dafür einsetzte, dass dem Volk die üblichen Steuern von siebeneinhalb auf nur fünf gesenkt werden. So hatte dieser den Vorschlag in dieser Sitzung gemacht. Der Tumult brachte jedoch keine größeren Konsequenzen mit sich, wie man hätte denken können, weil sie mit der Befreiung ihres Gefangenen zufrieden waren und mit der Absolution von jeglicher Anklage oder Verurteilung, sodass nichts gegen ihn aufgebracht werden konnte, und alles blieb ruhig und ging ohne weitere Störungen zur Wahl. ${ }^{375}$

Boccapaduli war dann vor allem mit den Verhandlungen zwischen Zürich und den „alten katholischen Orten“ über den Thurgau beschäftigt. ${ }^{376}$ Das führte ihn dazu, über die Beziehung zwischen Katholiken und Protestanten nachzudenken, und so schrieb er am 29. Dezember 1651 nach Rom:

Bezüglich der Information, die Eure Eminenz gnädigster zu Befehl geben, betreffend den Ursprung und die Grundlagen der Vereinbarungen, die Katholiken und Ketzer in diesen

372 Vgl. Helmut Binder (Hrsg.): 850 Jahre Prämonstratenserabtei Weissenau.

373 Segreteria Stato, Svizzera, Volume 41, f. 40.

374 Vgl. Segreteria Stato, Svizzera, Volume 43, f. 43. Da schreibt er am 21. Februar 1651 nach Rom: „In Übereinstimmung mit Eurer Eminenz meinte ich, dass der Abt von Wettingen sich darauf reduziert hatte, die Bestätigung seiner Wahl aus dieser Nuntiatur zu nehmen, so dass er sie auch vollzog, indem er zu diesem Zweck das Glaubensbekenntnis ablegte, und den üblichen Eid ablegte, so dass ich denke, dass das Beispiel festgestellt werden kann, und der Besitz für dieselbe Nuntiatur auch für die Zukunft. [...]“

375 Segreteria Stato, Svizzera, Volume 43, f. 151.

376 Vgl. Segreteria Stato, Svizzera, Volume 43, f. 388. 
Gebieten zur Benützung derselben Kirche machen, muss ich sagen, dass ich trotz der Anstrengung, die ich unternommen habe, nichts anderes erkenne als das Prinzip, dass das Land mit Ketzerei infiziert ist. Davon wurde an Orten Gebrauch gemacht, die mit Katholiken und Ketzern gemischt waren. Nachdem die Katholiken mit ihren Andachten in der Kirche zufrieden waren, wurde die Kirche den Ketzern rechtmäßig überlassen, damit auch sie ihre Gottesdienste dort ausführen können, ohne dass man eine andere ausdrückliche Vereinbarung gefunden hätte; Es wird jedoch angenommen, dass der Gebrauch davon begann, weil die Ketzer nicht ihre angebliche Vernunft verlieren wollten, da sie dachten, dass auch sie Anrechte an den Kirchen hätten, die ursprünglich die gemeinsamen für alle waren, und dass die Kosten von Neuanfertigungen verpflichtend seien; Und als dann der Gebrauch eingeführt wurde, haben die Katholiken es nicht einfach hingenommen, dass die Ketzer, selbst wenn sie es wollten, keine neuen Kirchen herstellten, damit sie sich nicht so sehr etablieren konnten, sondern weiterhin ihren Ursprung erkennen mussten. Auf diese Weise mussten die Ketzer weiterhin die heiligen Bilder betrachten, so dass sie mit dem Bildnis des Geheimnisses unserer Erlösung oder der Tugenden der Heiligen zu tun hatten und so hätten sie sie in irgendeiner Weise zur Frömmigkeit anregen können. $[\ldots]^{377}$

Die Richterwahl in der Eidgenossenschaft war durch die religiöse Teilung sehr komplex und für „römische Augen“ nicht klar. Nuntius Boccapaduli versuchte dennoch, sich Klarheit zu verschaffen und dies nach Rom mit entsprechenden Erläuterungen zu übersenden, wie beispielsweise im Brief vom 28. Juni 1652:

Ich habe bei der Ausführung der Befehle Eurer Eminenz alles getan, was ich konnte, um zu verhindern, dass die Wahl des Landrichters an ein ketzerisches Subjekt gerät; aber wie Eure Eminenz in der Kopie sehen kann, die ich dem Bischof von Chur in einem Brief schickte, war die Wahl bereits getroffen, und so konnte man nicht entkommen und das hätte nicht ohne die Hilfe der Katholiken sein können, die außerdem bekannter waren; Aber sie befinden sich in einem Konzept, indem sie denken, dass man manchmal den Ketzern klein beigeben soll, denn es sei Brauch, dass der Landrichter nur aus katholischen Gemeinden gewählt wird, mit Ausnahme einer Gemeinde, die gemischt ist und die in diesem Jahr von der Wahl betroffen war. So nehme ich an, dass die Nachfolgeregelung der Ketzer ausschließt, dass sie uns jemals untergraben wollen, und weniger noch, dass es für alle anderen Gemeinden gilt, [...]

Jetzt will der Bischof, dass ich glaube, dass die Angst vor Nachteilen angegangen wurde, die man fürchten sollte, weil man die Hände an den Ketzer gefesselt hat, sodass man nichts für das unternehmen kann, was ihm zusteht, und dass er auch dieses Mittel ablehnt, als ob es zu minderwertig sei, [...]. ${ }^{378}$

Auch Boccapaduli erlebte wie einige seiner Vorgänger am Schluss seiner Amtszeit enttäuschende Momente, bei denen er von den Katholiken, die eigentlich

377 Segreteria Stato, Svizzera, Volume 43, f. 400.

378 Segreteria Stato, Svizzera, Volume 44, f. 185. 
auf seiner Seite sein sollten, offen kritisiert wurde. So schrieb er mit bitterem Unterton am 1. Oktober 1652 nach Rom:

\begin{abstract}
Mit all den Anstrengungen, die ich selbst unternehme, und mit Hilfe guter Ordensleute, versuche ich, die Leute des Kantons Altdorf verstehen zu lassen, dass die Apostolischen Nuntien nicht in diese Gegend kommen, um etwas von ihrer Freiheit wegzunehmen, sondern zum Wohle der Seelen und der Bestätigung und Vermehrung unserer Heiligen Religion, und trotzdem versäumen sie es nicht, verletzende Briefe an andere Kantone zu schicken, und in Übereinstimmung auch an diesen von Luzern. [.... $]^{379}$
\end{abstract}

1652 wurde er zum Päpstlichen Thronassistenten ernannt und kehrte nach Rom zurück. Sein Vertrauter und Protégé, Bischof Jost Knab, wurde bis zur offiziellen Nachfolge als Internuntius eingesetzt. Boccapaduli wirkte aber stattdessen noch als Diplomat in Venedig, da die diplomatischen Beziehungen mit der Lagunenstadt sehr kritisch waren. 25 Jahre lang führte er danach die Diözese Città di Castello als Bischof und nach der endgültigen Pensionierung kehrte er definitiv nach Rom zurück, wo er zum Titularerzbischof von Athen erhoben wurde. Er starb am 23. November 1680 und wurde in der Basilika Santa Maria in Aracoeli begraben..$^{380}$

\title{
4.2.14 Carlo Carafa della Spina (1653-1654)
}

Der letzte Nuntius unter den Diözesanbischöfen stammte wie die meisten seiner Vorgänger von einer römischen Adelsfamilie ab. Geboren wurde Carlo Carafa della Spina am 21. April 1611 in Rom. Der Kirchenrechtler trat dem Orden der Theatiner bei, der 1524 auf Initiative von Gian Pietro Carafa, dem späteren Papst Paul IV., und von Kajetan von Thiene gegründet wurde. Nach einer mehrjährigen Karrierelaufbahn an der römischen Kurie wurde Carlo Carafa della Spina nach Bologna versetzt, doch als im April 1644 sein Onkel Carlo Carafa, Bischof von Aversa, starb und nachdem er die Tonsur im Juni erhalten hatte, wurde er am 13. Juli zu dessen Nachfolger ernannt, mit einer Dispens, da Carlo Carafa della Spina die Priesterweihe noch gar nicht erhalten hatte. Am folgenden 1. Januar wurde er in der römischen Kirche Sant'Andrea della Valle von Kardinal Ciriaco Rocci geweiht. In Aversa erwarb sich Carlo Carafa della Spina das Vertrauen des spanischen Hofes anlässlich der Masaniello-Revolte und fungierte als

379 Segreteria Stato, Svizzera, Volume 44, f. 283.

380 Vgl. Stichwort „Francesco Boccapaduli“, in: https://hls-dhs-dss.ch/de/articles/017885/ 2004-06-04/ (31. Dezember 2020).

381 Vgl. Dizionario biografico degli Italiani, Volume 19: S. 513-517; Caspar Wirz: Bullen und Breven aus Italienischen Archiven, S. XL. 
Vermittler zwischen dem Haus Österreich und dem Herzog von Guise. Dies brachte ihm 1653 die Ernennung durch Innozenz X. zum Nuntius bei den Schweizern ein. Diese Nuntiaturstelle hatte nach Ende des Dreißigjährigen Kriegs offenbar eine wichtigere Rolle eingenommen, galt sie doch zuvor noch als zweitrangige Stelle. Wie von seinen Vorgängern wurde aber die Nuntiatur in Luzern als Karrieresprungbrett verstanden. ${ }^{382}$

Am 24. April 1653 kam Carafa della Spina in Luzern an. Auch er begann seine neue Aufgabe zunächst damit, dass er die Reise in die Schweiz beschrieb, und zwar in einem Brief vom 13. April 1653:

Ich bin in Como, wo ich zwei Tage lang zurückgehalten wurde, nicht so sehr durch das schlechte Wetter, weil es ständig regnet, sondern wegen der Osterfeierlichkeiten, und morgen, Montag, werde ich nach Lugano abreisen, um meine Reise nach Luzern fortzusetzen, wo ich weiß, dass die Schwierigkeiten mit diesem untergebenen Volk überwunden wurden, aber neue Probleme sind wegen des Aufstands der Kantone Bern und Freiburg entstanden, nicht ohne Hoffnung, dass alles bald gelöst wird. [...] $]^{383}$

Doch bei dieser ersten Etappe, die ihn ins Tessin führt, wurde ihm ein unfreundliches Bild der Eidgenossenschaft gezeichnet, und so schrieb er am 24. April 1653:

Bei meiner Ankunft in Lugano raten mir einige Herren, die mit dem Apostolischen Stuhl sehr verbunden sind, durch ihre Briefe, nicht weiter zu gehen und hier in ihrem Land zu bleiben, solange wir das Ergebnis des Aufstands jener Untertanen nicht gesehen haben. Ansonsten setzen wir uns einer Gefahr aus, denn das ganze Land steht unter Waffen. Ich dachte jedoch nicht daran, ihren Rat anzunehmen, denn angesichts des großen Nachteils, den die katholische Religion von diesen Aufständen erhalten könnte, schien es mir nicht ratsam, aus der Ferne untätig zu bleiben, nur um abzuwarten, ohne etwas zu tun; deshalb setzte ich fleißig meine Reise fort, und ich kam am Montag gegen Abend in Luzern an, und diese Herren begrüßten mich mit den üblichen Ausführungen und mit Zeichen besonderer Liebe und Sympathie. [...] $]^{384}$

Sein Aufenthalt in Luzern war dann vom bürokratischen Tagesgeschäft geprägt. Schnell lebte er sich ein. Ihn wunderte aber, dass trotz der Aufstände und Unruhen, die man ihm aus Rom vor seiner Ankunft mitgeteilt hatte, er sich hingegen ein anderes Bild vor Ort machen musste: So fand er „ruhige“ Menschen vor, die „so viel beschäftigt sind mit den Unruhen“, dass sie kaum Zeit gehabt hätten,

382 Vgl. Stichwort „Carlo Carafa della Spina“, in: https://hls-dhs-dss.ch/de/articles/017898/ 2003-07-29/ (31. Dezember 2020).

383 Segreteria Stato, Svizzera, Volume 45, f. 97.

384 Segreteria Stato, Svizzera, Volume 45, f. 114. 
den Nuntius „zu stören“, wie er wohl mit ironischem Unterton nach Rom schrieb. ${ }^{385}$

Als Beobachter der Aufstände beschrieb Nuntius Carafa della Spina dann im Juni 1653 in seinen Briefen nach Rom, was die Kriegsparteien vorhatten und wo sie sich aufhielten. ${ }^{386}$ So stellte er fest, dass sich die „Landbevölkerung“ („Villani“) ${ }^{387}$ untereinander vereinigte und gegen ihre „Herren“ („Padroni“) mit Gewalt vorging. So seien diese „Herren“ zu stark für die „bäuerlichen Krieger“, schreibt Carafa della Spina am 12. Juni 1653 nach Rom. ${ }^{388}$ Das „Landvolk“, das nun keine Nahrung mehr hatte, nahm sich deshalb jenen Vorrat, der eigentlich für den Klerus vorgesehen war. Dagegen protestierte der Nuntius. Er versuchte demonstrativ vorzugehen, ohne auf die Not des „Landvolks“ näher einzugehen. ${ }^{389}$

Die Lage am Vierwaldstättersee war zwar idyllisch, wie der Nuntius anerkannte, doch die Orte seien auch gefährlich und seiner Meinung nach alles andere als lebenswert, wie er am Beispiel des Kantons Uri in einem Brief vom 6. September 1653 schrieb:

\begin{abstract}
Als blühendes Land liegt der Kanton Uri am Ufer des Sees, umgeben von Sümpfen, und ist gemeinhin wegen seiner schlechte Luft bekannt, was dazu geführt hat, dass es dort bereits seit mehr als einem Jahr keinen üblichen Kaplan gibt, und trotz vielem Fleiß durch den Landesrichter, wurde niemand gefunden, der die Unannehmlichkeiten in Kauf nehmen will, und dass der Subdiakon Andrea Gander, Bürger von Altdorf, noch zwei Jahre warten muss, um zum Priester geweiht zu werden. [...] $]^{390}$
\end{abstract}

Was Graubünden betraf, so sah Carafa della Spina die Geldgier und den Einsatz der Protestanten als Gründe für die - aus seiner Sicht - missliche Lage der Katholiken, wie er am 20. November 1653 schrieb:

Der schlechte Zustand, in dem sich die katholische Religion in Rätien befindet, ist auf das Zusammenleben zurückzuführen, das der Bischof von Chur mit den Ketzern führt, und auf den fehlenden Eifer der spanischen Vertreter, die die Bedingungen der Liga einhalten sollten, und selbst wenn sie immer versprechen, verärgert sein zu wollen, betreiben sie im Wesentlichen jedoch aus politischen Interessen nichts, wie ich es in der Angelegenheit des Klosters St. Nikolaus erlebt habe.

Der Bischof von Chur hat sich sehr schlecht verhalten, weil er auf nichts anderes wartet, als mit dem Geld davonzukommen und den Protestanten, mit denen er in enger Verbin-

385 Vgl. Segreteria Stato, Svizzera, Volume 45, f. 142.

386 Vgl. Segreteria Stato, Svizzera, Volume 45, f. 164.

387 Vgl. http://www.treccani.it/vocabolario/villano/ (31. Dezember 2020)

388 Vgl. Segreteria Stato, Svizzera, Volume 45, f. 183.

389 Vgl. Segreteria Stato, Svizzera, Volume 45, f.209. Ein Brief vom 26. Juni 1653.

390 Segreteria Stato, Svizzera, Volume 45, f. 456. 
dung steht, was dazu führt, dass ihn hier alle als Ketzer einstufen. Bei den Behandlungen der zivil- und strafrechtlichen Fälle reicht es nicht aus, einen Prozess zu führen oder die Parteien zu zitieren, denn es wird denen die günstige Strafe gewährt, die mehr Geld anbieten. Jeden Tag kommen in diesem Gerichtshof der Nuntiatur ununterbrochene Klagen wegen Diebstahls, Sakrilegs, Simonie, Verkauf von Sakramenten, Inzest und andere ähnliche Anschuldigungen gegen den Bischof an. Meinerseits, obwohl ich es nicht unterlassen habe, ihn mehrmals zu warnen, und um alles zu korrigieren, was möglich war, denke ich dennoch, dass ich so schnell wie möglich diese Kirche besuchen soll, vorausgesetzt, dass die Härte der Jahreszeit nicht so weit fortgeschritten ist, dass ich nicht reisen dürfte, und aus diesem Grund weiß ich, wie ich den Dienst Unseres Lieben Herrn, Eurer Eminenz, erfüllen kann, und bitte um Anweisungen, ob ich den Besuch auch im Einverständnis abstatten muss, [...]. ${ }^{391}$

Was den Osten der Eidgenossenschaft betraf, so merkte der Nuntius an, dass der Abtfürst von St. Gallen mit dem Fürsten von Innsbruck zusammenarbeitete, aber nur aus Eigeninteresse. Und da ging es vor allen Dingen um Geldfragen. ${ }^{392}$ Doch gleichzeitig sei in St. Gallen die Lage der Priester - wie in der gesamten Eidgenossenschaft - sehr prekär, wie der Nuntius feststellte, und er versuchte alles zu tun, um den „Priesternachwuchs“ zu fördern, wie er in einem Brief von Ende Februar 1654 schrieb:

Und dieses Land leidet so sehr an den knapp zählenden Kirchenmitarbeitern, dass ich, da ich viele Gläubige von der Verabreichung der Sakramente befreien musste, nicht entkommen konnte, um Eurer Eminenz die Petition vorzubringen, die die Kleriker Anastasio Henzenbergen aus Steinach, Franziskus Wirtt [sic!] aus Liechtensteig und Peter Bock von Oberegg aus der Diözese Konstanz einbringen. Sie werden von dreizehn Monaten dispensiert, die ihnen fehlen, um zum Priester geweiht zu werden. Auf diese Weise sind sie in der Lage, in konkreter Not einigen Pfarreien zu helfen, zu denen sie durch den Abt von St. Gallen bestimmt waren. Die jungen Männer sind genauso tugendhaft und lebensfroh, wie sie gleichzeitig auch arm sind, so dass ihnen nur durch Gottes Gnade die Freiheit geschenkt wurde. Denn sie haben nicht die Mittel dazu, die notwendigen Einkäufe zu tätigen, [.....$^{393}$

Das Schweiz-Bild, das Nuntius Carafa della Spina hatte, entsprach einem Land, in dem viel Armut herrschte. So beschrieb er in einem Brief vom 16. April 1654 eine konkrete Situation, die den Kanton Uri betraf:

In Altdorf, dem Hauptort des Kantons Uri, herrschen zwei Fraktionen, die so gegensätzlich waren, sodass eine der beiden Seiten, um die Zustimmung des Volkes zu gewinnen, in der allgemeinen Versammlung vorschlug, angesichts der allgemeinen Armut vorzugehen. Ihr Vorschlag war, dass das Erbe nach dem Tod der Nonnen an ihre Verwandten zu-

391 Segreteria Stato, Svizzera, Volume 45, f. 472.

392 Vgl. Segreteria Stato, Svizzera, Volume 46, f. 191.

393 Segreteria Stato, Svizzera, Volume 47, f. 75. 
rückkehren und nicht zugunsten der beiden Klöster fallen sollte, die an diesem Ort unmittelbar dem Apostolischen Stuhl unterstehen, und indem sie sich einen übertriebenen beträchtlichen Gewinn versprachen, der sich daraus ergeben würde, siegte diese Partei mit einem so überwältigenden Beifall, dass ich dem kleinen Senat, in dessen Händen über solche Angelegenheiten befunden wird, befohlen habe, ein Gegendekret zu erlassen, was sofort geschah, und sie hätten fast dennoch die falsche Version veröffentlicht, wenn ich nicht mit Bestimmtheit dagegen gestimmt hätte, was ein Vorschlag von solcher Bedeutung erfordert [...].

Der glückliche Erfolg dieser Angelegenheit ließ die Sehnsucht schwinden, die viele in den anderen Kantonen hatten, um dem Beispiel von Uri zu folgen [.... ${ }^{394}$

Während des Bauernkrieges ${ }^{395}$ vermittelte er erfolgreich zwischen den gegnerischen Parteien und verhinderte, dass die weltlichen Gerichte die Priester auf dem Land verurteilten. In Chur kämpfte er gegen den Verkauf von Kirchenbesitz an die Stadt durch den Bischof der Diözese, Johann Flugi d'Apremont, und im folgenden Jahr besuchte der Nuntius diese Diözese. Im Streit um die Wiederherstellung der Abtei Reichenau stellte er sich auf die Seite des Konstanzer Bischofs Christoph Metzler von Andelberg und befahl dem Prior der Abtei, sich in die Abtei Weingarten zurückzuziehen.

Am 15. Oktober 1654 erhielt Carafa della Spina die Nachricht von seiner Ernennung zum päpstlichen Nuntius in Venedig. Er kam im folgenden Frühjahr in der neuen Nuntiatur an. Der Heilige Stuhl bat den erfahrenen Diplomaten, sich mit der Frage der Jesuiten zu befassen, und ließ von den venezianischen Behörden die Möglichkeit einer Rückkehr der Jesuiten in die Republik der Serenissima feststellen, die 1606 aus der Stadt vertrieben wurden. Mit geschickten Verhandlungen gelang es Carafa della Spina in den vier Jahren seiner Tätigkeit in Venedig, die Rückübernahme der Jesuiten von der Republik zu erreichen.

Im August 1658 wurde Carafa della Spina offiziell zum Nuntius beim Kaiser des Heiligen Römischen Reiches Deutscher Nation ernannt. Papst Alexander VII. hatte schon seit einiger Zeit über seinen erfolgreichen Nuntius in Venedig für diese prestigeträchtige Nuntiatur nachgedacht, aber er wurde durch den Tod von Ferdinand III. und das folgende Interregnum aufgehalten. Von diesem Beobachtungsstandort aus konnte Carafa della Spina wichtige Berichte nach Rom über die politische Situation in Mitteleuropa senden. Es waren die Jahre auf dem Weg zu einem schwierigen Frieden, der von außen durch die furchte-

394 Segreteria Stato, Svizzera, Volume 47, f. 168.

395 Der Schweizer Bauernkrieg war ein Volksaufstand in der Alten Eidgenossenschaft im Jahr 1653. Eine Abwertung der Berner Währung führte im bernischen Emmental und im angrenzenden luzernischen Entlebuch zu weit verbreiteter Steuerverweigerung, die sich nach Solothurn, Basel und in den Aargau ausweitete. Vgl. André Holenstein: Der Bauernkrieg von 1653, in: https://www.bezg.ch/img/publikation/04_1/holenstein.pdf (31. Dezember 2020). 
inflößenden türkischen Kräfte bedroht schien. Seine Position am Hof war jedoch nicht die einfachste: Hinter einer formalen Korrektheit der Beziehungen standen viele Streitigkeiten, wie die Ernennung von Bischöfen und der Krieg gegen die Türken, den Rom mit einer riesigen Vereinigung aller katholischen Kräfte auf das Feld zu führen gehofft hatte, den der Kaiser aber mit dem Frieden von Vasvar vorübergehend unterbrach.

Erst dann kam die Rückkehr von Carafa della Spina in seine Heimat in Frage. Das war in den ersten Monaten des Jahres 1665. Zuvor hatte er die angesehene Nuntiatur am Deutschen Reich mit dem am 14. Januar 1664 im Regensburger Dom erhaltenen Kardinalsbirett krönen können. Dann wurde ihm der Sitz von Bologna als Gesandter anstelle von Kardinal Pietro Vidoni zugewiesen. Am 13. April 1665 erhielt er den Titel des Kardinal-Presbyters der Heiligen Susanna, und nach seinem Rücktritt als Bischof von Aversa im Juni war er in Bologna, wo das politische Klima von Gewalt geprägt war, die das Stadtleben störte. Mit groBer Bestimmtheit stellte Carafa della Spina die Ordnung wieder her und wies die gefährlichsten Störenfriede aus.

Er nahm am Konklave von 1667 teil, das zur Wahl von Papst Clemens IX. führte, sowie am Konklave von 1669-1670 mit der Wahl von Clemens X. Er war von 1676 bis 1678 Kammerherr des Kardinalskollegiums. Er nahm auch am Konklave von 1676 teil, das Papst Innozenz XI. wählte.

Er starb am 19. Oktober 1680 in Rom. Die Beerdigung fand in der römischen Kirche „Il Gesù“ statt, wo er begraben wurde. ${ }^{396}$

\subsection{Die Instruktionen an die Nuntien und ihre Berichte ${ }^{397}$}

In dieser Arbeit wurden drei Instruktionen und drei Berichte untersucht. ${ }^{398}$ Beim ersten Dokument handelt es sich um einen Bericht über Nuntius Ottavio Paravicini (1587-1591). Der Bericht beschreibt, wie dem Nuntius in Luzern die Kardinalswürde überreicht wurde. Die Beschreibung zeigt auf, dass die Schweizer - oder genauer gesagt die Luzerner - die Feier als große Ehre empfanden. Die Ständige Nuntiatur stand zu Paravicinis Zeit noch in der Anfangsphase und war vom Besuch von Karl Borromäus geprägt. Aus dem Text geht hervor, wie die politischen Machthaber Luzerns bei der Zeremonie involviert waren. Para-

396 Vgl. Stichwort „Carlo Carafa della Spina“, in: https://hls-dhs-dss.ch/de/articles/017898/ 2003-07-29/ (31. Dezember 2020).

397 Dieser Teil bezieht sich auf die im Anhang aufgeführten Instruktionen und Berichte. 398 Vgl. dazu den Anhang in diesem Werk. 
vicini wird positiv ${ }^{399}$ dargestellt, und beim Durchlesen des Berichts hat man den Eindruck, dass zwischen dem Nuntius und den Luzerner Herren ein gutes Verhältnis herrschte. Es wird hervorgehoben, dass alle Luzerner teilnahmen und es sich bei der Überreichung der Kardinalswürde nicht einfach um ein Volksfest, sondern um das wichtigste Ereignis in der Stadt in jener Zeit handelte. Immer wieder wird die Rolle des Schultheißen unterstrichen. Auf diese Weise soll die Zusammenarbeit zwischen den politischen Herrschern und dem Papstgesandten akzentuiert werden. Was in dem Text ebenfalls zum Vorschein kommt, wenn auch nicht wertend beschrieben, ist die Feier nach der Zeremonie. Wie in den meisten Instruktionen und im Bericht von Karl Borromäus über die Schweizer beschrieben wird, gehört der Hinweis auf die Schweizer Festkultur zu einem Leitmotiv - auch der negativen Kritik -, um das Volk nördlich der Alpen zu beschreiben. Im Bericht über Paravicini wird dies oberflächlich ge$\tan .400$ So waren unter den europäischen Diplomaten die Bankette in der Schweiz berüchtigt. Wie Andreas Würgler schreibt, konnten sie auch sechs bis zwölf Stunden dauern und „nicht selten mehrere Hundert Gäste zu unterhalten waren". 401

Ausgehend von den in dieser Arbeit untersuchten Instruktionen und Berichten lassen sich zwei Phasen in der Zeit zwischen 1596 und 1654 feststellen. In einer ersten Phase, in die sich der Bericht über Paravicini einreiht, geht es der Nuntiatur in Luzern darum, die Katholiken nördlich der Alpen zu schützen. ${ }^{402}$ Dazu gehörte neben der Glaubensfrage auch die militärische Dimension. Aus Sicht der römischen Kurie bedeutet dies aber auch eine wirtschaftliche Frage, denn die Anwerbung von Söldnern ist mit Kosten verbunden. ${ }^{403} \mathrm{Im}$ Bericht

399 Es ist nicht bekannt, wer genau der Autor der Schrift war, aber es stellt auf jeden Fall die Sicht des Nuntius dar.

400 Vgl. Rüdiger Fikentscher (Hrsg.): Trinkkulturen in Europa: Mit allen Mitteln kämpften Humanisten und Reformatoren, in diesem speziellen Fall mit den Katholiken Seite an Seite, gegen den „Saufteufel“. Ein Jahrhunderte langes, zähes Ringen um Nüchternheit setzte ein. „Wir predigen und schreien und predigen. Es hilft leider wenig“, klagte Luther.

401 Vgl. Andreas Würgler: Individuelle und kollektive Akteure der Alten Eidgenossenschaft, S. 89.

402 In den Instruktionen wird dazu immer der Begriff „Geschäfte“ („offici“) verwendet, um diese Angelegenheiten hervorzuheben.

403 Vgl. Schweizerisches Idiotikon, Band VI, Spalte 1288 ff., Artikel Reis: „Reisläufer (abgeleitet von Reisige) waren spätmittelalterliche Schweizer Söldner, die bis ins 17. Jahrhundert im Dienste zahlreicher europäischer Herrscher standen. Das mittelhochdeutsche „reise“ bedeutet „kriegerischer Auszug, Kriegszug, Feldzug“ und ist der Vorläufer des neuhochdeutschen Wortes „Reise“. Der Reisläufer verdingte sich auf eigene Faust in fremdem Dienst - im Gegensatz zum kapitulierten Dienst, der auf der Basis einer Militärkapitulation beruhte, das heißt einem Liefervertrag für Soldaten zwischen zwei Ländern.“ 
wird festgehalten, dass Paravicini bei den Verhandlungen Schwierigkeiten vorfand, die dann zu seinem Abgang führten. Die unterschiedlichen Meinungen zu den Gründen seines Abgangs werden im Bericht jedoch sehr distanziert beschrieben. ${ }^{404}$

Die zweite Phase der Nuntiatur in Luzern lässt sich aus der Instruktion für Fabio Verallo herauslesen. Nachdem die Gesandtschaft auf Anraten Borromäus' als Unterstützung für die Schweizer Katholiken initiiert und fix in der Zentralschweizer Stadt eingeführt worden war, ging die römische Kurie dazu über, den Nuntien den Auftrag zu geben, eine Rückeroberung der an die Reformation verlorengegangenen Territorien zu starten. In der Instruktion von 1606 wird zunächst darauf Wert gelegt, keine weiteren Streitigkeiten und Konflikte auszulösen. Im Allgemeinen ist man in Rom davon überzeugt, dass die Schweizer Katholiken die Linie der römischen Kurie mittragen. Um das auch künftig zu garantieren, wurde der Schwerpunkt auf den Bildungsbereich gelegt: mit der Entsendung der Jesuiten und Kapuziner sowie der Förderung der Priesterausbildung durch das Kolleg Helveticum in Mailand. Diese Anliegen wurden von Karl Borromäus angegeben und weiter verfolgt. ${ }^{405}$

In der Instruktion an Fabio Verallo werden die Protestanten als Häretiker bezeichnet. Zwar war noch zu Verallos Zeit die Lage für die Katholiken - zumindest war dies die römische Sicht - noch so schwierig, dass es in erster Linie um die Sicherung des Status quo ging. Man ging aber dazu über, die politische Ebene vermehrt in Anspruch zu nehmen, um die gegnerische Seite unter Druck zu setzen..$^{406}$

Was ebenfalls auffällt, ist die Tatsache, wie viele Einzelheiten in der Instruktion an Verallo aufgelistet werden. Die Situation und auch die Einzelfälle waren klar. Es werden dieselben Vorgehensweisen angeführt, die Borromäus in seiner Schrift aufgeführt hatte. Die Visitationen und somit der direkte Kontakt spielte hierbei eine Schlüsselrolle. ${ }^{407}$

404 Vgl. Stichwort „Ottavio Paravicini“, in: https://hls-dhs-dss.ch/de/articles/017911/2009-0609/ (31. Dezember 2020): „Da von ihm geworbene Schweizer Truppen im Dienste der kath. Liga ihren Sold nicht erhielten, geriet der sonst beliebte P. in Bedrängnis und musste die Schweiz verlassen.“

405 Vgl. Paul M. Krieg: Das Collegium Helveticum in Mailand, S. 122-133.

406 Seit der Mitte des 16. Jahrhunderts gestattete es die relative Stabilisierung der italienischen Verhältnisse den Päpsten, sich stärker als ihre Vorgänger über die Interessen des Kirchenstaats hinaus machtpolitisch zu engagieren. Vgl. Martin Papenheim: Machen Päpste Politik?

407 Vgl. Stichwort „Visitationen“, in: https://hls-dhs-dss.ch/de/articles/027049/2015-01-03/ (31. Dezember 2020): „In den ersten Jahrzehnten des 16. Jh. nahmen sowohl die Qualität als auch die Quantität der V. erneut zu... Eine weitere in der kath. Kirche gebräuchliche Visitationsform war der Besuch von Klöstern und Gotteshäusern durch Bischöfe, päpstliche Legaten 
In der Instruktion an Ladislao d'Aquino (1608-1613) wird zunächst die Zusammenarbeit mit den katholischen Kantonen hervorgehoben. Die Beschreibung der politischen Strukturen zeigt auf, dass der komplexe Aufbau aus römischer Sicht sehr fremd und konfus gewirkt haben mag. Die Vermischung verschiedener Sprachkulturkreise wurde wie selbstverständlich hingenommen, wobei die Dominanz der Deutschsprachigen eindeutig hervorsticht. Die Verknüpfung von grundlegend positiven Voraussetzungen wie der Frömmigkeit bei den Katholiken mit gut strukturierten landwirtschaftlichen Rahmenbedingungen soll wohl aufzeigen, dass der Einsatz der Nuntien in Luzern nicht nur sinnvoll sei, sondern dem Verständnis des Papsttums als Garant des Katholizismus entspreche. Doch gleich neben der Aufzählung dieser positiven Elemente werden die negativen Seiten aufgelistet. Es handele sich um ein Volk, das streitsüchtig und wirtschaftlichen Interessen mehr zugeneigt sei als den positiven Grundwerten des christlichen Glaubens. ${ }^{408}$

Dennoch wäre es falsch, dies als Hauptmotive der Anliegen aus Rom zu betrachten. In der Instruktion an d'Aquino wird der Fokus vor allem auf die Anliegen der tridentinischen Reform gelegt, was ja das Hauptanliegen auch von Karl Borromäus war. Was Borromäus ebenfalls feststellte, war die schwierige Zusammenarbeit mit den Bischöfen in der Schweiz. Es wird auf die Mentalitätsunterschiede zwischen den Würdenträgern nördlich der Alpen und den italienischen Bischöfen aufmerksam gemacht. Hierbei kommen die Bischöfe aus dem Norden, allen voran der Konstanzer, eher schlecht weg. Angeprangert wird die schädliche Einstellung der Bischöfe in Bezug auf das Zusammenleben mit den weltlichen Herrschern. Auch der Nuntius selber soll achtgeben, dass er sich nicht wie die Schweizer Bischöfe verhält. Rom betrachtet die Schweizer Kirchenmänner als zu ungeeignet im Umgang mit Herrschenden. Das hat aber auch damit zu

und Gesandte der Generalkapitel. In der Schweiz führte oft der Nuntius solche Visitationen aus. Zur Vor- und Nachbereitung der V. wurden Instruktionen, Fragebogen, Briefe und Mahnschreiben bzw. Protokolle und Weisungen aufgrund der Visitationsberichte verfasst; zudem regelten Konzilsbeschlüsse und Artikel des Kirchenrechts den Inspektionsrahmen und die Pflichten des Visitators. Diese Urkunden erweisen sich v. a. als Quellen für versch. Aspekte der Kirchengeschichte, so z. B. die Stellung des Bischofs, die Diözesanorganisation, die Geistlichkeit, die Pfarrei und Pfarreiangehörige, Liturgie und Andacht sowie deren Abweichungen, die Lage der Nichtchristen und schließlich die Fürsorge- und Spitaleinrichtungen. Zudem enthalten sie auch Informationen zur Wirtschafts- und Sozialgeschichte, etwa zur Bevölkerungsentwicklung und zur Armut, und geben Aufschluss über die Archäologie, die Kunst-, Geistesund Literaturgeschichte, die Sprache und das Textverständnis, das Brauchtum sowie die materielle Kultur.“

408 Dies entsprach in etwa der Beschreibung, die 1570 Karl Borromäus über die Schweizer gemacht hatte. Vgl. Mario Galgano: Borromeos Informationsreise durch die Schweiz (1570). 
tun, so die Argumentation in der Instruktion, dass die Herrschenden nördlich der Alpen zu diesem schwierigen Verhältnis beitragen. 409

Sehr schlecht kommen die Häretiker, also Protestanten, in der Instruktion an d'Aquino weg. Fast scheinen sie verlorene Seelen zu sein, bei denen nichts mehr zu machen ist. Ein Ausweg wird nur auf politischen Wegen gesucht. Hierbei spielten die Bündnisse und Rollen Frankreichs, Spaniens, Habsburg-Österreichs und Venedigs eine zentrale Rolle. Trotz des Umstands, dass die Häretiker eigentlich von katholischen Großmächten umzingelt waren, traute die römische Kurie dieser Ausgangslage nicht. Wie allgemein aus den Instruktionen und Briefen ersichtlich ist, war man sich in Rom durchaus bewusst, dass die Realität viel komplexer ist als die einfachen Schemata von Gut und Böse. Realpolitik prägte gerade in der Instruktion an d'Aquino die Grundausrichtung und Beschreibung der Schweizer. ${ }^{410}$

Der eigentliche Absender der Instruktion an d'Aquino, Kardinal Scipione Borghese, der Leiter des päpstlichen Staatssekretariats, ist vor allem als Kunstmäzen (etwa von Caravaggio) bekannt. Als Papstnepote und Mitglied des römischen Adels vertrat er einen Kulturkreis, der sich grundlegend von den damaligen kulturellen Verständnissen in der Schweiz unterschied. ${ }^{411}$

Die Relation d'Aquinos, die somit als eine Art Bestätigung oder Korrektur der von Kardinal Borghese an ihn gerichteten Instruktion zu verstehen ist, geht vor allem mit Daten um, die man nicht bestreiten kann. Die Aufzählung der Größe und Geschichte der Schweizer Völker soll nicht nur sein Wissen vermitteln, sondern auch aufzeigen, dass seine Beobachtungen und Vorschläge eine ernste Grundlage haben. Auch die Tatsache, dass er Begriffe der Schweizer aufzählt, hatte wohl eher das Ziel, den Empfänger und Leser in Rom zu beeindrucken und zu beweisen, dass der Absender und Autor der Relation ein Kenner und Experte der Schweizer Angelegenheit sei. ${ }^{412}$

Besonders interessant ist hierbei die Aufzählung der Quellen, die d'Aquino für sein Wissen nennt. Autoren wie Tschudi und Guillimann kommen ebenso vor wie frühere Instruktionen und Texte seiner Vorgänger. Mit d'Aquino ist ein päpstlicher Diplomat am Werk, der nicht nur die Vorgaben seiner Herren aus Rom befolgt und umsetzt, sondern auch selber mitzudenken versucht. ${ }^{413}$

409 Vgl. Ludwig Freiherr von Pastor: Charakterbilder kath. Reformatoren des 16. Jahrhunderts.

410 Vgl. Jakob Burkhardt: Die päpstliche Nuntiatur in der Schweiz 1612.

411 Vgl. Dietrich Harth (Hrsg.): Fiktion des Fremden.

412 Ebd.

413 Vgl. Michael Jucker: Ein einig Volk von Brüdern?, S. 32-48. 
Vor allem in letzteren Teil der Instruktion wird auf die unterschiedlichen Mentalitäten zwischen Italienern und Deutschen aufmerksam gemacht. Die Schweizer werden in der Auflistung als Deutsche bezeichnet. Dazu wird der römische Autor Tacitus zitiert. Was dieser in der Antike auflistet, wird als Vergleichsmerkmal für die damalige Gegenwart des 17. Jahrhunderts genommen. Die Merkmale werden nicht hinterfragt, sondern als selbstverständlich und zeitlos betrachtet. 414

Ein Hindernis für die Tätigkeit der Nuntien sei das Problem der Schweizer, sich auf Einzelheiten zu fixieren und Zeit damit zu verlieren. Bemängelt werden die fehlende Flexibilität und sozusagen der gesunde Menschenverstand, der somit den Schweizern fehlen würde. ${ }^{415}$

Dummheit wird auch mit Gewaltbereitschaft gleichgesetzt, und diese könnte den Nuntien gefährlich werden. Deshalb gingen die Ratschläge in den Instruktionen auch in jene Richtung, die man oberflächlich betrachtet schlicht als „diplomatisch“ bezeichnen würde. Doch im Schweizer Falle hat das weniger mit Diplomatie als vielmehr mit Schutzmaßnahme vor den wütenden Gastgebern zu tun..$^{416}$

Der Schein spielte ebenfalls eine Rolle. So wird dem Auftritt der Nuntien was bereits im genannten Bericht über Paravicini zur Sprache kam - ein großer Stellenwert beigemessen. Sich in der Kirche zu zeigen, gehört ebenso wie die Kleidung dazu, um bei den Schweizern zu punkten. Auch da geht man in Rom davon aus, dass einfach gestrickte Menschen sich leicht durch Äußeres beeindrucken lassen. Aber nicht nur der Nuntius selber soll darauf achtgeben: Die römische Kurie setzt auch viel auf die engsten Mitarbeiter und Diener des Gesandten. Die Mannschaft in Luzern soll somit als Ganzes gut auftreten. ${ }^{417}$

Die Teilnahme an Feierlichkeiten, das Einladen von Gästen und vor allem, sich dem Trinkverhalten der Schweizer anzupassen, gehören zu den Leitmotiven in den Instruktionen. Auch da greift die römische Kurie auf ein Bild zurück, das bei Tacitus über die Germanen vorkommt. Menschen mit wenig Kultur, die also einer unterlegenen Zivilisation angehören, galten als „bauchfixiert“. Essen und Trinken spielten da eine größere Rolle als alles Übrige. ${ }^{418}$

In der Instruktion an d'Aquino wird aber auch ein Schwerpunkt auf die Geistlichen (Klerus und Ordensleute) gelegt. Die detaillierte Auflistung der Ordensgemeinschaften, der Kirchen und Seminare belegen dies. Die Tatsache,

414 Vgl. Hubert Jedin: Papst und Konzil, S. 429-440.

415 Hier sind Parallelen zum Germanenbild bei Tacitus festzustellen.

416 Man denke an Aufstände, wie in: André Holenstein: Der Bauernkrieg von 1653.

417 Hier geht es also um das Selbstbild nach außen.

418 Vgl. Rüdiger Fikentscher (Hrsg.): Trinkkulturen in Europa. 
dass man es mit einer unterlegenen Zivilisation $\mathrm{zu}$ tun habe, führte aber auch dazu, dass man sich vor allem auf den Bildungsbereich konzentrieren wollte. ${ }^{419}$

Als Anhang wird dann ein Kompendium angefügt, in der die Resultate d'Aquinos aufgelistet werden. Damit wird schon ein Grundstein dafür gelegt, dass die beschriebene Instruktion nicht einfach als eine einmalige Angelegenheit, sondern als Maßstab für die künftigen Nuntien verwendet werden sollte. ${ }^{420}$

Das besondere Augenmerk mit zwei zusätzlichen Anhängen auf Graubünden und das Wallis zeigen auf, dass man in Rom durchaus das Bewusstsein hatte, wie komplex und trotz allem sehr uneinheitlich die Schweiz war. ${ }^{421}$

Die Instruktion an Alessandro Scappi (1621-1628) ist im Vatikanischen Geheimarchiv in zwei Teilen zu finden, die in zwei verschiedenen Bänden aufbewahrt werden, die aber zusammengehören. Einerseits merkt man, dass die Instruktion, die zuvor an d'Aquino gesandt worden war, nochmals verwendet wurde, und andererseits verfolgte die Zentrale in Rom eine Kurskorrektur ihrer bisherigen Linie und richtete sich immer mehr an einer Rückeroberung der protestantischen Gebiete aus.

Was in dieser Instruktion besonders auffällt, ist die Bewusstseinsbildung in Rom, dass neben den religiösen Problemen auch die machtpolitischen Interessen stärker zu beachten seien. Vielleicht hatte man gemerkt, dass die unzivilisierte Schweiz trotzdem von Persönlichkeiten gelenkt wurde, die über ein ausgeklügeltes geopolitisches Denken verfügten. Gerade im zweiten Teil der Instruktion an Scappi wird dies deutlich, wobei dies auf die Einmischung der europäischen Großmächte wie Frankreich und Spanien zurückgeführt wurde. ${ }^{422}$

Im Bericht von Ranuccio Scotti (1630-1639) wird das bisherige Wissen über die Schweiz dahingehend korrigiert, dass man das Land unterschätzt habe. War man in den vorhergehenden Instruktionen davon ausgegangen, dass mit wenig Aufwand die Ziele erreicht werden könnten, stellte Scotti fest, dass es viel Geld und Ausdauer brauchen würde. Die einfach gestrickten Schweizer wurden somit zu einer komplexen Gemeinschaft, in die man viel investieren müsste, um die erhofften Resultate zu erreichen, so lautet der Grundtenor des Berichts.

419 Dies war eines der großen Anliegen Karl Borromäus'. Vgl. Paul M. Krieg: Das Collegium Helveticum in Mailand, S. 112-133.

420 Vgl. Eduard His: Die Nuntiatur in der Schweiz.

421 Vgl. Michael Jucker: Ein einig Volk von Brüdern?

422 Italien war zwischen 1530 und 1559 mächtepolitisch in die spanische Vorherrschaft gefallen. Seit 1494 hatten Spanien und Frankreich in Süd- wie in Norditalien heftig um Einfluss und Besitzungen gerungen. Nach der kläglichen Niederlage des Papstes Paul IV. (1555-1559), der ein Gegner Spaniens war, wagte er dennoch einen weiteren Krieg an der Seite Frankreichs. Doch daraufhin arrangierten sich die Päpste mit Spanien, während umgekehrt die spanische Krone daran interessiert blieb, dass der Stuhl Petri mit einem Freund Spaniens besetzt war. 
Liest man die Berichte und Briefe und vergleicht sie mit den Instruktionen, so gibt es durchaus Bemühungen der Nuntien, die Schweizer besser zu verstehen. Die politische Lage - man denke an die Konfessionskriege bis hin zum Dreißigjährigen Krieg - sowie die komplett andere Struktur der Eidgenossenschaft im Vergleich zum Kirchenstaat waren wohl ein Hindernis für die Nuntien, ihre Einblicke über die Schweizer nach Rom nicht nur zu übermitteln, sondern auch als „Bild-Korrektur“ durchzusetzen. ${ }^{423}$

In den Briefen und auch in den Berichten wird dies - aus verständlichen Gründen - nicht hervorgehoben, aber die Betroffenen dachten zuerst an ihr eigenes Schicksal und ihre Kirchenkarriere und weniger an Änderungen in der Meinungsbildung bei ihren Herren an der römischen Kurie. Mit der Veröffentlichung der Korrespondenz und der Übersetzung der Instruktionen wird vieles über das Wirken der päpstlichen Nuntien in der Schweiz bekannt. Das liegt daran, und das kann man an den vielen Briefen und den ausführlichen Instruktionen sehen, dass die Quellenbestände sehr reichhaltig und ergiebig sind. Mit der Aufarbeitung des Quellenmaterials werden einerseits die einzelnen Biographien der Protagonisten beleuchtet, andererseits erlaubt der Vergleich zwischen den Instruktionen auch eine allgemeine Einordnung sowie die Merkmale der päpstlichen Diplomatie in der Schweiz. Das Bild, das man von der Schweiz hatte, wies viele Unvollständigkeiten und falsche Vorstellungen auf, was die Umsetzung der Reformnuntiatur erschwerte und das Verhältnis zu den Schweizern auch negativ beeinflusste. Erst mit der einvernehmlichen Zusammenarbeit mit den katholischen Kantonen und somit einer gewissen Akzeptanz der Schweizer Katholiken auf Augenhöhe gelangen den Nuntien in der ersten Hälfte des 17. Jahrhunderts Erfolge, wie sie von Rom gewünscht waren. Mehrere Einzelbeispiele zwischen 1586 und 1654 erlauben nicht nur einen Einblick in die Alltagsgeschäfte der Nuntiatur, sie verdeutlichen auch, wie die römische Kurie damals funktionierte und wie falsche Vorstellungen und voreingenommene Einstellungen die Zusammenarbeit der Nuntien mit den katholischen Kantonen mehrmals stark in Gefahr brachten und meist unergiebige Resultate zeitigten. ${ }^{424}$

So werden in den Briefen und in den Instruktionen kleinlich anmutende Zwistigkeiten genannt und verstärkt, die dann eine gute Zusammenarbeit der untereinander oft konkurrierenden geistlichen und weltlichen Magistraten verhinderten. Ein Beispiel hierfür ist der Umgang mit den Bündnern, die man in

423 Vgl. Oliver Hidalgo, Kai Nonnenmacher (Hrgs.): Die sprachliche Formierung der politischen Moderne.

424 Vgl. Rufin Steimer: Die päpstliche Gesandten in der Schweiz. 
Rom einzig als eine Art Bauernopfer betrachtete. Ihre geopolitische Lage galt an der römischen Kurie als wichtigstes Kriterium. ${ }^{425}$

Das Wirken der italienischen Nuntien in der Schweiz ist jedoch erst vor dem Hintergrund ihrer adligen Herkunft, ihrer Ausbildung und Karriere verständlich, wie bereits Fink in seiner Arbeit feststellte. In den Instruktionen und Berichten der Nuntien selber kommt der abschätzende Ton auf die nicht-adeligen Schweizer explizit zum Ausdruck. Das wurde nie verborgen. Selbst die herrschende Klasse in der Eidgenossenschaft wurde nicht als ebenbürtig wahrgenommen, zumindest nicht im kulturellen Bereich. Die Nuntien fühlten sich im Bereich der Politik, des Verhandelns und der Lebensweise überlegen. Die Lebensgeschichten der einzelnen Nuntien bringen aber auch Unvermutetes zu Tage. So erstaunt es, dass sie sich erst mit der Übernahme ihrer hochrangigen diplomatischen Aufgabe zu Priestern weihen ließen - eine Berufswahl im Rahmen der Familienpolitik. Sie galten als Kenner des kirchlichen und zivilen Rechts, waren aber im Allgemeinen theologisch schlecht geschult. Dies führte auch zu Auseinandersetzungen mit Priestern und Bischöfen in der Schweiz. ${ }^{426}$

Das ungewohnte politische System und die konfessionellen Verhältnisse in der Schweiz sorgten bei den Nuntien für Misstrauen, sie bemühten sich aber vor allem, die Katholiken zu verstehen und Strategien zu erarbeiten, um die Gegner zu besiegen, die in diesem Falle Häretiker - also Protestaten - waren. Dennoch ist kaum der Versuch zu finden, ein vertieftes Verständnis ihrer fremdartigen Umwelt zu erlangen. Luzern galt als Zwischenstation einer Karriere, die durchaus oft zum Kardinalat führte. Somit gelangten sie von der Peripherie und dem Abgrund der Zivilisation wieder ins Zentrum der Weltkirche. ${ }^{427}$

425 Vgl. Melchior Schuler: Die Thaten und Sitten der Eidgenossen.

426 Die Ausbildung der Priester im 16. und 17. Jahrhundert reichte oft nur zum Lesen der Messe auf Latein. Die meisten Geistlichen hatten auch keine theologische Ausbildung. Häufig klaffte eine große Kluft zwischen kirchlichem Anspruch und klerikaler Wirklichkeit im priesterlichen Lebenswandel. Das Konkubinat war ein prinzipielles Problem. Vgl. Helmut Meyer: Die Schweiz im Zeitalter der konfessionellen Spaltung.

427 Vgl. Jürgen Dendorfer, Ralf Lützelschwab (Hrsg.): Geschichte des Kardinalats im Mittelalter. 